Board of Governors of the Federal Reserve System

International Finance Discussion Papers

Number 1119

September 2014

“The Impact of Regional and Sectoral Productivity Changes on the U.S. Economy”

\author{
Lorenzo Caliendo
}

Fernando Parro

Esteban Rossi-Hansberg

Pierre-Daniel Sarte

NOTE: International Finance Discussion Papers are preliminary materials circulated to stimulate discussion and critical comment. References to International Finance Discussion Papers (other than an acknowledgment that the writer has had access to unpublished material) should be cleared with the author or authors. Recent IFDPs are available on the Web at www.federalreserve.gov/pubs/ifdp/. This paper can be downloaded without charge from the Social Science Research Network electronic library at www.ssrn.com. 


\title{
The Impact of Regional and Sectoral Productivity Changes on the U.S. Economy*
}

\author{
Lorenzo Caliendo \\ Yale University \\ Fernando Parro \\ Federal Reserve Board \\ Esteban Rossi-Hansberg \\ Pierre-Daniel Sarte \\ Princeton University \\ FRB Richmond
}

August 6, 2014

\begin{abstract}
We study the impact of regional and sectoral productivity changes on the U.S. economy. To that end, we consider an environment that captures the effects of interregional and intersectoral trade in propagating disaggregated productivity changes at the level of a sector in a given U.S. state to the rest of the economy. The quantitative model we develop features pairwise interregional trade across all 50 U.S. states, 26 traded and non-traded industries, labor as a mobile factor, and structures and land as an immobile factor. We allow for sectoral linkages in the form of an intermediate input structure that matches the U.S. input-output matrix. Using data on trade fbws by industry between states, as well as other regional and industry data, we obtain the aggregate, regional and sectoral elasticities of measured TFP, GDP, and employment to regional and sectoral productivity changes. We find that such elasticities can vary significantly depending on the sectors and regions affected and are importantly determined by the spatial structure of the US economy. We highlight the role of these elasticities by tracing out the effects of productivity gains in California in the Computers and Electronics industry between 2002 and 2007 on all other U.S. sectors and regions.
\end{abstract}

JEL classification: F10, F11, O40, O47, R12, R13.

Keywords: Interregional Trade, Intersectoral Linkages, Total Factor Productivity, Gross Domestic Product, Factor Mobility.

\footnotetext{
${ }^{*}$ We thank Treb Allen, Costas Arkolakis, Arnaud Costinot, Dave Donaldson, Jonathan Eaton, Gene Grossman, Tom Holmes, Miklos Koren, Samuel Kortum, Peter Schott, Steve Redding, Richard Rogerson, Harald Uhlig, Kei-Mu Yi and many seminar participants for useful conversations and comments. We thank Robert Sharp and Jonathon Lecznar for excellent research assistance. Caliendo: lorenzo.caliendo@yale.edu, Parro: fernando.j.parro@frb.gov, Rossi-Hansberg: erossi@princeton.edu, and Sarte: pierre.sarte@rich.frb.org. The views expressed in this paper are those of the authors and do not necessarily reflect those of the Federal Reserve Bank of Richmond, the Federal Reserve Board, or the Federal Reserve System.
} 


\section{INTRODUCTION}

Fluctuations in aggregate economic activity result from a wide variety of disaggregated phenomena. These phenomena can reflect underlying changes that are sectoral in nature, such as process or product innovations, or regional in nature, such as natural disasters or changes in local regulations. In other cases, fundamental productivity changes are actually specific to a sector and a location: a large corporate bankruptcy or bailout. The heterogeneity of these potential changes in productivity at the sectoral and regional levels implies that the particular sectoral and regional composition of an economy is essential in determining their aggregate impact. That is, regional trade, the presence of local factors such as land and structures, regional migration, as well as input-output relationships between sectors, all determine the impact of a disaggregated sectoral or regional productivity change on aggregate outcomes. In this paper, we present a model of the sectoral and regional composition of the U.S. economy and use it to measure the elasticity of aggregate measured productivity, output, and welfare, to disaggregated fundamental productivity changes.

The major part of research in macroeconomics has traditionally emphasized aggregate disturbances as sources of aggregate changes. ${ }^{1}$ Exceptions to this approach were Long and Plosser (1983), and Horvath (1998, 2000), who posited that because of input-output linkages, productivity disturbances at the level of an individual sector would be propagated throughout the economy in a way that led to notable aggregate movements. ${ }^{2}$ More recently, the view that idiosyncratic disturbances to individual firms or sectors can have sizeable effects has been further articulated in terms of the network structure implied by input-output or other linkages (Acemoglu, Carvalho, Ozdaglar, Tahbaz-Salehi, 2012, and Oberfield, 2012), and the fact that when the size distribution of firms or sectors is fat-tailed, idiosyncratic disturbances do not average out even in the absence of network effects (Gabaix, 2011). Foerster, Sarte, and Watson (2011) find empirical support for the importance of sectoral linkages highlighted in these papers.

To this point, the literature studying the aggregate implications of disaggregated productivity disturbances has largely abstracted from the regional composition of sectoral activity. However, in the U.S., the distribution of sectoral production across regions is far from uniform. Moreover, in previous work, Blanchard and Katz (1992) provide empirical evidence that factors related to geography, such as labor mobility across states, matter importantly for macroeconomic adjustments to disturbances. This notion is addressed more recently in Fogli, Hill and Perri (2012), while Hamilton and Owyang (2012) further establish the empirical importance of regional characteristics for overall macroeconomic activity. What then are the mechanisms through which geographical considerations help determine the effects of disaggregated productivity changes? What is their quantitative importance? These are the issues that we take up in this paper.

The fact that different regions of the U.S. differ significantly in what they produce has two important

\footnotetext{
${ }^{1}$ This emphasis, for example, permeates the large Real Business Cycles literature that followed the seminal work of Kydland and Prescott (1982).

${ }^{2}$ See also Jovanovic (1987) who shows that strategic interactions among firms or sectors can lead micro disturbances to resemble aggregate factors.
} 
implications. First, to the degree that economic activity involves a complex network of interactions between sectors, these interactions take place over potentially large distances by way of regional trade, but trading across distances is costly. Second, since sectoral production has to take place physically in some location, it is then influenced by a wide range of changing circumstances in that location, from changes in policies affecting the local regulatory environment or business taxes to natural disasters. Added to these regional considerations is that some factors of production are fixed locally and unevenly distributed across space, such as land and structures, while others are highly mobile, such as labor. ${ }^{3}$ For example, in the three months following hurricane Katrina, estimates from the Current Population Survey indicate that the total population of Louisiana fell by more than 6 percent, and is only getting back to its pre-Katrina trend six years later.

To study how these different aspects of economic geography influence the effects of disaggregated productivity disturbances, we develop a quantitative model of the U.S. economy broken down by regions and sectors. In each sector and region, there are two factors of production, labor and a composite factor comprising land and structures. As emphasized by Blanchard and Katz (1992), labor is allowed to move across both regions and sectors. Land and structures can be used by any sector but are fixed locally. Sectors are interconnected by way of input-output linkages but, in contrast to Long and Plosser (1983) and its ensuing literature, shipping materials to sectors located in other regions is costly in a way that varies with distance. Using newly released data on pairwise trade flows across states by industry, as well as other regional and industry data, we calibrate the model and explore the regional, sectoral, and aggregate effects of disaggregated productivity changes. Specifically, for a given productivity change located within a particular sector and region, the model delivers the effects of this change on all sectors and regions in the economy.

We find that disaggregated productivity changes can have dramatically different implications depending on the regions and sectors affected. These effects arise in part by way of endogenous changes in the pattern of regional trade through a selection effect that determines what types of goods are produced in which regions. They also arise by way of labor migration towards regions that become more productive. When such migration takes place, the inflow of workers strains local fixed factors in those regions and, therefore, mitigates the direct effects of any productivity increases. ${ }^{4}$ For example, the aggregate GDP elasticity of a regional fundamental productivity increase in Florida is 0.89. In contrast, the aggregate GDP elasticity of a regional fundamental productivity increase in New York state, which is of comparable employment size relative to aggregate employment (6.1\% versus $6.2 \%$, respectively), is 1.6. Thus, the effects of disaggregated productivity changes depend in complex ways on the details of which sectors and regions are affected, and how these are linked through input-output and trade relationships to other sectors and regions.

These spatial effects affect significantly the magnitude of the aggregate elasticity of sectoral shocks; for example, failure to account for regional trade understates the aggregate GDP elasticity of an increase in productivity in the Petroleum and Coal industry - the most spatially concentrated industry in the U.S.

\footnotetext{
${ }^{3}$ See Kennan and Walker (2011) for a recent detailed empirical study of migration across U.S. states.

${ }^{4}$ In very extreme cases, regional productivity increases can even have negative effects on aggregate GDP (although welfare effects are always positive). In our calibration this happens only for Hawaii (See Figure 8f).
} 
economy - by about $10 \%$ but overstates it by $19 \%$ in the Transportation Equipment industry - an industry that exhibits much less spatial concentration. Ultimately, regional trade linkages, and the fact that materials produced in one region are potentially used as inputs far away, are essential in propagating productivity changes spatially and across sectors. We emphasize this point, and the role of the elasticities we present, through an application that describes how TFP gains in the Computers and Electronics industry in California, over the period 2002-2007, affected all other regions and sectors of the U.S. This particular case highlights not only how these gains adversely affected neighboring states competing in the same industry, but also how other states geographically removed from California, and with virtually no production in Computers and Electronics, nevertheless benefited through a change in the pattern of trade in other sectors.

Because U.S. economic activity is not distributed uniformly across regions, a full treatment of the effects of disaggregated disturbances cannot be carried out without an explicit modeling of regional trading patterns in different industries. In that context, distance and other trade barriers play a key role in determining allocations. Thus, we find that eliminating U.S. regional trading costs associated with distance would result in aggregate TFP gains of approximately 50 percent, and in aggregate GDP gains on the order of 126 percent. These figures are evidently significant, and may be interpreted as upper bounds on the extent to which advances in shipping and other transportation technology can eventually contribute to productivity and value added. More importantly, they also represent a foundation for the role of economic geography in the study of the macroeconomic implications of disaggregated disturbances.

Our paper builds on the seminal work of Eaton and Kortum (2002), and the growing international trade literature that extends their model to multiple sectors. ${ }^{5}$ In particular, we are influenced by recent contributions that highlight the importance of intermediate goods and sectoral linkages in shaping the trade and welfare effects from openness (Caliendo and Parro, 2014), the welfare effects arising from reduced differences in fundamental productivity across sectors and countries (Caselli, Koren, Lisicky, and Tenreyro, 2012, Costinot, Donaldson, and Komunjer, 2012, Levchenko and Zhang, 2012), and the spillover effects from productivity growth in China (Hsieh and Ossa, 2011, di Giovanni, Levchenko, and Zhang, 2013). Relative to this literature, we develop a model that captures the interrelations across sectors and regions within the U.S. economy. The geographic nature of our problem, namely the presence of labor mobility, local fixed factors, and heterogeneous productivities, introduce a different set of mechanisms through which changes in fundamental productivity affect production across sectors and regions compared to an open economy model. From a more regional perspective, two related papers, Redding (2012), and Allen and Arkolakis (2013), study the implications of labor mobility for the welfare gains of trade, but abstract from studying the role of sectoral linkages or from presenting a quantitative assessment of the effects of disaggregated fundamental productivity changes on U.S. aggregate measures of TFP, GDP, or welfare.

\footnotetext{
${ }^{5}$ For instance, Arkolakis, Costinot, Rodriguez-Clare (2012), Burstein, Cravino, and Vogel (2013), Burstein and Vogel (2012), Caliendo and Parro (2010), Chor (2010), Donaldson (2012), Dekle, Eaton and Kortum (2008), Eaton, Kortum, Neiman, and Romalis (2011), Fieler (2011), Kerr (2009), Ossa (2012), Parro (2013), Ramondo and Rodriguez-Clare (2012), and Shikher (2011). Eaton and Kortum (2012) and Costinot and Rodriguez-Clare (2013) present surveys of recent quantitative extensions of the Ricardian model of trade.
} 
The rest of the paper is organized as follows. The next subsection describes the composition of U.S. economic activity. We make use of maps and figures to show how economic activity varies across U.S. states and sectors. Section 2 presents the quantitative model. Section 3 describes in detail how to compute and aggregate measures of TFP, GDP, and welfare across different states and sectors, and shows how these measures relate to fundamental productivity changes. Section 4 describes the data, shows how to carry out counterfactuals, and how to calibrate the model to 50 U.S. states and 26 sectors. Section 5 quantifies the effects of different disaggregated fundamental productivity changes. In particular, we measure the elasticity of aggregate productivity and output to sectoral, regional, as well as sector and region specific productivity changes. Section 6 decomposes the trade costs of moving goods across U.S. states into a geographic distance component and other regional trade barriers. We then evaluate the importance of geographic distance for aggregate measures of TFP, GDP, and welfare. Section 7 concludes.

\subsection{The Composition of U.S. Economic Activity}

Throughout the paper, we break down the U.S. economy into 50 U.S. states and 26 sectors pertaining to the year 2007, our benchmark year. We motivate and describe in detail this particular breakdown in Section 4. As shown in Figure 1a, shares of GDP vary greatly across states. In part, these differences stem from differences in geographic size. However, as Figure 1a makes clear, differences in geographic size are not large enough to explain observed regional differences in GDP. New York state's share of GDP, for example, is slightly larger than Texas' even though its geographic area is several times smaller. The remaining differences cannot be explained by any mobile factor such as labor, equipment, or other material inputs, since those just follow other local characteristics. In fact, as illustrated in Figure 1b, the distribution of employment across states, although not identical to that of GDP, matches it fairly closely. Why then do some regions produce so much more than others and attract many more workers? The basic approach in this paper argues that three local characteristics, namely total factor productivity, local factors, and access to products in other states, are essential to the answer. Specifically, we postulate that changes to total factor productivity (TFP) that are sectoral and regional in nature, or specific to an individual sector within a region, are fundamental to understanding local and sectoral output changes. Furthermore, these changes have aggregate effects that are determined by their geographic and sectoral distribution.

One initial indication that different regions indeed experience different circumstances is presented in Figure 1c, which plots average annualized percentage changes in regional GDP across states for the period 20022007 (Section 4 describes in detail the disaggregated data and calculations that underlie aggregate regional changes in GDP). The figure shows that annualized GDP growth rates vary across states in dramatic ways; from 7.1 percent in Nevada, to 0.02 percent in Michigan. Of course, some of these changes reflect changes in employment levels. Nevada's employment relative to aggregate U.S. employment grew by 3.1 percent during this period while that of Michigan declined by -1.97 percent. Figure 1d indicates that employment shares 
FIG. 1. Distribution of economic activity in the U.S.

a: Share of GDP by region $(\%, 2007)$

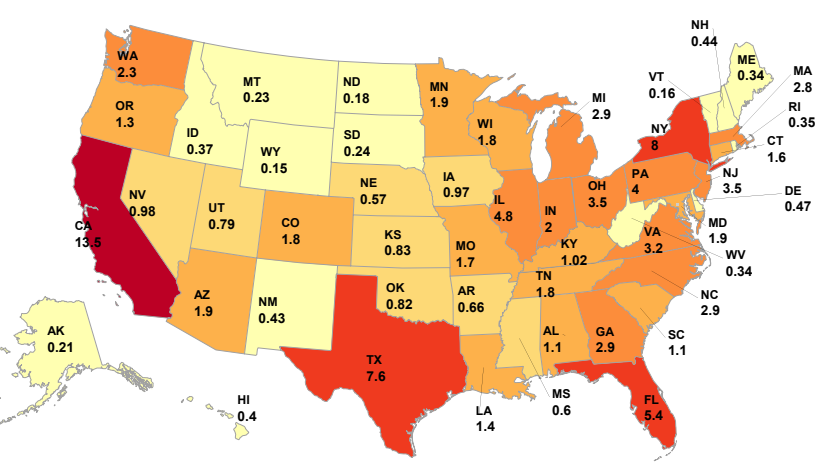

c: Change in GDP $(\%, 2002$ to 2007)

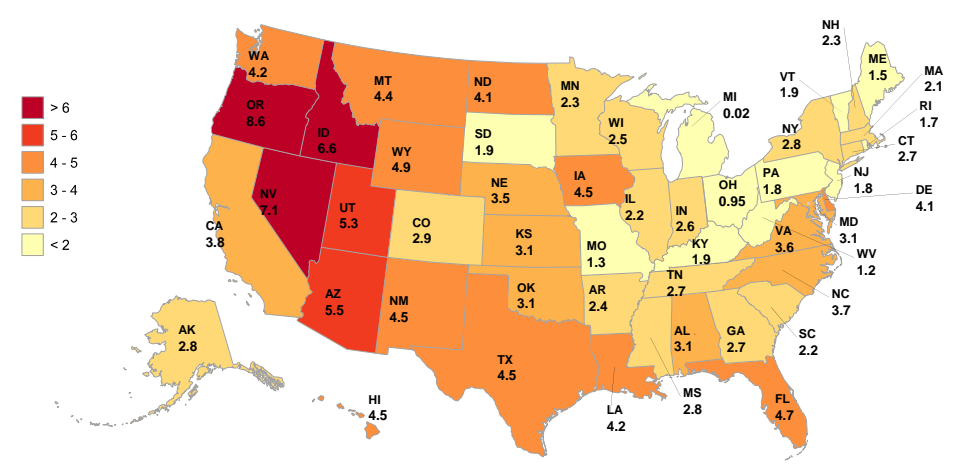

b: Share of Employment by region $(\%, 2007)$

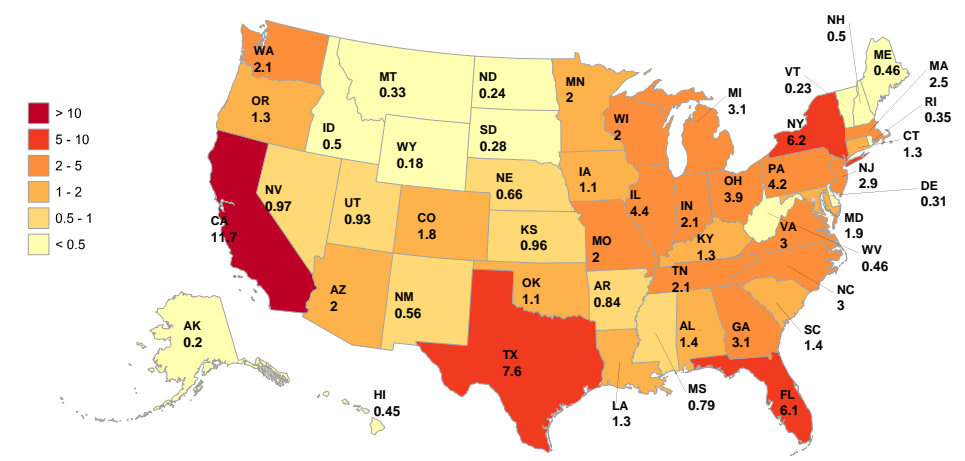

d: Change in Employment shares (\%, 2002 to 2007)

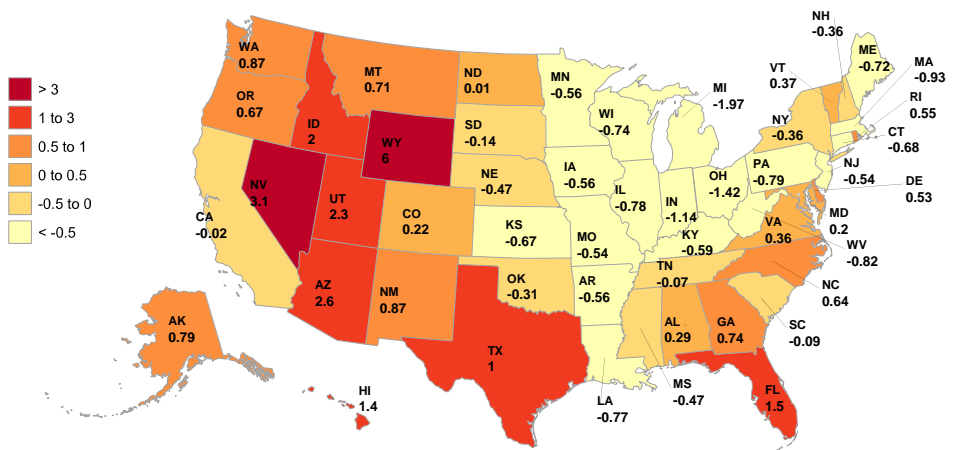

also vary substantially over time, although somewhat less than GDP. The latter observation supports the view that labor is a mobile factor, driven by changes in fundamentals, such as productivity.

While our discussion thus far has underscored overall economic activity across states, one may also consider particular sectors. Doing so immediately reveals that the sectoral distribution of economic activity also varies greatly across space. An extreme example is given by the Petroleum and Coal industry in Figure 2a. This industry is manly concentrated in only 3 states, namely California, Louisiana, and Texas. In contrast, Figure 2b presents GDP shares in the Wood and Paper industry, the most uniformly dispersed industry in our sample. The geographic concentration of industries may, of course, be explained in terms of differences in local productivity or access to essential materials. In this paper, these sources of variation are reflected in individual industry shares across states. For now, we simply make the point that variations in local conditions are large, and that they are far from uniform across industries.

Figure 3a shows the sectoral concentration of economic activity while Figure 3b presents the Herfindahl index of GDP concentration across states for each industry in our study. Differences in the spatial distribution 
FIG. 2. Sectoral concentration across regions (shares, 2007)

a: Petroleum and Coal

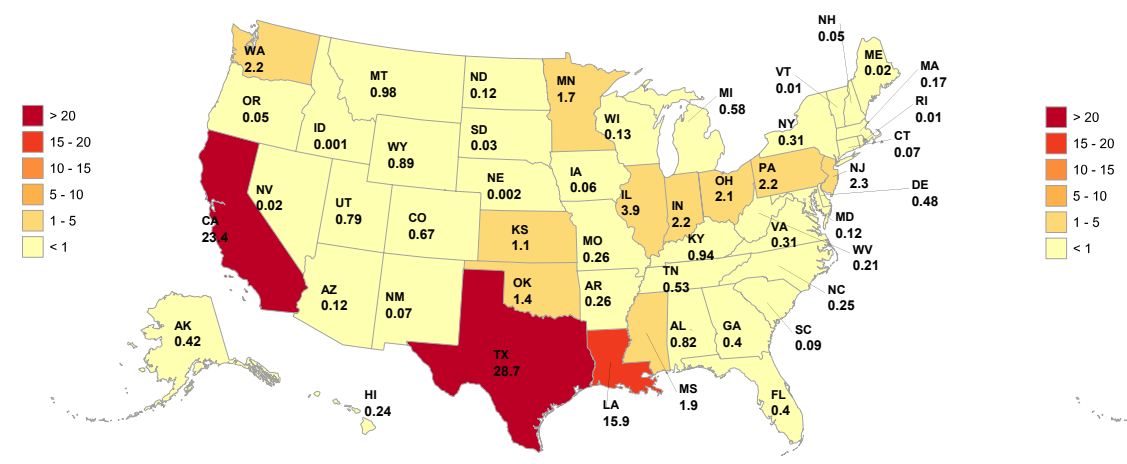

b: Wood and Paper

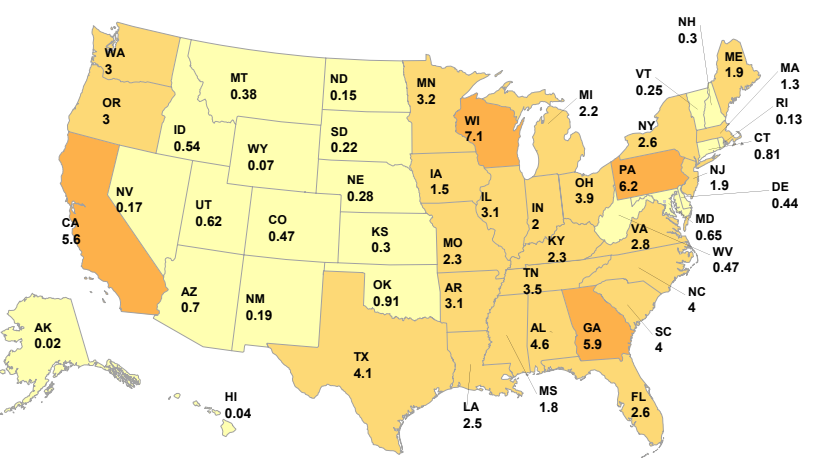

FIG. 3. Economic activity across sectors in the U.S.

a: Sectoral concentration (GDP share, 2007)

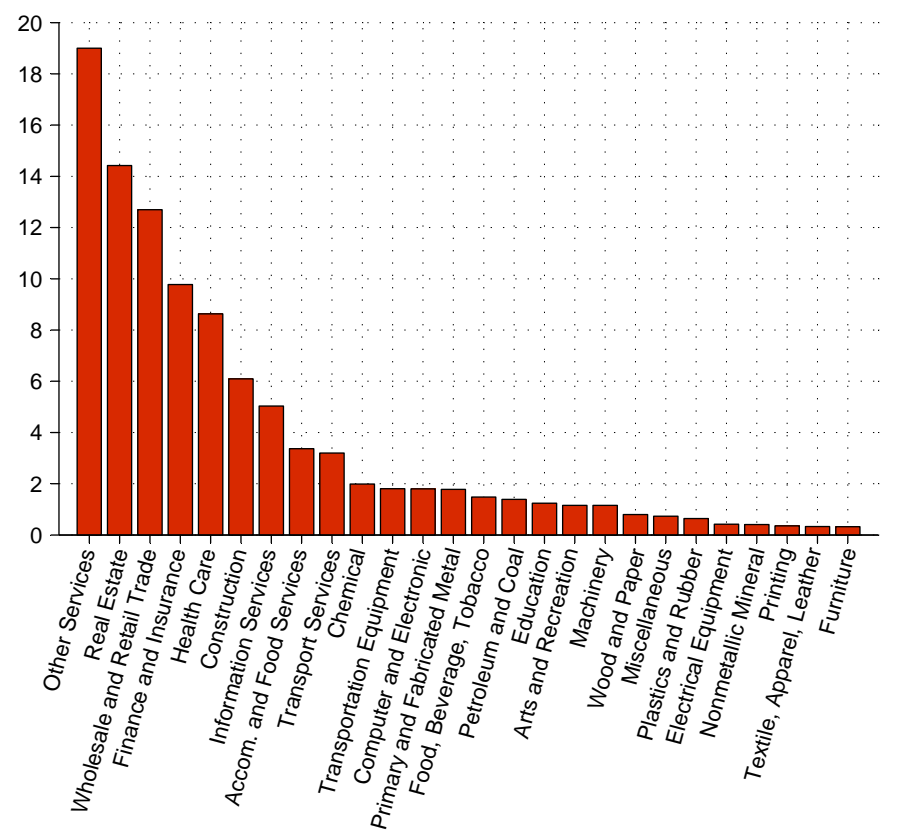

b: Regional concentration (Herfindahl, 2007)

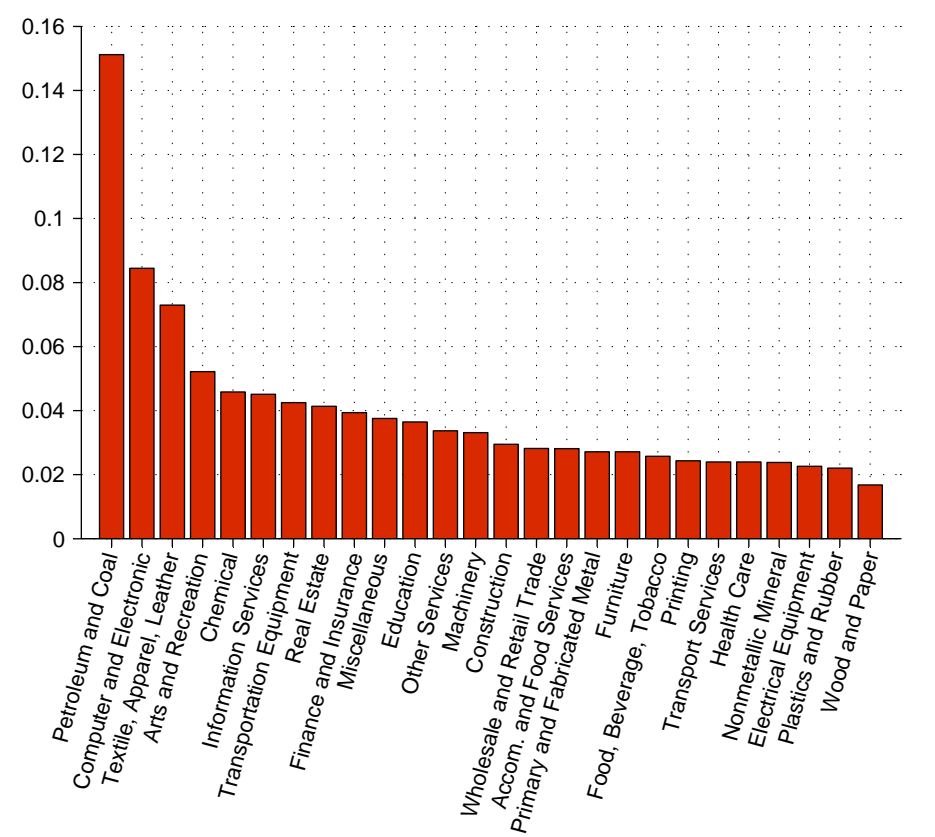

of economic activity for different sectors imply that sectoral disturbances of similar magnitudes will affect regions very differently and, therefore, that their aggregate impact will vary as well. Hence, to assess the implications of technological changes in different sectors, one needs to be cognizant of how these changes are filtered through the regional economy. Studying this process and its quantitative implications is the main purpose of this paper.

An important channel through which the geographic distribution of economic activity, and its breakdown 
across sectors, affects the impact of changes in total factor productivity relates to interregional trade. Trade implies that disturbances to a particular location will affect prices in other locations and thus consumption and, through input-output linkages, production in other locations. This channel has been studied widely with respect to trade across countries but much less with respect to trade across regions within a country. That is, we know little about the propagation of local productivity changes across regions within a country through the channel of interregional trade, when we take into account that people move across states. This is perhaps surprising given that trade is considerably more important within than across countries. Table 1 presents U.S. imports and exports as a percentage of GDP in 2007. Overall, trade across regions amounts to about two thirds of the economy and it is more than twice as large as international trade. This evidence underscores the need to incorporate regional trade in the analysis of the effects of productivity changes, as we do here.

Table 1. : Importance of Regional Trade

U.S. trade as a share of GDP $(\%, 2007)$

\begin{tabular}{lccc} 
& Exports & Imports & Total \\
\hline International trade & 11.9 & 17.0 & 28.9 \\
Interregional trade & 33.4 & 33.4 & 66.8 \\
\hline \hline
\end{tabular}

Source: World Development indicators and CFS

While interregional trade and input-output linkages have the potential to amplify and propagate technological changes, they do not generate them. Furthermore, if all disturbances were only aggregate in nature, regional and sectoral channels would play no role in explaining aggregate changes.

Figure 4a shows that annualized changes in sectoral measured TFP vary dramatically across sectors, from 14 percent per year in the Computer and Electronics industry to a decline in measured productivity of more than 2 percent in Construction. We describe in detail the data and assumptions needed to arrive at disaggregated measures of productivity by sector and region in Section 4 . In that section, we underscore the distinction between fundamental productivity and the calculation of measured productivity that includes the effect of trade and sectoral linkages. In fact, the structure of the model driving our analysis helps precisely in understanding how changes in fundamental productivity affect measured productivity. ${ }^{6}$

Figure $4 \mathrm{~b}$ presents the contribution of sectoral changes in measured TFP to aggregate TFP changes. The distinction between Figures $4 \mathrm{a}$ and $4 \mathrm{~b}$ reflects the importance or weight of different sectors in aggregate productivity. Once more, the heterogeneity across sectors is surprising. Moreover, this heterogeneity implies that changes in a particular sector will have very distinct effects on aggregate productivity, even conditional

\footnotetext{
${ }^{6}$ Regional measures of TFP at the state level are not directly available from a statistical agency. As explained in Section 4, our calculations of disaggregated TFP changes rely on other information directly observable by region and sector, such as value added or gross output calculated from trade flows, as well as on unobserved information inferred using equilibrium relationships consistent with the model presented in Section 2. Importantly, our measures of disaggregated TFP changes sum up to the aggregate TFP change for the same period directly available from the OECD productivity database.
} 
FIG. 4. Sectoral measured TFP of the U.S. economy from 2002 to 2007

a: Change in sectoral TFP $(\%)$

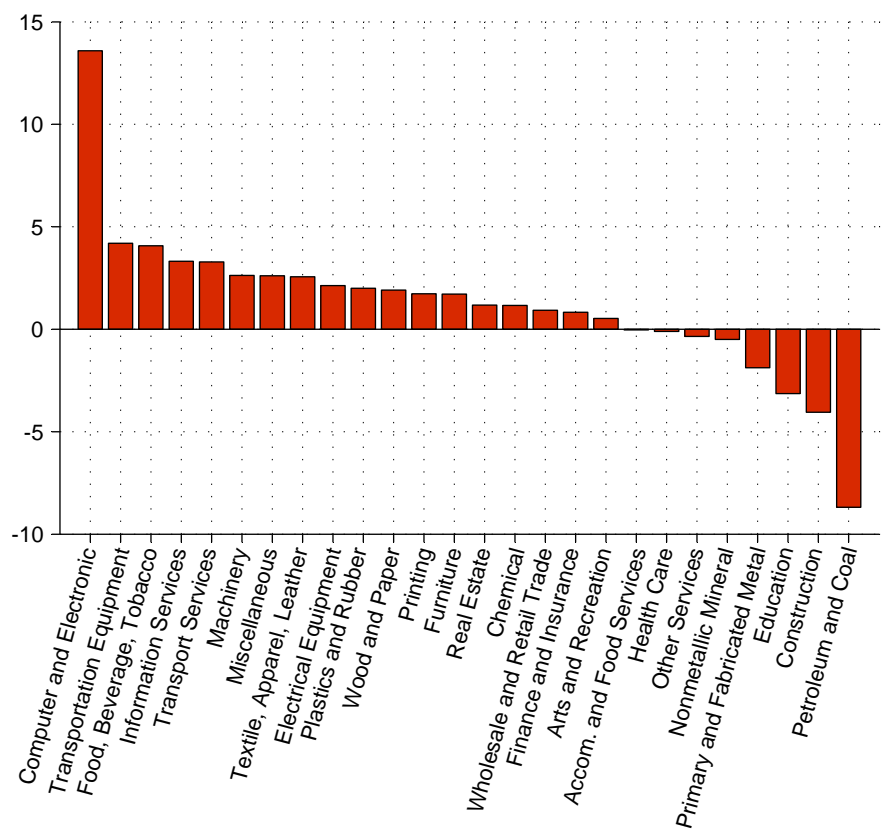

b: Sectoral contribution to the change in aggregate TFP (\%)

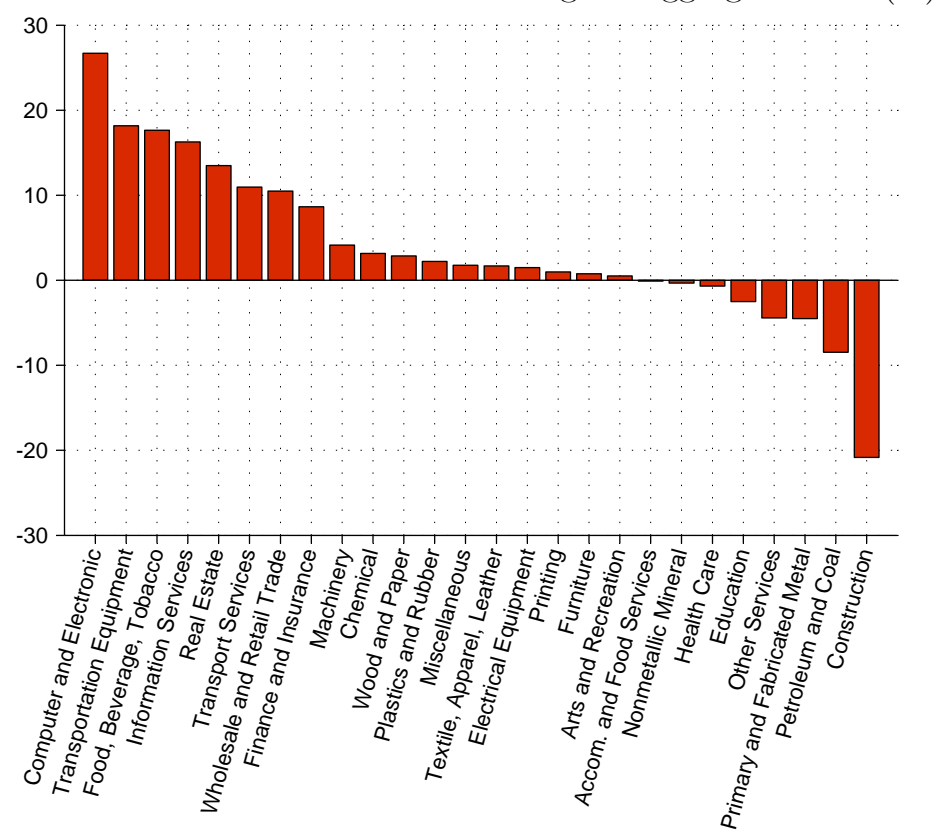

on the size of the changes.

Variations in TFP across sectors have received considerable attention in the macroeconomics literature (see Foerster et al., 2011, Gabaix, 2011, and Acemoglu, et al., 2012, among others). In contrast, this literature has paid virtually no attention to the regional composition of TFP changes. Figures $5 \mathrm{a}$ and $\mathrm{b}$ shows that this lack of attention is potentially misguided. Changes in measured TFP vary widely across regions. Furthermore, the contribution of regional changes in measured TFP to variations in aggregate TFP is also very large. The difference between Figures 5a and 5b reflects the weight of different states in aggregate productivity.

The change in TFP over the period 2002-2007 was 1.4 percent per year in Nevada but 1.1 percent in Michigan. These differences in TFP experiences naturally contributed to differences in employment and GDP changes in those states. More generally, variations across states result in part from sectoral productivity changes as well as changes in the distribution of sectors across space which, as we have argued, is far from uniform. However, even if all the variation in Figures $5 \mathrm{a}$ and $\mathrm{b}$ were ultimately traced back to sectoral changes, their uneven regional composition would influence their impact on trade and, ultimately, aggregate TFP.

One of the key economic determinants of income across regions is the stock of land and structures. To our knowledge, there is no direct measure of this variable. However, as we explain in detail in Section 4, we can use the equilibrium conditions from our model to infer the regional distribution of income from land and structures across U.S. states. Figure 6 shows that per capita income from land and structures in 2007 U.S. 
FIG. 5. Regional measured TFP of the U.S. economy from 2002 to 2007

a: Change in TFP by regions (\%)

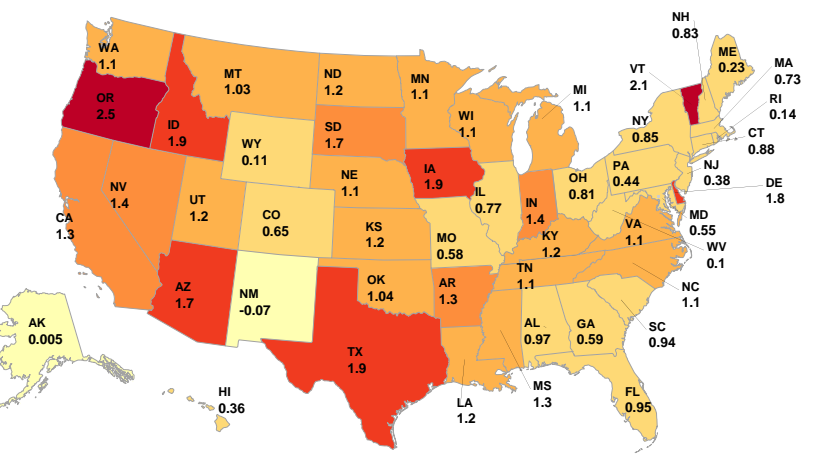

b: Regional contribution to the change in aggregate TFP (\%)

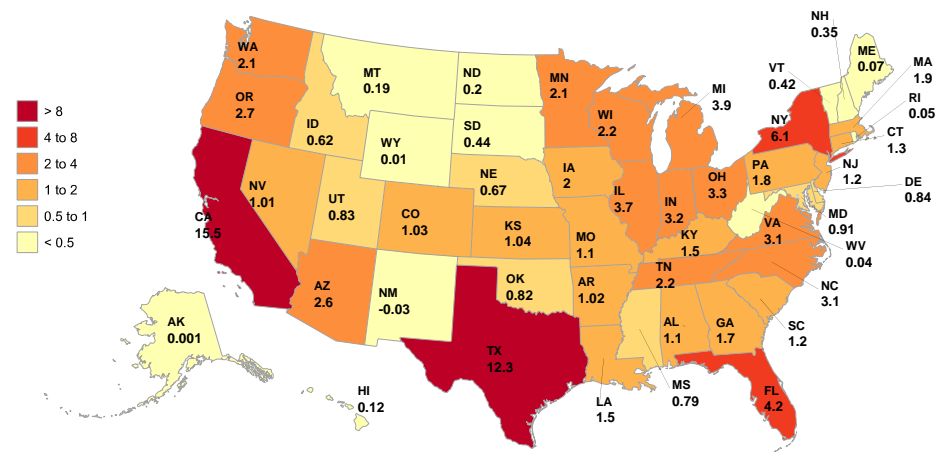

dollars varies considerably across states. The range varies from a low of 10,200 and 13,000 dollars per capita for the case of Vermont and Wisconsin respectively, to a high of 47,000 dollars in Delaware. We will argue that this regional dispersion of land and structures across regions in the U.S. is central to understanding the aggregate effects of disaggregated fundamental productivity changes.

FIG. 6. Per capita regional rent from land and structures (10,000 of 2007 U.S. dollars)

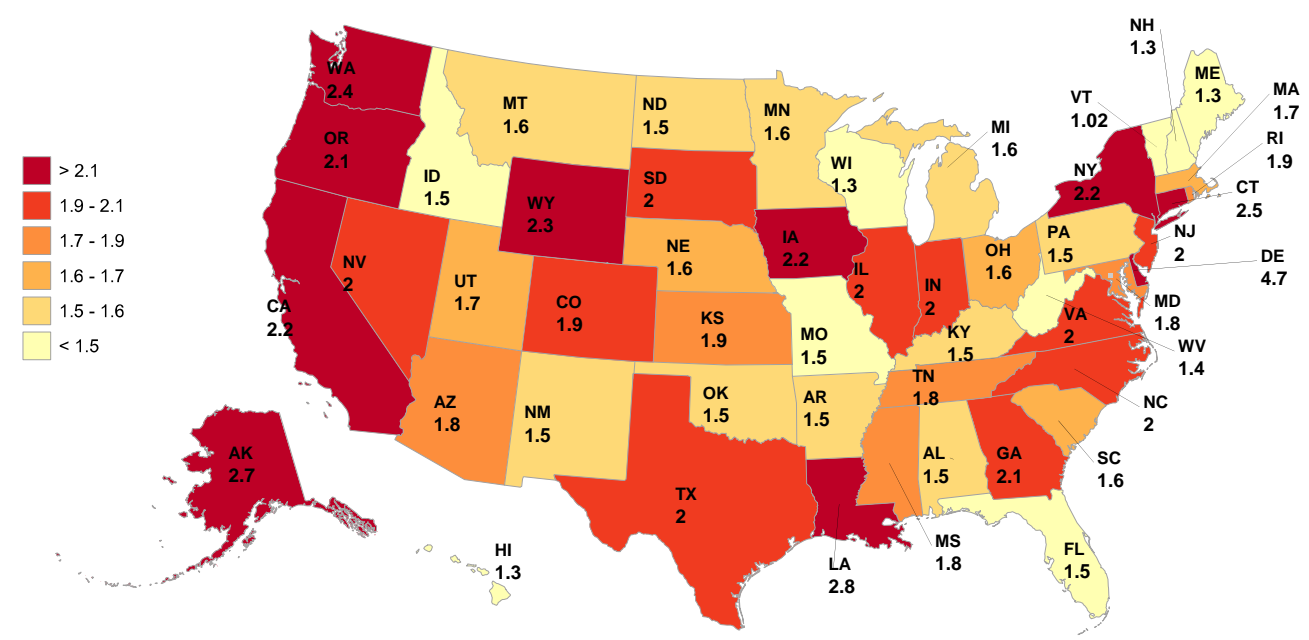

\section{THE MODEL}

Our goal is to produce a quantitative model of the U.S. economy disaggregated across regions and sectors. For this purpose, we develop a static two factor model with $N$ regions and $J$ sectors. We denote a particular 
region by $n \in\{1, \ldots, N\}$ (or $i$ ), and a particular sector by $j \in\{1, \ldots, J\}$ (or $k$ ). The economy has two factors, labor and a composite factor comprising land and structures. Labor can freely move across regions and sectors. Land and structures, $H_{n}$, are a fixed endowment of each region but can be used by any sector. We denote total population size by $L$, and the population in each region by $L_{n}$. A given sector may be either tradable, in which case goods from that sector may be traded at a cost across regions, or non-tradable. Throughout the paper, we abstract from international trade and other international economic interactions.

\subsection{Consumers}

Agents in each location $n \in\{1, \ldots, N\}$ order consumption baskets according to Cobb-Douglas preferences, with shares, $\alpha^{j}$, over their consumption of final domestic goods, $c_{n}^{j}$, bought at prices, $P_{n}^{j}$, in all sectors $j \in\{1, \ldots, J\}$. Preferences are homothetic of degree one, so $\sum_{j=1}^{J} \alpha^{j}=1$.

Agents supply one unit of labor inelastically and receive the return to local factors. We assume that a fraction $\iota_{n} \in[0,1]$ of the local factor is part of a national portfolio of local assets. All residents hold an equal number of shares in that portfolio and so receive the same proportion of its returns. The remaining share, $\left(1-\iota_{n}\right)$, of local factors is owned by the local government in region $n$. The returns to this fraction of the local factors is distributed lump-sum to all local residents. This ownership structure of local factors result in a model that is flexible enough (through the determination of $\iota_{n}$ ) to match almost exactly observed trade imbalances across states (see Section 4). It allows individuals living in certain states to receive higher returns from local factors but avoids the complications of individual wealth effects, and the resulting heterogeneity across individuals, that result from individual holdings of local assets. We refer to $1-\iota_{n}$ as the share of local rents from land and structures.

The income of an agent residing in region $n$ is

$$
I_{n}=w_{n}+\chi+\left(1-\iota_{n}\right) \frac{r_{n} H_{n}}{L_{n}}
$$

where $w_{n}$ is the wage and $r_{n}$ is the rental rate of structures and land, and $r_{n} H_{n} / L_{n}$, is the per capita income from renting land and structures to firms in region $n$. The term $\chi$ represents the return per person from the national portfolio of land and structures from all regions. In particular,

$$
\chi=\frac{\sum_{i=1}^{N} \iota_{i} r_{i} H_{i}}{\sum_{i=1}^{N} L_{i}} .
$$

The last term, $\left(1-\iota_{n}\right) r_{n} H_{n} / L_{n}$, denotes the rents on land and structures distributed locally by the government. Thus, total income in region $n$ is

$$
L_{n} I_{n}=w_{n} L_{n}+r_{n} H_{n}-\Upsilon_{n}
$$

where $\Upsilon_{n}=\iota_{n} r_{n} H_{n}-\chi L_{n}$ is a measure of regional trade imbalance that emerges from interregional transfers implied by the national portfolio of fixed assets. ${ }^{7}$

\footnotetext{
${ }^{7}$ An alternative option is to allow some immobile agents in each state to own state-specific shares of a national portfolio
} 
The problem of an agent in region $n$ is then given by

$$
v_{n} \equiv \max _{\left\{c_{n}^{j}\right\}_{j=1}^{J}} \prod_{j=1}^{J}\left(c_{n}^{j}\right)^{\alpha^{j}}, \text { subject to } \sum_{j=1}^{J} P_{n}^{j} c_{n}^{j}=I_{n} .
$$

It follows that total demand of final good $j$ in region $n$ is

$$
L_{n} c_{n}^{j}=\alpha^{j} \frac{L_{n} I_{n}}{P_{n}^{j}} .
$$

Agents move freely across regions. From the household problem, the value of locating in a particular region $n$ is

$$
v_{n}=\frac{w_{n}+\chi+\left(1-\iota_{n}\right) \frac{r_{n} H_{n}}{L_{n}}}{P_{n}}
$$

where $P_{n}=\prod_{j=1}^{J}\left(P_{n}^{j} / \alpha^{j}\right)^{\alpha^{j}}$ is the ideal price index in region $n$. In equilibrium, households are indifferent between living in any region so that

$$
v_{n}=\frac{I_{n}}{P_{n}}=U
$$

for all $n \in\{1, \ldots, N\}$, for some $U$ determined in equilibrium.

\subsection{Technology}

Sectoral final goods are used for consumption and as material inputs into the production of intermediate goods in all industries. In each sector, final goods are produced using a continuum of varieties of intermediate goods in that sector. We refer to the intermediate goods used in the production of final goods as 'intermediates,' and to the final goods used as inputs in the production of intermediate goods as 'materials.'

\subsubsection{Intermediate Goods}

Representative firms, in each region $n$ and sector $j$, produce a continuum of varieties of intermediate goods that differ in their idiosyncratic productivity level, $z_{n}^{j} \cdot{ }^{8} \mathrm{In}$ each region and sector, this productivity level is a random draw from a Fréchet distribution with shape parameter $\theta^{j}$. Note that $\theta^{j}$ varies only across sectors. We assume that all draws are independent across goods, sectors, and regions. The productivity of all firms producing varieties in a region-sector pair $(n, j)$ is also determined by a deterministic productivity level, $T_{n}^{j}$,

that includes all the rents of the immobile factor (namely $\chi=\sum_{i} r_{i} H_{i}$ ). As long as these shares sum to one, and the rentiers cannot move, such a model is as tractable as the one we propose in the main text. The allocation of such a model is also efficient as long as the constraint on the mobility of rentiers is not binding in equilibrium. We have computed our main results with this alternative model and find very similar results. For example, the correlation of the elasticities of aggregate TFP and real GDP to regional fundamental productivity changes between the model we propose and this alternative model is $95.2 \%$ and $95.1 \%$, respectively. Ultimately, although not particular important given these numbers, the choice between having some local distribution of rents, or some immobile agents that own all the shares in the national portfolio, involves choosing between similar, albeit perhaps not ideal, simplifying assumptions.

${ }^{8}$ In a parallel extension of Eaton and Kortum (2002), in each sector within a region, each variety that is used by firms in production within that sector and region is associated with an idiosyncratic productivity level. Since technology is constantreturns-to-scale (CRS), the number of firms producing any given variety is indeterminate and irrelevant for the equilibrium allocation. Hence, throughout the analysis, we work with firms, or representative firms, that produce different varieties of a sectoral good within a region. 
specific to that region and sector. We refer to $T_{n}^{j}$ as fundamental productivity. The production function for a variety associated with idiosyncratic productivity $z_{n}^{j}$ in $(n, j)$ is given by

$$
q_{n}^{j}\left(z_{n}^{j}\right)=z_{n}^{j}\left[T_{n}^{j} h_{n}^{j}\left(z_{n}^{j}\right)^{\beta_{n}} l_{n}^{j}\left(z_{n}^{j}\right)^{\left(1-\beta_{n}\right)}\right]^{\gamma_{n}^{j}} \prod_{k=1}^{J} M_{n}^{j k}\left(z_{n}^{j}\right)^{\gamma_{n}^{j k}}
$$

where $h_{n}^{j}(\cdot)$ and $l_{n}^{j}(\cdot)$ denote the demand for structures and labor respectively, $M_{n}^{j k}(\cdot)$ is the demand for final material inputs by firms in sector $j$ from sector $k$ (variables representing final goods are denoted with capital letters), $\gamma_{n}^{j k} \geqslant 0$ is the share of sector $j$ goods spent on materials from sector $k$, and $\gamma_{n}^{j} \geqslant 0$ is the share of value added in gross output. We assume that the production function has constant returns to scale, $\sum_{k=1}^{J} \gamma_{n}^{j k}=1-\gamma_{n}^{j}$. Observe that $T_{n}^{j}$ scales value added and not gross output. This feature ensures that an increase in $T_{n}^{j}$, for all $j$ and $n$, has a proportional effect on aggregate real GDP.

The unit cost of producing varieties with draw $z_{n}^{j}$ in $(n, j)$ is given by

$$
\min _{\left\{h_{n}^{j}\left(z_{n}^{j}\right), l_{n}^{j}\left(z_{n}^{j}\right), M_{n}^{j k}\left(z_{n}^{j}\right)\right\}_{k=1}^{J}} w_{n} l_{n}^{j}\left(z_{n}^{j}\right)+r_{n} h_{n}^{j}\left(z_{n}^{j}\right)+\sum_{k=1}^{J} P_{n}^{k} M_{n}^{j k}\left(z_{n}^{j}\right),
$$

subject to

$$
z_{n}^{j}\left[T_{n}^{j} h_{n}^{j}\left(z_{n}^{j}\right)^{\beta_{n}} l_{n}^{j}\left(z_{n}^{j}\right)^{\left(1-\beta_{n}\right)}\right]^{\gamma_{n}^{j}} \prod_{k=1}^{J} M_{n}^{j k}\left(z_{n}^{j}\right)^{\gamma_{n}^{j k}}=1,
$$

where $P_{n}^{k}$ is the price of final goods in industry $k$ in region $n$. Let $x_{n}^{j}$ denote the cost of the input bundle needed to produce intermediate good varieties in $(n, j)$. Then

$$
x_{n}^{j}=B_{n}^{j}\left[r_{n}^{\beta_{n}} w_{n}^{1-\beta_{n}}\right]^{\gamma_{n}^{j}} \prod_{k=1}^{J}\left(P_{n}^{k}\right)^{\gamma_{n}^{j k}}
$$

where

$$
B_{n}^{j}=\left[\left(1-\beta_{n}\right)^{\left(\beta_{n}-1\right)}\left(\beta_{n}\right)^{-\beta_{n}}\right]^{\gamma_{n}^{j}}\left[\prod_{k=1}^{J}\left(\gamma_{n}^{j k}\right)^{-\gamma_{n}^{j k}}\right] .
$$

The unit cost of an intermediate good with idiosyncratic draw $z_{n}^{j}$ in region-sector pair $(n, j)$ is then given by

$$
\frac{x_{n}^{j}}{z_{n}^{j}\left(T_{n}^{j}\right)^{\gamma_{n}^{j}}} .
$$

Firms located in region $n$ and operating in sector $j$ will be motivated to produce the variety whose productivity draw is $z_{n}^{j}$ as long as its price matches or exceeds $x_{n}^{j} / z_{n}^{j}\left(T_{n}^{j}\right)^{\gamma_{n}^{j}}$. Assuming a competitive market for intermediate goods, firms that produce a given variety in $(n, j)$ will price it according to its corresponding unit cost, given by Equation (6).

Let $p_{n}^{j}\left(z^{j}\right)$ represent the equilibrium price of a variety for which the vector of idiosyncratic productivity draws in all $N$ regions is given by $z^{j}=\left(z_{1}^{j}, z_{2}^{j}, \ldots z_{N}^{j}\right)$. The determination of this price in equilibrium is discussed in detail below. Since the production function is Cobb-Douglas, profit maximization implies that input demands, $h_{n}^{j}\left(z_{n}^{j}\right), l_{n}^{j}\left(z_{n}^{j}\right)$, and $M_{n}^{j k}\left(z_{n}^{j}\right)$ for all $k$, satisfy ${ }^{9}$

\footnotetext{
${ }^{9}$ Factor demands are evidently also a function of the price, although we do not acknowledge this fact explicity to ease notation.
} 


$$
\begin{aligned}
\frac{h_{n}^{j}\left(z_{n}^{j}\right) r_{n}}{p_{n}^{j}\left(z^{j}\right) q_{n}^{j}\left(z_{n}^{j}\right)} & =\gamma_{n}^{j} \beta_{n}, \\
\frac{l_{n}^{j}\left(z_{n}^{j}\right) w_{n}}{p_{n}^{j}\left(z^{j}\right) q_{n}^{j}\left(z_{n}^{j}\right)} & =\gamma_{n}^{j}\left(1-\beta_{n}\right), \\
\frac{P_{n}^{k} M_{n}^{j k}\left(z_{n}^{j}\right)}{p_{n}^{j}\left(z^{j}\right) q_{n}^{j}\left(z_{n}^{j}\right)} & =\gamma_{n}^{j k} .
\end{aligned}
$$

\subsubsection{Final Goods}

Final goods in region $n$ and sector $j$ are produced by combining intermediate goods in sector $j$. Denote the quantity of final goods in $(n, j)$ by $Q_{n}^{j}$, and denote by $\tilde{q}_{n}^{j}\left(z^{j}\right)$ the quantity demanded of an intermediate good of a given variety such that, for that variety, the particular vector of productivity draws received by the different $n$ regions is $z^{j}=\left(z_{1}^{j}, z_{2}^{j}, \ldots z_{N}^{j}\right)$. The production of final goods is given by

$$
Q_{n}^{j}=\left[\int \tilde{q}_{n}^{j}\left(z^{j}\right)^{1-1 / \eta_{n}^{j}} \phi^{j}\left(z^{j}\right) d z^{j}\right]^{\eta_{n}^{j} /\left(\eta_{n}^{j}-1\right)},
$$

where $\phi^{j}\left(z^{j}\right)=\exp \left\{-\sum_{n=1}^{N}\left(z_{n}^{j}\right)^{-\theta^{j}}\right\}$ denotes the joint density function for the vector $z^{j}$, with marginal

densities given by $\phi_{n}^{j}\left(z_{n}^{j}\right)=\exp \left\{-\left(z_{n}^{j}\right)^{-\theta^{j}}\right\}$, and the integral is over $\mathbb{R}_{+}^{N}$. For non-tradeable sectors, the only relevant density is $\phi_{n}^{j}\left(z_{n}^{j}\right)$ since final good producers use only locally produced goods.

Producers of composite sectoral goods then solve

$$
\max _{\left\{\tilde{q}_{n}^{j}\left(z^{j}\right)\right\}_{\mathbb{R}_{+}^{N}}} P_{n}^{j} Q_{n}^{j}-\int p_{n}^{j}\left(z^{j}\right) \tilde{q}_{n}^{j}\left(z^{j}\right) \phi^{j}\left(z^{j}\right) d z^{j} .
$$

where $p_{n}^{j}\left(z^{j}\right)$ denotes the price of intermediate goods. Then, the demand function is given by

$$
\tilde{q}_{n}^{j}\left(z^{j}\right)=\left(\frac{p_{n}^{j}\left(z^{j}\right)}{P_{n}^{j}}\right)^{-\eta_{n}^{j}} Q_{n}^{j},
$$

where $P_{n}^{j}$ is a price index for sector $j$ in region $n$,

$$
P_{n}^{j}=\left[\int p_{n}^{j}\left(z^{j}\right)^{1-\eta_{n}^{j}} \phi^{j}\left(z^{j}\right) d z^{j}\right]^{1 /\left(1-\eta_{n}^{j}\right)} .
$$

There is free entry in the production of final goods with competition implying zero profits.

\subsection{Prices and Market Clearing}

Final goods are non-tradable. Intermediate goods in tradable sectors are costly to trade. One unit of any intermediate good in sector $j$ shipped from region $i$ to region $n$ requires producing $\kappa_{n i}^{j} \geq 1$ units in $i$, with $\kappa_{n n}^{j}=1$ and, for intermediate goods in non-tradable sectors, $\kappa_{n i}^{j}=\infty$. Thus, the price paid for a particular variety whose vector of productivity draws is $z^{j}, p_{n}^{j}\left(z^{j}\right)$, is given by the minimum of the unit costs across 
locations, adjusted by the transport $\operatorname{costs} \kappa_{n i}^{j}$. That is,

$$
p_{n}^{j}\left(z^{j}\right)=\min _{i}\left\{\frac{\kappa_{n i}^{j} x_{i}^{j}}{z_{i}^{j}\left(T_{i}^{j}\right)^{\gamma_{i}^{j}}}\right\} .
$$

Given our assumptions governing the distribution of idiosyncratic productivities, $z_{i}^{j}$, we follow Eaton and Kortum (2002) to solve for the distribution of prices. Having solved for the distribution of prices, when sector $j$ is tradeable, the price of final good $j$ in region $n$ is given by

$$
P_{n}^{j}=\Gamma\left(\xi_{n}^{j}\right)^{1-\eta_{n}^{j}}\left[\sum_{i=1}^{N}\left[x_{i}^{j} \kappa_{n i}^{j}\right]^{-\theta^{j}}\left(T_{i}^{j}\right)^{\theta^{j} \gamma_{i}^{j}}\right]^{-1 / \theta^{j}},
$$

where $\Gamma\left(\xi_{n}^{j}\right)$ is a Gamma function evaluated at $\xi_{n}^{j}=1+\left(1-\eta_{n}^{j}\right) / \theta^{j}$. When $j$ denotes a non-tradeable sector, the price index is instead given by

$$
P_{n}^{j}=\Gamma\left(\xi_{n}^{j}\right)^{1-\eta_{n}^{j}} x_{n}^{j}\left(T_{n}^{j}\right)^{-\gamma_{n}^{j}}
$$

Regional labor market clearing requires that

$$
\sum_{j=1}^{J} L_{n}^{j}=\sum_{j=1}^{J} \int_{0}^{\infty} l_{n}^{j}(z) \phi_{n}^{j}(z) d z=L_{n}, \text { for all } n \in\{1, \ldots, N\},
$$

where $L_{n}^{j}$ denote the number of workers in $(n, j)$, and national labor market clearing is given by

$$
\sum_{n=1}^{N} L_{n}=L
$$

In a regional equilibrium, land and structures must satisfy

$$
\sum_{j=1}^{J} H_{n}^{j}=\sum_{j=1}^{J} \int_{0}^{\infty} h_{n}^{j}(z) \phi_{n}^{j}(z) d z=H_{n}, \text { for all } n \in\{1, \ldots, N\},
$$

where $H_{n}^{j}$ denotes land and structure use in $(n, j)$.

Profit maximization by intermediate goods producers, together with these equilibrium conditions, implies that

$$
r_{n} H_{n}=\frac{\beta_{n}}{1-\beta_{n}} w_{n} L_{n}, \text { for all } n \in\{1, \ldots, N\} .
$$

Then, defining $\omega_{n} \equiv\left(r_{n} / \beta_{n}\right)^{\beta_{n}}\left(w_{n} /\left(1-\beta_{n}\right)\right)^{\left(1-\beta_{n}\right)}$, free mobility gives us

$$
L_{n}=H_{n}\left[\frac{\omega_{n}}{P_{n} U}\right]^{\frac{1}{\beta_{n}}}
$$

which, combined with the labor market clearing condition, yields an expression for labor input in region $n$,

$$
L_{n}=\frac{H_{n}\left[\frac{\omega_{n}}{P_{n} U}\right]^{1 / \beta_{n}}}{\sum_{i=1}^{N} H_{i}\left[\frac{\omega_{i}}{P_{i} U}\right]^{1 / \beta_{i}}} L .
$$

It remains to describe market clearing in final and intermediate goods markets. Regional market clearing in final goods is given by

$$
L_{n} c_{n}^{j}+\sum_{k=1}^{J} M_{n}^{k j}=L_{n} c_{n}^{j}+\sum_{k=1}^{J} \int_{0}^{\infty} M_{n}^{k j}(z) \phi_{n}^{k}(z) d z=Q_{n}^{j}
$$


for all $j \in\{1, \ldots, J\}$ and $n \in\{1, \ldots, N\}$. where $M_{n}^{k j}$ represents the use of intermediates of sector $j$ in sector $k$ at $n$.

Let $X_{n}^{j}$ denote total expenditures on final good $j$ in region $n$ (or total revenue). Then, regional market clearing in final goods implies that

$$
X_{n}^{j}=\sum_{k=1}^{J} \gamma_{n}^{k j} \sum_{i=1}^{N} \pi_{i n}^{k} X_{i}^{k}+\alpha^{j} I_{n} L_{n}
$$

where $\pi_{n i}^{j}$ denotes the share of region $n$ 's total expenditures on sector $j$ 's intermediate goods purchased from region i. As in Eaton and Kortum (2002), and Alvarez and Lucas (2007), it is convenient to define an equilibrium in the intermediate goods market, and their associated trade flows, in terms of trade and expenditure shares, rather than the flows and expenditures related to individual varieties. Define

$$
X_{n i}^{j}=\operatorname{Pr}\left[\frac{\kappa_{n i}^{j} x_{i}^{j}}{z_{i}^{j}\left(T_{i}^{j}\right)^{\gamma_{i}^{j}}} \leq \min _{m \neq i} \frac{\kappa_{n m}^{j} x_{m}^{j}}{z_{m}^{j}\left(T_{m}^{j}\right)^{\gamma_{m}^{j}}}\right] X_{n}^{j},
$$

and recall that, because of zero profits in final goods sectors, total expenditures on intermediate goods in a given sector exhaust total revenue from final goods in that sector. Then, given properties of the Fréchet distribution, equilibrium in the intermediate goods market implies that

$$
\pi_{n i}^{j}=\frac{X_{n i}^{j}}{X_{n}^{j}}=\left(\Gamma\left(\xi_{n}^{j}\right)^{1-\eta_{n}^{j}} \frac{\kappa_{n i}^{j} x_{i}^{j}}{\left(T_{i}^{j}\right)^{\gamma_{i}^{j}} P_{n}^{j}}\right)^{-\theta^{j}} .
$$

In non-tradable sectors, $\kappa_{n i}^{j}=\infty$ for all $n\{1, \ldots, N\}$ so that $\pi_{n n}^{j}=1$.

In equilibrium, in any region $n$, total expenditures on intermediates purchased from other regions must equal total revenue from intermediates sold to other regions, formally,

$$
\sum_{j=1}^{J} \sum_{i=1}^{N} \pi_{n i}^{j} X_{n}^{j}+\Upsilon_{n}=\sum_{j=1}^{J} \sum_{i=1}^{N} \pi_{i n}^{j} X_{i}^{j}
$$

Trade is, in general, not balanced within each region since a particular region can be a net recipient of national returns on land and structures while another might be a net contributor. As such, our model, through its ownership structure, presents a theory of trade imbalances and how these imbalances are affected by changes in fundamental productivity. In Section 4 we explain how to use information on regional trade imbalances to estimate the parameters that determine the ownership structure, $\left\{\iota_{n}\right\}_{n=1}^{N}$.

Given factor supplies, $L$ and $\left\{H_{n}\right\}_{n=1}^{N}$, a competitive equilibrium for this economy is a utility level $U$, a set of factor prices in each region, $\left\{r_{n}, w_{n}\right\}_{n=1}^{N}$, a set of labor allocations, structure allocations, final good expenditures, consumption of final goods per person, and final goods prices, $\left\{L_{n}^{j}, H_{n}^{j}, X_{n}^{j}, c_{n}^{j}, P_{n}^{j}\right\}_{n=1, j=1}^{N, J}$, pairwise sectoral material use in every region, $\left\{M_{n}^{j k}\right\}_{n=1, j=1, k=1}^{N, J, J}$, regional transfers $\left\{\Upsilon_{n}\right\}_{n=1}^{N}$, and pairwise regional intermediate expenditure shares in every sector, $\left\{\pi_{n i}^{j}\right\}_{n=1, i=1, j=1}^{N, N, J}$, such that the optimization conditions for consumers and intermediate and final goods producers hold, all markets clear - equations (14), (15), (18), (19) hold -, aggregate trade is balanced - (20) holds- , and utility is equalized across regions, (16) holds. 


\section{AGGREGATION AND CHANGES IN MEASURED TFP, GDP, AND WELFARE}

Given the model we have just laid out, this section describes how to arrive at measures of total factor productivity, GDP, and welfare, that are disaggregated across both regions and sectors. These calculations of measures at the level of sector in a region, using available industry and regional trade data for the U.S., underlie Figures 1 through 8 and their discussion in Section 1.1, as well as all calculations in the rest of the paper.

\subsection{Measured TFP}

Measured sectoral total factor productivity in a region-sector pair $(n, j)$ is commonly calculated as

$$
\ln A_{n}^{j}=\ln \frac{w_{n} L_{n}^{j}+r_{n} H_{n}^{j}+\sum_{k=1}^{J} P_{n}^{k} M_{n}^{j k}}{P_{n}^{j}}-\left(1-\beta_{n}\right) \gamma_{n}^{j} \ln L_{n}^{j}-\beta_{n} \gamma_{n}^{j} \ln H_{n}^{j}-\sum_{k=1}^{J} \gamma_{n}^{j k} \ln M_{n}^{j k} .
$$

The first term is gross output revenue over price -a measure of gross production in $(n, j)$ which we denote by $Y_{n}^{j} / P_{n}^{j}$, and which is equal to $Q_{n}^{j}$ in the case of non-tradables-, while the last three terms denote the $\log$ of the aggregate input bundle. ${ }^{10}$ This last equation assumes that we use gross output and final good prices to calculate region-sector TFP. Observe that (7), (8), and (9) imply that

$$
Y_{n}^{j}=w_{n} L_{n}^{j}+r_{n} H_{n}^{j}+\sum_{k=1}^{J} P_{n}^{k} M_{n}^{j k}=\frac{w_{n} L_{n}^{j}}{\gamma_{n}^{j}\left(1-\beta_{n}\right)} .
$$

Therefore, we may calculate changes in measured TFP, $\hat{A}_{n}^{j}$, following a change in fundamental productivity, $\widehat{T}_{n}^{j}$, using the ratio of the change in the cost of the input bundle to the change in the price of final goods. ${ }^{11}$ That is,

$$
\ln \hat{A}_{n}^{j}=\ln \frac{\widehat{x}_{n}^{j}}{\hat{P}_{n}^{j}}=\ln \frac{\left(\hat{T}_{n}^{j}\right)^{\gamma_{n}^{j}}}{\left(\hat{\pi}_{n n}^{j}\right)^{1 / \theta^{j}}},
$$

where the second equality follows from (19). Equation (23) is central to understanding the sources of changes in measured productivity in an individual sector within a region following a change in fundamental productivity, $\hat{T}_{n}^{j}$.

Consider first an economy with infinite trading $\operatorname{costs} \kappa_{n i}^{j}=\infty$ for all $j$, so that trade is non-operative and $\pi_{n n}^{j}=1$ in every region. Furthermore, let us abstract from material input use so that the share of value added in gross output is equal to one, $\gamma_{n}^{j}=1$. In such an economy, which we abbreviate with the letters

\footnotetext{
${ }^{10}$ One can prove that total gross output in $(n, j)$ uses this aggregate input bundle. To do so, aggregate Equations ( 7 ), (8) and (9). Using these equations, it is straightforward to derive that factor usage for an intermediate is just the revenue share of that intermediate in gross revenue, $Y_{n}^{j}$. Substituting in Equation (4), and using the fact that prices of produced intermediates are equal to unit costs, leads to

$$
\frac{Y_{n}^{j}}{P_{n}^{j}}=\frac{x_{n}^{j}}{P_{n}^{j}}\left[\left(H_{n}^{j}\right)^{\beta_{n}}\left(L_{n}^{j}\right)^{\left(1-\beta_{n}\right)}\right]^{\gamma_{n}^{j}} \prod_{k=1}^{J}\left(M_{n}^{j k}\right)^{\gamma_{n}^{j k}},
$$

where $A_{n}^{j}=x_{n}^{j} / P_{n}^{j}$ measures region and sector specific TFP.

${ }^{11}$ The 'hat' notation denotes $A^{\prime} / A$, where $A^{\prime}$ is the new level of total factor productivity.
} 
"NRNS" for "no regional trade and no sectoral linkages," Equation (23) implies that changes in measured productivity $\hat{A}_{n}^{j}$ are identical to changes in fundamental productivity, $\hat{T}_{n}^{j}$. Any fundamental productivity change at the level of a sector within a region translates into an identical change in measured productivity in that sector and region, and has otherwise no effect on any other sectors or regions.

This exact relationship between fundamental and measured productivity, $\ln \hat{A}_{n}^{j}=\ln \hat{T}_{n}^{j}$, no longer holds once either trade or sectoral linkages are operative. Consider first adding sectoral linkages, so that $\gamma_{n}^{j}<1$, but still abstracting from trade (labeled "NRS" for "no regional trade but with sectoral linkages"). In that case, Equation (23) indicates that the effect of a change, $\hat{T}_{n}^{j}$, improves measured productivity less than proportionally. The reason is that the change affects the productivity of value added in that region and sector but not the productivity of sectors and regions in which materials are produced. Therefore, in the presence of input output linkages, the effect of a fundamental productivity change $\hat{T}_{n}^{j}$ on measured productivity in $(n, j)$ falls with $1-\gamma_{n}^{j}=\sum_{k=1}^{J} \gamma_{n}^{j k}$.

This last result follows from our assumption that productivity changes scale value added and not gross output (as in Acemoglu et al. 2012). If productivity instead affected all of gross output, a sector that just processed materials, without adding any value by way of labor or capital, would see an increase in output at no cost. That alternative modelling implies that aggregate fundamental productivity changes have abnormally large effects on real GDP while, with our technological assumption, aggregate fundamental changes have proportional effects on real GDP. This distinction matters greatly in quantitative exercises.

Evidently, with trade still shut down, a region and sector specific change in an NRS economy has no effect on the measured productivity of any other region or sector. In contrast, with trade, productivity changes are propagated across sectors and regions. The main effect of regional trade on productivity arises by way of a selection effect. Thus, let $\kappa_{n i}^{j}$ be finite for tradable sectors, and consider first the region-sector $(n, j)$ that experiences a change or increase in fundamental productivity, $\hat{T}_{n}^{j}$. Equation (23) implies that the effect of trade is ultimately summarized through the change in the region's share of its own intermediate goods, $\hat{\pi}_{n n}^{j}$. Since an increase in fundamental productivity in $(n, j)$ raises its region and sector comparative advantage, it generally also leads to an increase in $\pi_{n n}^{j}$ so that $\hat{\pi}_{n n}^{j}>1$. Similarly, it reduces $\pi_{i i}^{k}$, for $i \neq n$ and all $k$, since other regions and sectors now buy more sector- $j$ intermediates from region $n$. Hence, since $\theta^{j}>0$, trade reduces the effect of a fundamental productivity increase to $(n, j)$ on measured productivity in that region-sector while, at the same time, raising measured productivity in other regions and sectors.

Intuitively, the selection effect underlying the change in expenditure shares works as follows. As everyone purchases more goods from the region-sector pair $(n, j)$ that experienced a fundamental productivity increase, that region-sector pair now produces a greater variety of intermediate goods. However, the new varieties of intermediate goods, since they were not being initially produced, are associated with idiosyncratic productivities that are relatively worse than those of varieties produced before the change. This negative selection effect in $(n, j)$ partially offsets the positive consequences of the fundamental productivity change, relative to an economy with no trade, in that region-sector pair. In other region-sector pairs, $(i, j)$ for $i \neq n$, 
the opposite effect takes place. As the latter regions do not directly experience the fundamental productivity change, their own trade share of intermediates decreases. As a result, the varieties of intermediate goods that continue being produced in those regions have relatively higher idiosyncratic productivities, thereby yielding higher measured productivity in those locations. All of these trade-related effects are present whether material inputs are considered (case RS) or are absent from the analysis (case RNS).

\subsubsection{Computing Aggregate, Regional, and Sectoral Measured TFP.-}

Since measured TFP at the level of a sector in a region is calculated based on gross output in Equation (21), we use gross output revenue shares to aggregate these TFP measures into regional, sectoral, or national measures. Changes in regional and sectoral measured TFP are then simply weighted averages of changes in measured TFP in each region-sector pair $(n, j)$, where the weights are the corresponding $(n, j)$ gross output revenue shares. Thus, since gross output revenue, $Y_{n}^{j}$, is given by Equation (22), regional changes in measured TFP are given by

$$
\hat{A}_{n}=\sum_{j=1}^{J} \frac{Y_{n}^{j}}{\sum_{j=1}^{J} Y_{n}^{j}} \hat{A}_{n}^{j}=\sum_{j=1}^{J} \frac{\frac{w_{n} L_{n}^{j}}{\gamma_{n}^{j}\left(1-\beta_{n}\right)}}{\sum_{j=1}^{J} \frac{w_{n} L_{n}^{j}}{\gamma_{n}^{j}\left(1-\beta_{n}\right)}} \hat{A}_{n}^{j},
$$

while sectoral changes in measured TFP can be expressed as

$$
\hat{A}^{j}=\sum_{n=1}^{N} \frac{Y_{n}^{j}}{\sum_{n=1}^{N} Y_{n}^{j}} \hat{A}_{n}^{j}=\sum_{n=1}^{N} \frac{\frac{w_{n} L_{n}^{j}}{\gamma_{n}^{j}\left(1-\beta_{n}\right)}}{\sum_{n=1}^{N} \frac{w_{n} L_{n}^{j}}{\gamma_{n}^{j}\left(1-\beta_{n}\right)}} \hat{A}_{n}^{j} .
$$

Similarly, changes in aggregate TFP are then given by

$$
\hat{A}=\sum_{j=1}^{J} \sum_{n=1}^{N} \frac{Y_{n}^{j}}{\sum_{j=1}^{J} \sum_{n=1}^{N} Y_{n}^{j}} \hat{A}_{n}^{j}=\sum_{j=1}^{J} \sum_{n=1}^{N} \frac{\frac{w_{n} L_{n}^{j}}{\gamma_{n}^{j}\left(1-\beta_{n}\right)}}{\sum_{j=1}^{J} \sum_{n=1}^{N} \frac{w_{n} L_{n}^{j}}{\gamma_{n}^{j}\left(1-\beta_{n}\right)}} \hat{A}_{n}^{j} .
$$

\subsection{GDP}

Real GDP is calculated by taking the difference between real gross output and expenditures on materials. Given equations (7), (8), and (9), as well as factor market equilibrium conditions, changes in real GDP may be written as

$$
\begin{aligned}
\ln \widehat{G D P}_{n}^{j} & =\ln \frac{\hat{w}_{n} \hat{L}_{n}^{j}}{\hat{P}_{n}^{j}} \\
& =\ln \hat{w}_{n}+\ln \hat{L}_{n}^{j}-\ln \hat{P}_{n}^{j}
\end{aligned}
$$

This expression simplifies further since, from (19),

$$
\hat{P}_{n}^{j}=\frac{\left(\hat{\pi}_{n n}^{j}\right)^{\frac{1}{\theta^{j}}} \hat{x}_{n}^{j}}{\left(\hat{T}_{n}^{j}\right)^{\gamma_{i}^{j}}}
$$


so that GDP changes in a region-sector pair $(n, j)$, resulting from changes in fundamental TFP, $\hat{T}_{n}^{j}$, are given by

$$
\begin{aligned}
\ln \widehat{G D P}_{n}^{j} & =\ln \frac{\left(\hat{T}_{n}^{j}\right)^{\gamma_{n}^{j}}}{\left(\hat{\pi}_{n n}^{j}\right)^{1 / \theta^{j}}}+\ln \hat{L}_{n}^{j}+\ln \left(\frac{\hat{w}_{n}}{\widehat{x}_{n}^{j}}\right) \\
& =\ln \hat{A}_{n}^{j}+\ln \hat{L}_{n}^{j}+\ln \left(\frac{\hat{w}_{n}}{\widehat{x}_{n}^{j}}\right),
\end{aligned}
$$

where the second line uses Equation (23).

Equation (27) represents a decomposition of the effects of a change in fundamental productivity on GDP. The first term reflects the effect of the change on measured productivity discussed in Section 3.1. This effect is such that measured TFP and output move proportionally. In other words, the selection effect associated with intermediates and input-output linkages acts identically on measured TFP and real GDP. In addition to these effects, GDP is also influenced by two other forces captured by the second and third terms in Equation (27).

The second term in Equation (27) describes the effect of labor migration across regions and sectors on GDP. A positive productivity change that attracts population to a given region-sector pair $(n, j)$ will increase GDP proportionally to the amount of immigration, $\ln \hat{L}_{n}^{j}$. The reason is that all factors in $(n, j)$ change in the same proportions and the production function of intermediates in Equation (4) is constant-returns-to-scale. The effect of migration will be positive when the change in fundamental TFP is positive.

The third term in Equation (27) corresponds to the change in factor prices associated with the change in fundamental TFP. Consider first a case without materials (RNS). In that case, $\ln \left(\hat{w}_{n} / \widehat{x}_{n}^{j}\right)=\beta_{n} \ln \left(\hat{w}_{n} / \widehat{r}_{n}\right)=$ $\beta_{n} \ln 1 / \hat{L}_{n}$. Since land and structures are fixed, and therefore do not respond to changes in $T_{n}^{j}$, while labor is mobile across locations, a positive productivity change that attracts people to the region will increase land and structure prices more than wages. This mechanism leads to a reduction in real GDP, relative to the proportional increase associated with the first two terms. The presence of decreasing returns resulting from a regionally fixed factor implies that shifting population to a location strains local resources, such as local infrastructure, in a way that offsets the positive GDP response stemming from the inflow of workers. In regions that do not experience the productivity increase, the opposite is true so that the second and third terms in (27) will be negative and positive respectively. These forces are also present when we consider material inputs although, in that case, the relevant ratio is that of changes in wages to changes in the cost of the input bundle, $x_{n}^{j}$. The input bundle includes the rental rate, but it also includes the price of all materials. An overall assessment of the effects of fundamental productivity changes then requires a quantitative evaluation.

Observe that when considering the aggregate economy-wide effects of a positive $\hat{T}_{n}^{j}$, the end result for GDP may be larger or smaller than the original change. The overall impact of the last two terms in Equation (27) will depend on whether the direct effect of migration dominates the strain on local resources in the region experiencing the change, $n$, as well as the intensiveness with which this fixed factor is used 
in the regions workers leave behind, $i \neq n$. Thus, the size and sign of these effects depend on the overall distribution of $H_{n}$ and population $L_{n}$ in the economy and, therefore, on whether the productivity change increases the dispersion of the wage-cost bundle ratio, $\hat{w}_{n} / \widehat{x}_{n}$, across regions. If a productivity change leads to migration towards regions that lack abundant land and structures, the aggregation of the last two terms in Equation (27) may be negative or very small. In contrast, if a change moves people into regions with an abundance of local fixed factors, the impact of these last two terms will be positive. Evidently, whatever the case, one must still add the direct effect of the fundamental productivity change on measured productivity. These different mechanisms underscore the importance of geography, and that of the sectoral composition of technology changes, in order to assess the magnitude of such changes. In very extreme cases (only Hawaii in our numerical exercises), these mechanisms may even lead to negative aggregate GDP effects of productivity increases. However, even though the equilibrium allocation is Pareto efficient, in practice positive technological changes always lead to welfare gains.

Finally, it is worth noting that in the case of aggregate productivity changes, the distribution of population across locations is unchanged since people do not seek to move when all locations are similarly affected. Therefore, measured productivity and GDP unambiguously increase proportionally in that case.

\subsubsection{Computing Aggregate, Regional, and Sectoral real GDP.-}

Given that real GDP is a value added measure, we use value added shares in constant prices for aggregation purposes. Denote sectoral and regional value added $(n, j)$ shares in a given benchmark year by

$$
v_{n}^{j}=\frac{w_{n} L_{n}^{j}+r_{n} H_{n}^{j}}{\sum_{j=1}^{J}\left(w_{n} L_{n}^{j}+r_{n} H_{n}^{j}\right)},
$$

and

$$
\xi_{n}^{j}=\frac{w_{n} L_{n}^{j}+r_{n} H_{n}^{j}}{\sum_{n=1}^{N}\left(w_{n} H_{n}^{j}+r_{n} H_{n}^{j}\right)}
$$

respectively. Then, the change in regional real GDP arising from a change in fundamentals is given by

$$
\widehat{G D P}_{n}=\sum_{j=1}^{J} v_{n}^{j} \widehat{G D P}_{n}^{j} .
$$

Similarly, the change in sectoral real GDP may be expressed as

$$
\widehat{G D P}^{j}=\sum_{n=1}^{N} \xi_{n}^{j} \widehat{G D P}_{n}^{j} .
$$

Finally, aggregate change in GDP is given by

$$
\widehat{G D P}=\sum_{j=1}^{J} \sum_{n=1}^{N} \phi_{n}^{j} \widehat{G D P}_{n}^{j},
$$

where

$$
\phi_{n}^{j}=\frac{w_{n} L_{n}^{j}+r_{n} H_{n}^{j}}{\sum_{j=1}^{J} \sum_{n=1}^{N}\left(w_{n} L_{n}^{j}+r_{n} H_{n}^{j}\right)}
$$

is the share of region-sector pair $(n, j)$ in value added in the base year. 


\subsection{Welfare}

We end this section with a brief discussion of the welfare effects that result from changes in fundamental productivity. Using (3), (7), and (8), it follows that the change in welfare is given by $\hat{U}=\hat{I}_{n} / \hat{P}_{n}$. Then, using the definition of $P_{n}$ and equations (19) and (23), we have that

$$
\ln \hat{U}=\sum_{j=1}^{J} \alpha^{j}\left(\ln \hat{A}_{n}^{j}+\ln \left(\varpi_{n} \frac{\hat{w}_{n}}{\hat{x}_{n}^{j}}+\left(1-\varpi_{n}\right) \frac{\hat{\chi}}{\hat{x}_{n}^{j}}\right)\right),
$$

where $\varpi_{n}=\frac{\left(1-\beta_{n} \iota_{n}\right) w_{n}}{\left(1-\beta_{n} \iota_{n}\right) w_{n}+\left(1-\beta_{n}\right) \chi}$. Note that if $\iota_{n}=0$ for all $n$, then $\chi=0$ and $\varpi_{n}=1$. In that case $\ln \hat{U}=\sum_{j=1}^{J} \alpha^{j}\left(\ln \hat{A}_{n}^{j}+\ln \frac{\hat{w}_{n}}{\hat{x}_{n}^{j}}\right)$.

A change in fundamental productivity, $\hat{T}_{n}^{j}$, affects welfare through three main channels. First, the change affects welfare through changes in measured productivity, $\ln \hat{A}_{n}^{j}$, in all sectors (which in turn are influenced by the selection effect in intermediate goods production described earlier), weighted by consumption shares, $\alpha^{j}$. Second, the productivity change affects welfare through changes in the cost of labor relative to the input bundle, $\ln \left(\hat{w}_{n} / \widehat{x}_{n}^{j}\right)$. As in the case of GDP, when we abstract from materials (the RNS case), the second term is equivalent to the change in the price of labor relative to that of land and structures or, alternatively, the inverse of the change in population. Therefore, when a region-sector pair $(n, j)$ experiences an increase in fundamental productivity, it benefits from the additional measured productivity but loses from the inflow of population. In other regions that did not experience the productivity increase, population falls while measured productivity tends to increase (through a selection effect where remaining varieties in those regions are more productive), so that both effects on welfare are positive. These mechanisms are more complex once sectoral linkages are taken into account by way of material inputs, and their analysis then requires us to compute and calibrate the model. As Equation (31) indicates, welfare also simply reflects a weighted average across sectors of real GDP per capita. Third, welfare is affected by the change in the returns to the national portfolio, which constitutes part of the real income received by individuals.

The international trade literature has studied the welfare implications of a similar class of models in detail, as discussed in Arkolakis et al. (2012). Relative to these models, the study of the domestic economy compels us to include multiple sectors, input-output linkages, and two factors, one of which is mobile across sectors and the other across locations and sectors. Finally, our model also endogenizes trade surpluses and deficits. If we were to close all of these margins, it is straightforward to show that the implied change in welfare simply reduces to the change in measured productivity in the resulting one-sector economy, reproducing the formula highlighted by Arkolakis et. al. (2012).

\section{CALCULATING COUNTERFACTUALS AND CALIBRATION}

From the discussion in the last section, it should be clear that the ultimate outcome of a given change in fundamentals on the U.S. economy will depend on various aspects of its particular sectoral and regional composition. These aspects include the distribution of population across regions, that of land and structures, 
the nature of transport costs, material shares, etc. Therefore, to assess the magnitude of the responses of measured TFP, GDP and welfare to fundamental technology changes, one needs to compute a quantitatively meaningful variant of the model. This requires addressing four practical issues.

First, the U.S. economy exhibits aggregate trade deficits and surpluses between states. The model presented in Section 2 allows for the possibility of sectoral trade imbalances across states as well as aggregate trade imbalances due to inter-regional transfers of the returns from land and structures, (see equation 20). By incorporating variation in regional contributions to the national portfolio through the parameters $\iota_{n}$, our model is capable of matching quite well the observed aggregate trade imbalances in the U.S. economy. ${ }^{12}$ We estimate the regional contributions to the national portfolio, $\iota_{n}$, by minimizing the square differences between observed regional trade imbalances and those that emerge in the model through interregional transfers implied by the national portfolio of fixed assets. Figure 7 presents the resulting $\iota_{n}$ 's as well as the observed and predicted trade imbalances. Figure 7 a shows the match between the observed and predicted regional trade imbalances. The match is not perfect since the constraint $\iota_{n} \in[0,1]$ for all $n$ occasionally binds both above and below for some states, as shown in Figure 7b. States with large surpluses like Wisconsin contribute all of the returns to their land and structures to the national portfolio, while states with large deficits, like Florida, contribute nothing. Intuitively, Floridians own assets in the rest of the U.S. and live in part from the returns to these assets. In what follows, we set the unexplained component of trade imbalances to zero, as described in Appendix A.1., and we use the resulting economy as the baseline economy from which we calculate the elasticities to fundamental regional and sectoral changes. ${ }^{13}$

The second issue relates to our model incorporating regional but no international trade. Fortunately, the trade data across U.S. states that we use to calibrate the model, which is described in detail below, gives us expenditures in domestically produced goods across states. Even then, small adjustments are needed but, overall, we are able to use these data to assess the behavior of the domestic economy without considering international economic links. ${ }^{14}$ Thus, we study the domestic economy subject to the small data adjustments described below.

The third issue of practical relevance is that solving for the equilibrium requires identifying technology levels in each region-sector pair $(n, j)$, bilateral trade costs between regions for different sectors $(n, i, j)$, and the elasticity of substitution across varieties, all of which are not directly observable from the data. Following the method first proposed by Dekle, Eaton and Kortum (2008), and adapted to an international context with multiple sectors and input-output linkages by Caliendo and Parro (2014), we bypass this third issue by computing the model in changes. We show in Appendix A.2 that the same method works well in our setup. In particular,

\footnotetext{
${ }^{12}$ Unless one writes a dynamic model in which imbalances are the result of fundamental sources of fluctuations, one cannot explain either the level, or the potential changes, in the value of $\iota_{n}$. Explaining the observed ownership structure is certainly an interesting direction for future research, but one that is currently beyond reach in a rich quantitative model comparable to the one studied in this paper.

${ }^{13}$ Our approach differs from the one in Dekle, Eaton and Kortum (2007) in that we focus on trade across regions rather than countries and, more importantly, allow for endogenous transfers across regions that match observed trade imbalances.

${ }^{14}$ In principle, one might potentially think of the 'rest of the world' as another region in the model but, to the best of our knowledge, information on international trade by states is not systematically recorded.
} 
given a set of parameters $\left\{\theta^{j}, \alpha^{j}, \beta_{n}, \iota_{n}, \gamma_{n}^{j k}\right\}_{n=1, j=1, k=1}^{N, J, J}$, and data for $\left\{I_{n}, L_{n}, \Upsilon_{n}, \pi_{n i}^{j}, \hat{T}_{n}^{j}, \hat{\kappa}_{n i}^{j}\right\}_{n=1, i=1, j=1}^{N, N, J}$ the system of $2 N+3 J N+J N^{2}$ equations yields the values of $\left\{\hat{w}_{n}, \hat{L}_{n}, \hat{x}_{n}^{j}, \hat{P}_{n}^{j}, \hat{X}_{n}^{j}, \hat{\pi}_{n i}^{j}\right\}_{n=1, i=1, j=1}^{N, N, J}$, where $\hat{X}_{n}^{j}$ and $\hat{\pi}_{n i}^{j}$ denote expenditures and trade shares following fundamental changes $\left\{\hat{T}_{n}^{j}, \hat{\kappa}_{n i}^{j}\right\}_{n=1, i=1, j=1}^{N, N, J} \cdot$ The exact equations of the system are presented in Appendix A.2. We use all 50 U.S. states and 26 sectors, where 15 sectors produce tradable manufactured goods. Ten sectors produce services and we add construction for a total of 11 non-tradeable sectors. Assessing the quantitative effects on the U.S. economy of fundamental changes at the level of a sector within a region then requires solving a system of 69,000 equations and unknowns. This system can be solved in blocks recursively using well established numerical methods. The exact algorithm is described in Appendix A.3. Having carried out these calculations, it is then straightforward to obtain any other variable of interest such as $\hat{r}_{n}, \hat{\pi}_{n n}^{j}, \hat{A}_{n}^{j}, \widehat{G D P}_{n}^{j}$ and $\hat{U}$, among others.

In order to generate a calibrated model of the U.S. economy that gives a quantitative assessment of the effects of disaggregated changes in fundamental productivity, we need to obtain values for all parameters, $\left\{\theta^{j}, \alpha^{j}, \beta_{n}, \iota_{n}, \gamma_{n}^{j k}\right\}_{n=1, j=1, k=1}^{N, J, J}$ and variables $\left\{I_{n}, L_{n}, \Upsilon_{n}, \pi_{n i}^{j}\right\}_{n=1, i=1, j=1}^{N, N, J}$. Throughout, we let $\hat{\kappa}_{n i}^{j}=1$, for all $j, n, i$, and adjust $\hat{T}_{n}^{j}$ in different ways depending on the particular counterfactual exercise. We obtain $\iota_{n}$ using the calculations described above, and Appendix A.4 describes the data underlying our calculations and presents a detailed account of the rest of our calibration strategy.

Finally, the fourth issue relates to our assumption that labor can move freely across regions. The potential concern is that, in practice, there are frictions to labor mobility across regions in the U.S. Hence, our model could systematically generate too much labor mobility as a result of fundamental productivity changes. In order to study the extent to which the omission of mobility frictions can affect our results, we perform a set of exercises where we introduce the observed changes in fundamental TFP for all regions and sectors from 2002 to 2007 into the model and calculate the implied changes in employment shares. ${ }^{15}$ We find that the model generates changes in employment that are of the same order of magnitude as in the data. For instance, the mean annualized percentage change in employment shares implied by the model is 0.257 while the observed change was 0.213 . Of course, we do not expect the results of this exercise to match the observed changes in employment given that several factors, other than productivity changes, could have impacted the U.S. economy during this period. Still, the message from this exercise is that the changes in employment generated by observed productivity changes in our model are similar to observed employment changes. Thus, there is little room for migration frictions to be playing a quantitative important role in the data.

\section{THE IMPACT OF FUNDAMENTAL PRODUCTIVITY CHANGES}

Having calibrated the model against available industry and trade data, we study the effects of disaggregated productivity changes. Throughout the analysis, the calculations of all the elasticities are based on 10 percent

\footnotetext{
15 To compute changes in observed fundamental TFP we use equation (23). Note that the change in fundamental TFP is the same as the change in measured TFP, scaled by the share of value added in gross output, if the selection channel is not active. This is the case when using price indexes with constant weights as reported from 2002 to 2007 by the BEA.
} 
Fig. 7. Regional trade inbalances and contributions to the National Portfolio

a: Trade Balance: Model and data (2007 U.S. dollars, billions)

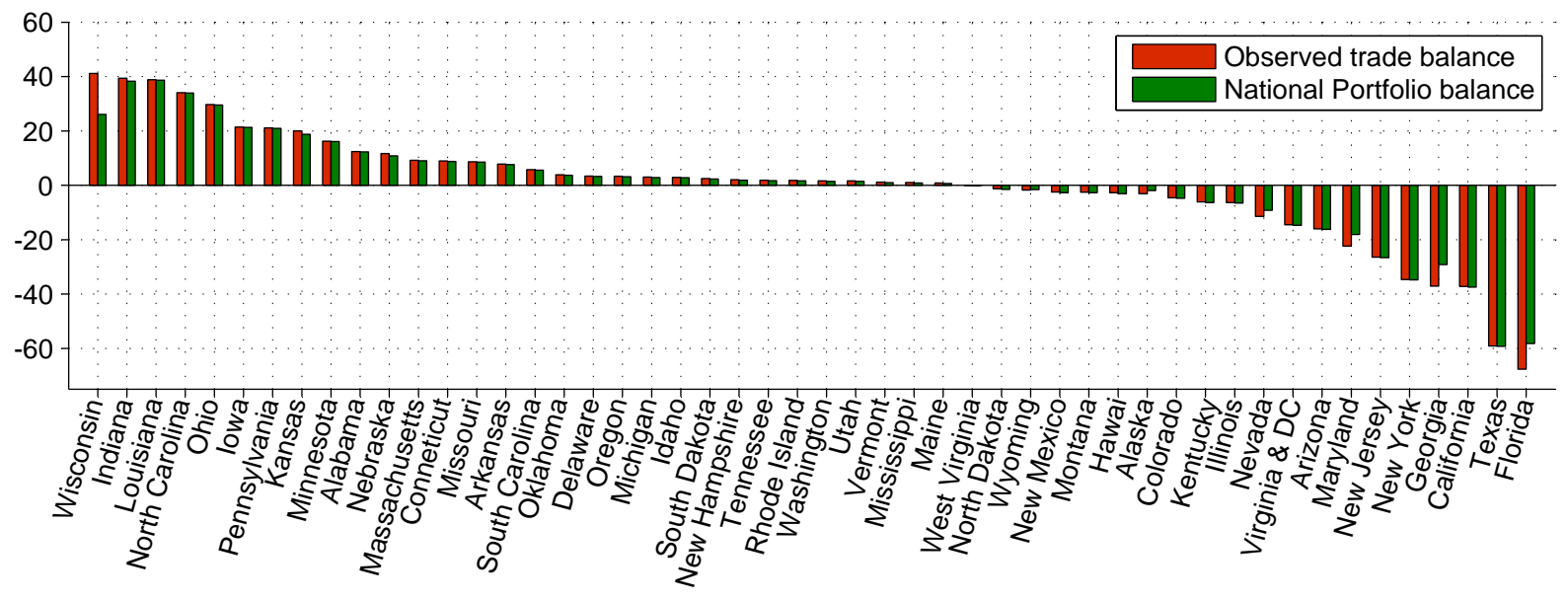

b: Share of local rents on land and structures contributed to the National Portfolio

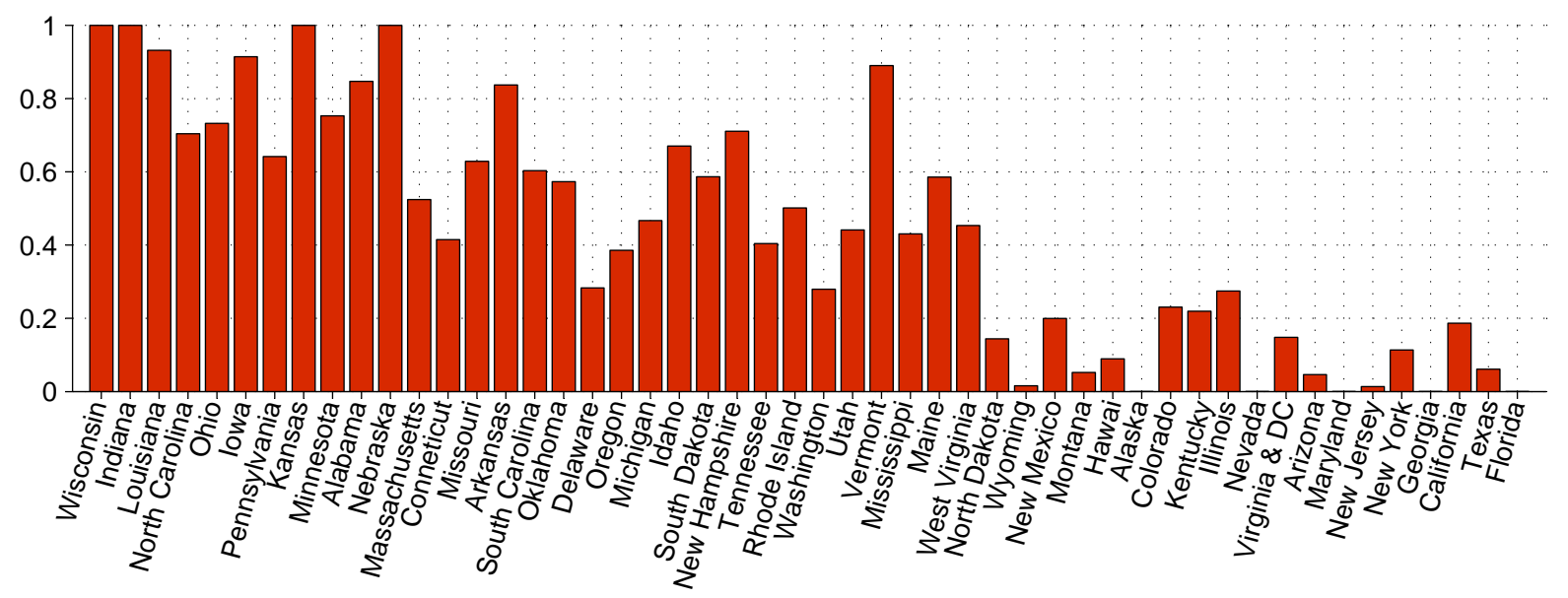

changes in fundamental productivity. Figures 4 and 5 showed that yearly changes in measured productivity range between 0 and 2.5 percent, while sectoral changes take values between - 4 percent and 4 percent, except for Computer and Petroleum which experienced large changes in opposite directions. Thus, over the course of five years (2002-2007), regions and sectors routinely experience changes in measured productivity in the vicinity of 10 percent. In addition, while the numbers in Figures 4 and 5 relate to measured TFP and not to fundamental TFP, the two concepts are closely related as we saw earlier. We begin by analyzing changes to all sectors in one region, which we refer to as regional changes. We then study changes to all regions in one sector, which we refer to as sectoral changes. Finally, we present examples of changes specific to a sector within a region.

To facilitate comparisons across states and sectors we present our results in terms of elasticities. To 
calculate aggregate elasticities of a given regional or sectoral productivity change we divide the effects by the share of the region or industry where the change was originated, and multiply by the size of the fundamental productivity change (which in our exercises is always 10\%). So the interpretation of an aggregate elasticity is the effect of a percentage change with constant national magnitude. In contrast, to calculate regional or sectoral elasticities we only multiply by the size of the fundamental productivity change. Hence, for regional or sectoral elasticities we are calculating the effect of a change that depends on the size of the region or sector affected.

We compute counterfactual exercises in which i) we eliminate regional trade and sectoral linkages, labeled as NRNS, ii) we eliminate sectoral linkages but allow interregional trade, labeled RNS, iii) we allow for sectoral linkages but eliminate interregional trade, labeled NRS, and iv) we allow for regional trade and sectoral linkages, labeled RS. The last case is the one relevant to the assessment of the consequences of a fundamental change for the U.S. economy. To study different scenarios under these variants of our model, we first compute allocations in the particular case of interest (say, without sectoral trade). We then introduce a fundamental change in that counterfactual economy to calculate the effect of the change in that case. This gives us the effects of fundamental changes in the presence or absence of a specific channel.

\subsection{Regional Productivity Changes}

\subsubsection{Aggregate Effects of Regional Productivity Changes.-}

As a starting point for our findings, consider Figure 8. The figure shows the aggregate elasticities of measured TFP and GDP to an increase in productivity in each of the 50 U.S. states in the three alternative models (NRNS, RNS, RS). For example, when all channels are included (RS), the elasticity of aggregate TFP to a fundamental productivity increase in all sectors in Texas is 0.4 and the elasticity of aggregate GDP is 1.1 .

Let us focus first on measured TFP in the top-left-hand map of the figure, Panel 8a. In the NRNS case, Equation (26) tells us that changes in aggregate measured TFP are simply the direct consequence of the change in fundamental productivity. The impact on aggregate TFP, therefore, amounts to the share of that region times the magnitude of the change, and so the elasticity of aggregate TFP to a regional change in TFP is equal to one. As we move down to Figure 8c, we see the effect on measured TFP in the presence of regional trade only (RNS). As discussed earlier, trade leads to a negative selection effect in the states that experience the change, whereby newly produced varieties in that state have relatively lower idiosyncratic productivities, and to a positive selection effect in other states. The overall effect on the aggregate elasticity

of measured TFP stemming from selection may thus have either sign, but it will tend to be more negative the larger the state experiencing the fundamental productivity increase. This selection effect implies that the impact on aggregate measured TFP in the case of, say, California, is dampened from 1 in the NRNS case to 0.9938 in the RNS case. Similarly, the aggregate elasticity of a fundamental regional change in Texas is 
also dampened from 1 to 0.9928 . In contrast, the selection effect tends to amplify the elasticity in aggregate measured TFP arising from fundamental changes in many small states. For example, Michigan's aggregate measured TFP elasticity increases to 1.037 in the RNS case.

Including input-output linkages reduces the elasticity of aggregate TFP significantly in all states. Recall from Equation (23) that fundamental TFP changes affect value added and not gross production directly. Hence, their effect on measured productivity are attenuated by the share of value added. The end result is that the effect of fundamental changes on measured TFP declines substantially relative to the models without input-output linkages. As we discuss below, this effect is not present in the case of real GDP. Indeed, input-output linkages imply that more of the gains from fundamental changes in productivity ensue from lower material prices, rather than direct increases in measured productivity.

Let us now turn to the second column in Figure 8. Since a productivity change in all regions and sectors has no implications on migration or trade flows, the aggregate elasticity of GDP to such a change is always equal to one in our model. This is not the case for regional changes. In the NRNS case in the top right-hand panel, 8b, the effect on aggregate GDP derives from the changes in measured TFP just discussed combined with the impact of migration. Thus, the outcome for aggregate GDP now depends on the whole distribution of land and structures across states. In some cases there is a large positive effect from migration on aggregate real GDP, as in the case of productivity changes in Illinois or New York. These are states that are relatively abundant in land and structures (see Figure 6) so that the economy benefits from immigration even at the cost of emptying other regions. The opposite is true of Wisconsin, where migration turns an elasticity of aggregate measured TFP of one (top left-hand map, 8a) into a negative elasticity of aggregate real GDP of -0.4 (top right-hand map, 8b). From Figure 8d, adding trade (RNS) generally implies smaller differences between aggregate measured TFP effects and real GDP effects. Trade allows residents in all locations to benefit from the high productivity of particular regions without them having to move. Put another way, trade substitutes for migration. This substitution is more concentrated towards nearby states when input-output linkages are added (RS). Specifically, trade makes firms benefit from a change in fundamental productivity in nearby states through cheaper materials as well. As alluded to earlier, more of the benefits from a given regional fundamental productivity increase are transmitted through the price of material inputs in the RS case so that the importance of regional trade increases. Ultimately, the difference between changes in measured TFP and changes in output are generally larger in the absence of one of these two channels.

When both input-output and trade linkages are present (RS), which captures the actual effect of regional fundamental productivity changes, we find that the aggregate elasticity of GDP to regional productivity changes substantially in many regions. This is clear for Florida. In terms of land and structures, Florida is small with relatively low wage to rental ratios. ${ }^{16}$ As a result of increased immigration the state's output increases less than it would in fixed-factor-abundant regions. Input-output linkages tend to reduce even more

\footnotetext{
${ }^{16}$ Even though some of these states are large in terms of area, they have low levels of infrastructure and other structures, as we saw in Figure 6.
} 
FIG. 8. Aggregate effects of regional fundamental productivity changes

a: Elasticity of aggregate TFP (model NRNS)

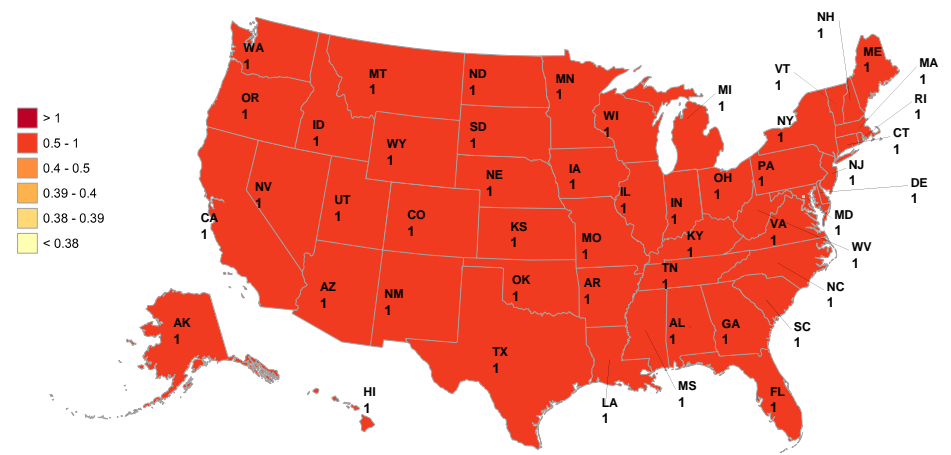

c: Elasticity of aggregate TFP (model RNS)

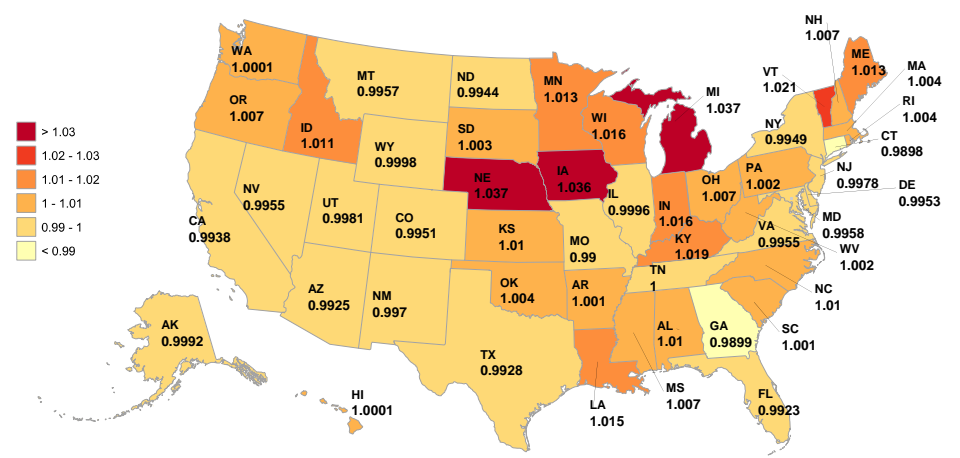

e: Elasticity of aggregate TFP (model RS)

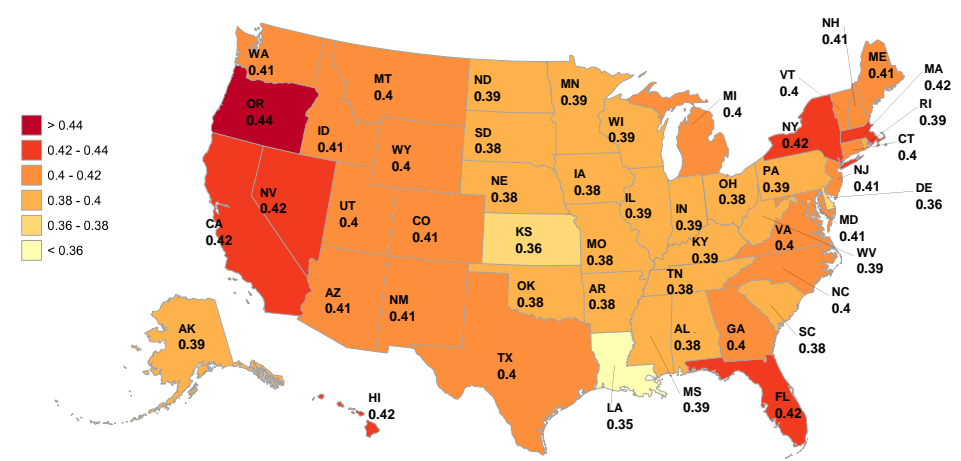

b: Elasticity of aggregate GDP (model NRNS)

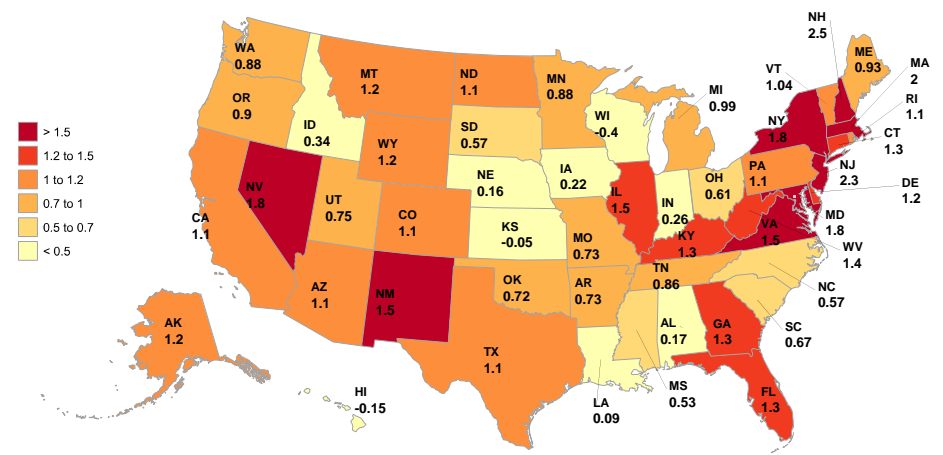

d: Elasticity of aggregate GDP (model RNS)

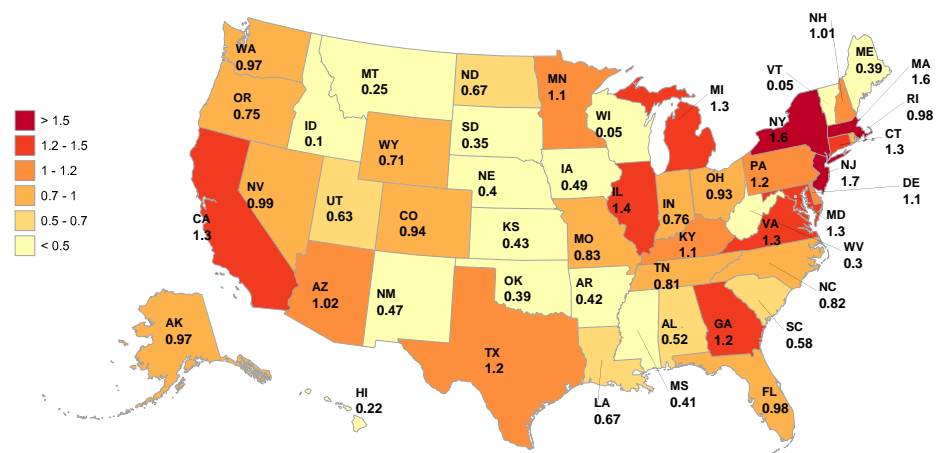

f: Elasticity of aggregate GDP (model RS)

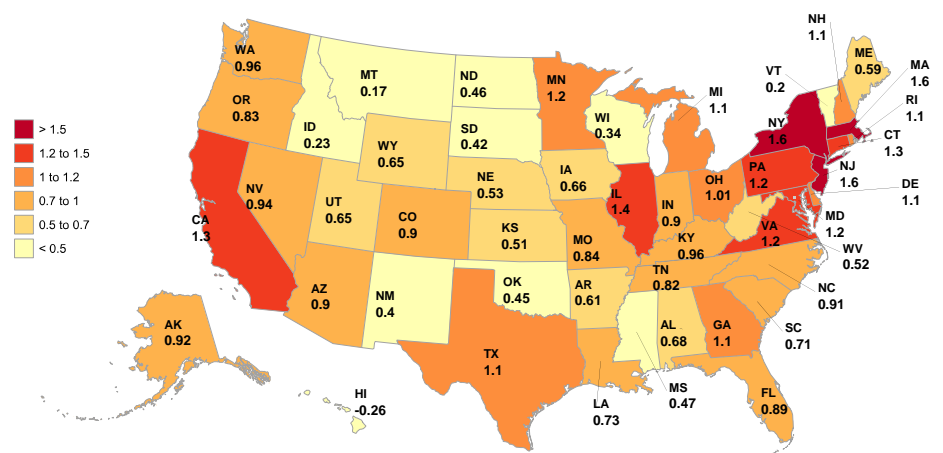

the elasticity in fixed-factor scarce states by inducing a larger inflow of workers. This leads to an elasticity of only 0.89 in Florida. In contrast, for California, with its abundant land and structures, we estimate an elasticity of 1.3. The difference is large in magnitude. A productivity change of the same national magnitude in California increases national output $46 \%$ more than in Florida. Figure $8 \mathrm{f}$ shows that the range 
of elasticities is even larger than that. It goes from -0.26 in Hawaii and 0.17 in Montana to 1.6 in New Jersey, New York, and Massachusetts. These large range illustrates how the geography of productivity changes is essential to understanding their aggregate consequences.

We also evaluated how the elasticities from our model change if we restrict labor not to move across regions. When there is no mobility and no interregional trade, both the aggregate TFP and GDP elasticities to regional fundamental productivity changes are equal to one. Adding trade makes the selection channel operative in both cases, and we find that the TFP elasticities are similar in both models. However, GDP elasticities are considerably different, and in our view much more credible, when we add migration. ${ }^{17}$

Figure 9 presents the welfare elasticity to regional fundamental productivity changes. ${ }^{18}$ Recall that because of free migration, welfare is identical across regions. Welfare elasticities are always positive but their range is again quite large. Welfare elasticities are in general large for centrally located states in the Midwest and the South. They range from 1.7 in Minnesota and Indiana to 0.6 in western states like Montana and 0.62 in Nevada. This is natural as the consumption price index tends to be lower in central states due to lower average transportation costs to the rest of the country. Adjustments through the ownership structure matter also when comparing aggregate GDP and welfare elasticities. In states where the contribution to the national portfolio is zero, $\iota_{n}=0$, like Florida, the welfare elasticity tends to be smaller than that of GDP. The reverse is true in states like Wisconsin, where $\iota_{n}=1$. In the latter states, agents benefit -through their ownership of the national portfolio- from the increase in the price of local factors that result from the fundamental productivity change without having to move to the state. This mitigates the congestion caused by local decreasing returns to labor in these states leading to larger welfare gains.

\subsubsection{Regional Propagation of Local Productivity Changes.-}

Thus far, we have emphasized the aggregate effect of regional changes. The model, evidently, also tells us how productivity changes in particular states propagate to other states. As an example, Figure 10 presents the regional elasticity of measured TFP, GDP, and employment from an increase in fundamental TFP in California. ${ }^{19}$ The top panel focuses first on the response of measured TFP. California presents an own elasticity of measured TFP of 0.4. The fact that the elasticity is lower than one reflects, first, the negative selection mechanism and, second, the fact that fundamental productivity scales value added. The elasticity of measured productivity in other states is mostly positive because the selection effect in those states means that varieties that continue to be produced there have relatively higher idiosyncratic productivities. Regions close to California, such as Nevada, benefit the most, with the effect decreasing as we move east due to higher transport costs. That is, distance matters, although its implications are not uniform. As a result of

\footnotetext{
${ }^{17}$ In Section 4 we feed into the model the observed change in fundamental TFP by regions and sectors to show that the model implied changes in employment shares are consistent with the patterns observed in the data. We also introduced these changes into a model with no migration and compare the implied regional GDP effects with the data. We find that the correlation is $26.3 \%$ while the correlation between the regional GDP effects implied from the model with mobility and the data is $56.5 \%$.

${ }^{18}$ To calculate welfare elasticities we use the share of employment in the state.

${ }^{19}$ To calculate this elasticity, we multiply the effect of the regional fundamental productivity increase only by the size of the fundamental productivity change.
} 
FIG. 9. Welfare elasticity of regional productivity changes

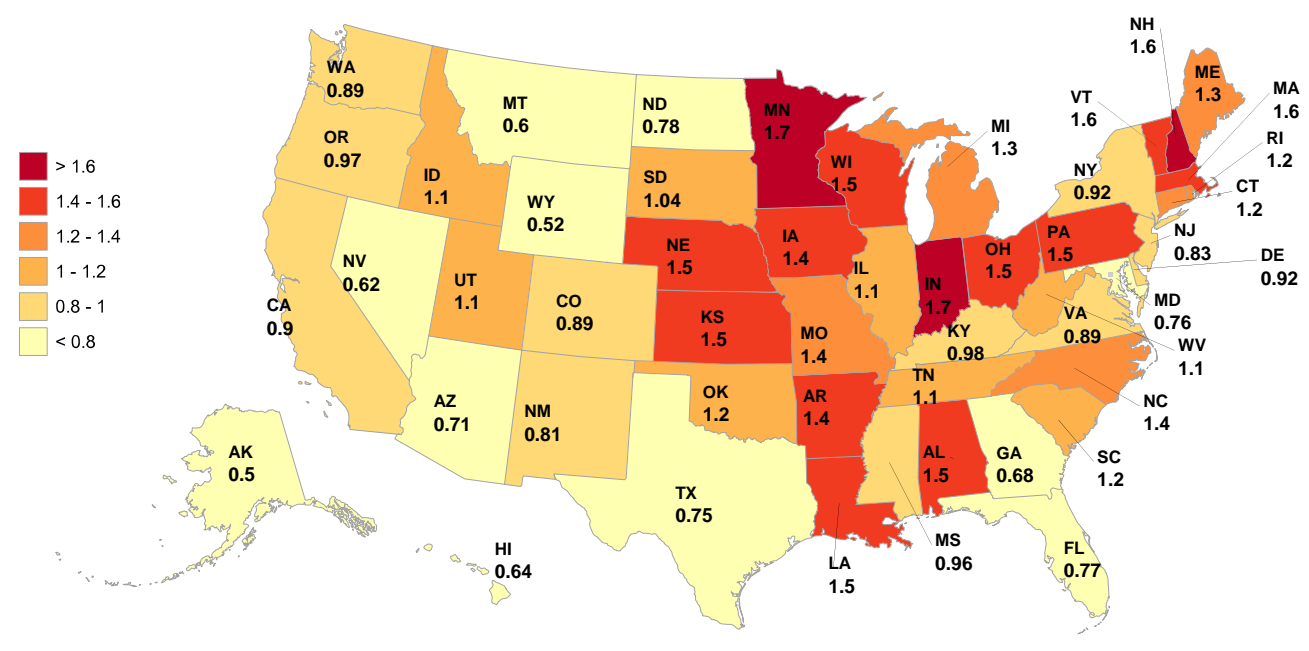

sectoral linkages, industries in states that supply material inputs to California benefit to a greater degree from their positive selection effect. Other states that compete with California, such as Texas and Louisiana in Petroleum and Coal, gain little or even lose in terms of measured TFP.

Figure 10b depicts the regional elasticity of GDP of a fundamental productivity increase in California. California's own GDP elasticity with respect to a fundamental productivity increase is 2.8 and, in part, derives from the influx of population to the state, (Figure 10c shows that the employment elasticity is equal to 2.7). All other states lose in terms of GDP and employment, and lose to a greater extent if they are farther away from California. This effect is particularly large since California has a relatively high wage to unit cost ratio. Therefore, the influx of population adds more to California than it subtracts from other states. Furthermore, the relatively small contribution of California to the national portfolio of land and structures results in a high regional elasticity of employment. Some large Midwestern states, like Illinois, and Northeastern states, like New York, lose substantial from the decrease in population caused by the migration to California. The reason is partly that the relatively high stock of land and structures in these states makes the population losses particularly costly there. Other states like Wisconsin or Minnesota are affected by the decline in the returns to the national portfolio of land and structures without benefiting disproportionately from the increase in their local returns given their high $\iota_{n}$.

As a last example of the effects of regional changes, we briefly discuss the case of Florida. Florida is interesting in that a an increase in its fundamental TFP generates a relatively small aggregate elasticity of real GDP. Figure 11 presents a set of figures analogous to those in Figure 10 but for Florida's case. Most of the effects that we underscore for California are evident for Florida as well. However, the region-specific productivity change induces more pronounced immigration. Florida's employment elasticity is equal to 3.3 which is very large even compared to California (2.7). This shift in population puts a strain on local fixed 
FIG. 10. Regional elasticities to a fundamental productivity change in California a: Regional TFP elasticity

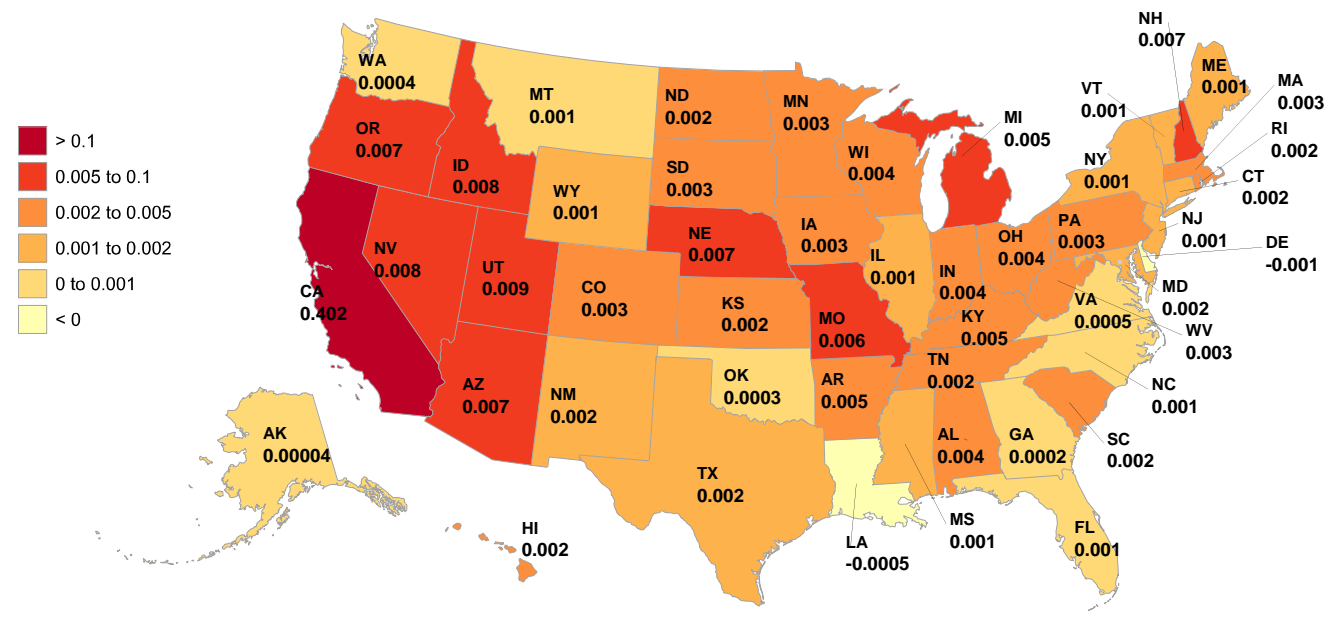

b: Regional GDP elasticity

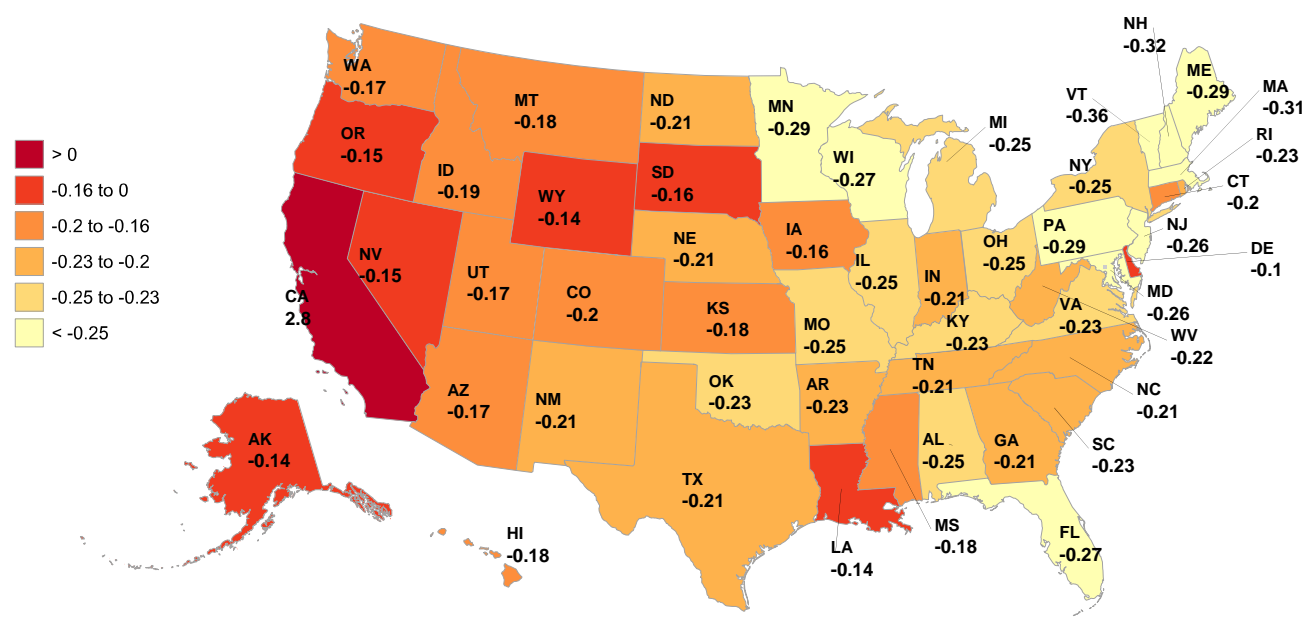

c: Regional Employment elasticity

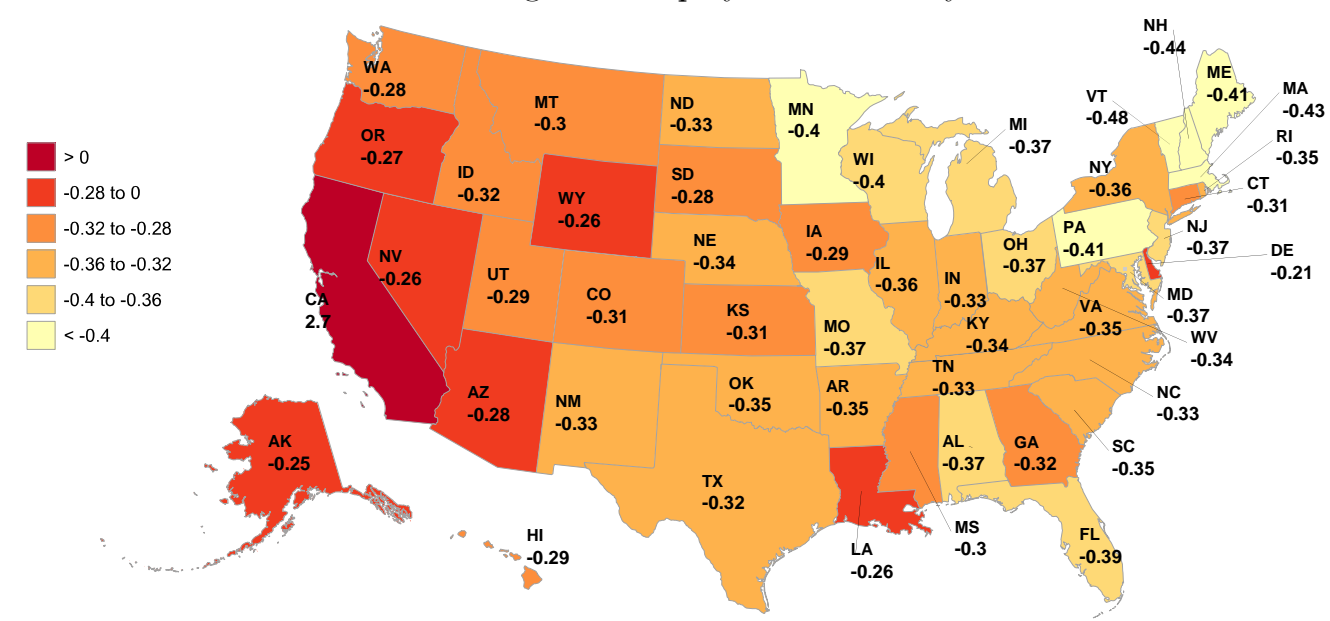


factors and infrastructure that are significant to the extent that Florida's real GDP increases only slightly more than its population. This strain on Florida's fixed resources is magnified by the fact that the state is relatively isolated and, in particular, sells relatively few materials to other states. Furthermore, because Florida contributes nothing to the national portfolio of land and structures, agents in other regions do not share the gains from the fundamental productivity change, which exacerbates migration flows into the state. The end result is that the loss in output in other regions balances to a larger extent Florida's increase in GDP, thus leading to a smaller overall aggregate elasticity of GDP.

\subsection{Sectoral Productivity Changes}

In contrast to regional changes, studying the effects of sectoral changes has a long tradition in the macroeconomics literature (see Long and Plosser, 1983, Horvath, 1998, Dupor, 1999, Foerster et al. 2011, and Acemoglu, et al. 2012, among many others). Despite this long tradition, little is known about how the geography of economic activity impinges on the effects of sectoral productivity changes. Our framework highlights two main channels through which geography affects the aggregate impact of sectoral changes. First, regional trade is costly so that, given a set of input-output linkages, sectoral productivity changes will produce different economic outcomes depending on how geographically concentrated these changes are. Second, land and structures, including infrastructure, are locally fixed factors. Therefore, changes that affect sectors concentrated in regions that have an abundance of these factors will tend to have larger effects.

\subsubsection{Aggregate Effects of Sectoral Productivity Changes.-}

Figure 12 presents aggregate responses of measured productivity to changes in fundamental productivity in each sector. In this case, a fundamental change in a given sector is identical across all regions in which the sector is represented. We present aggregate elasticities for the case in which all channels are operative (RS), as well as the ratio of the elasticity in the case without regional trade, NRS, and the RS case. Under the maintained assumptions that the share of land and structures in value added is constant across sectors $\left(\beta_{n}\right)$, and that the share of consumption across sectors is identical across regions $\left(\alpha^{j}\right)$, trade matters for the aggregate effects of sectoral fundamental TFP changes only in the presence of sectoral linkages. Absent sectoral linkages, a given sectoral fundamental TFP change does not affect the distribution of employment across regions. Therefore, in both the NRNS and RNS cases, the aggregate TFP elasticity with respect to changes in sectoral fundamental productivity is equal to one for all sectors.

Figure 12a shows that, compared to an economy with only land, structures, and labor, adding material inputs reduces significantly the aggregate TFP elasticity with respect to a given sectoral productivity change. Input-output linkages also skew the distribution of aggregate sectoral effects. These differences arise because material inputs serve as an insurance mechanism against changes that are idiosyncratic to a particular sector. That is, with input-output linkages, output in any sector depends on the productivity in other sectors. Trade influences this mechanism because intermediate inputs cannot be imported costlessly from other locations. 
FIG. 11. Regional elasticities to a fundamental productivity change in Florida a: Regional TFP elasticity
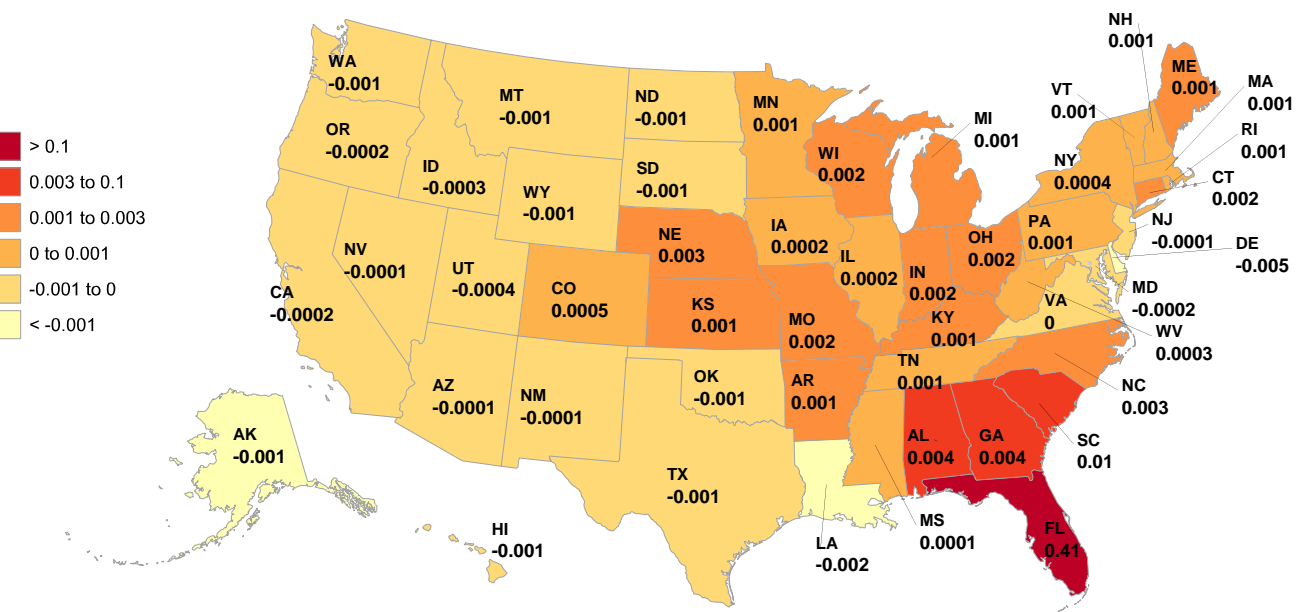

b: Regional GDP elasticity

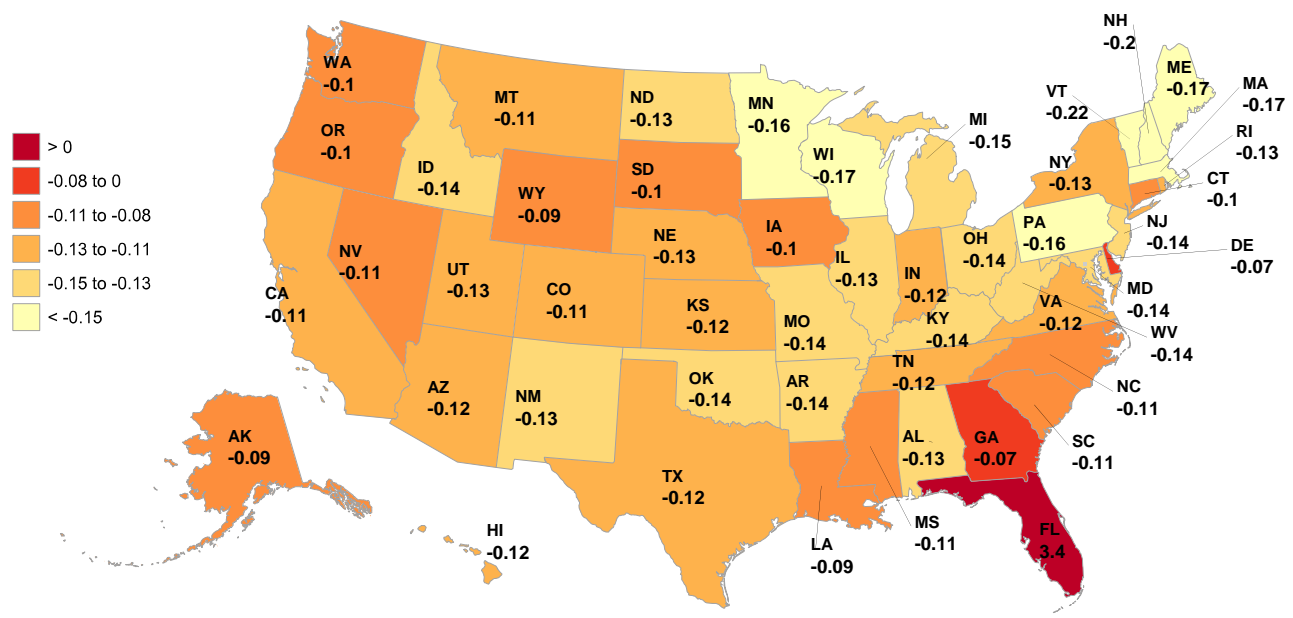

c: Regional Employment elasticity

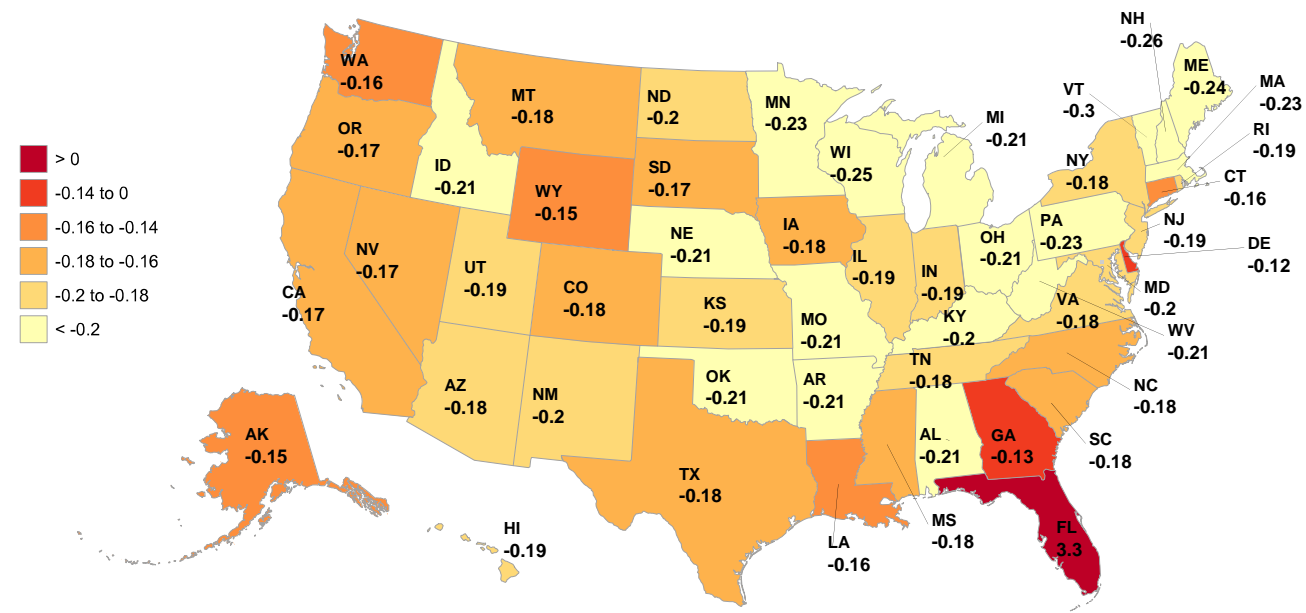


FIG. 12. Aggregate measured TFP elasticities to a sectoral fundamental productivity change

a: Elasticity of aggregate TFP (model RS)

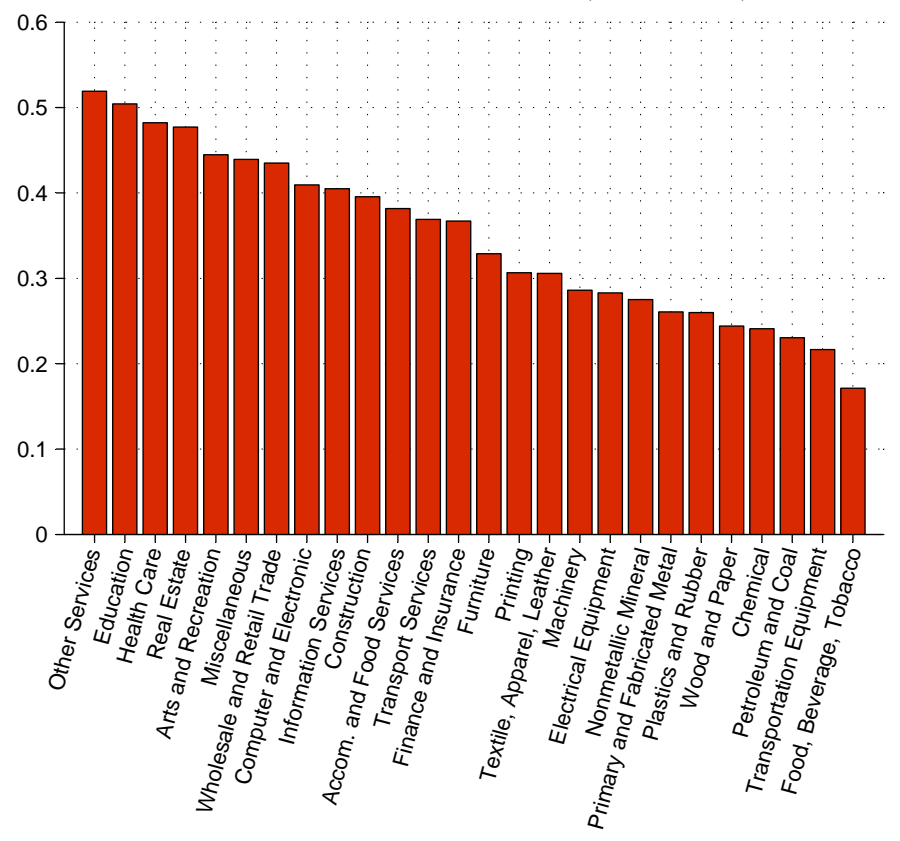

b: Ratio of TFP elasticities in NRS versus RS

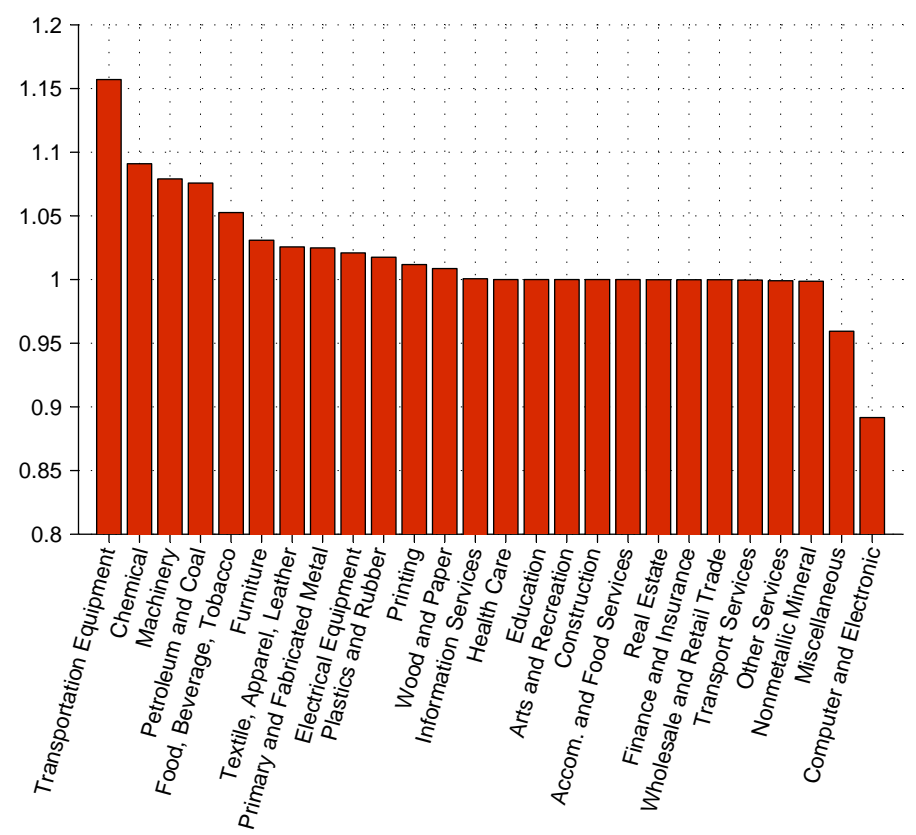

For example, as Figure 12b shows, eliminating trade leads to an elasticity of aggregate TFP that is about $15 \%$ larger in the Transportation Equipment industry, but about 10\% smaller in the Computer and Electronics industry.

When we focus on the elasticity of aggregate GDP it is even clearer that in sectors that are very concentrated geographically this influence of regional trade is smaller than in sectors that are more dispersed across regions. The Petroleum and Coal industry, for instance, is concentrated across less than a handful of states. Hence failure to account for regional trade understates the aggregate elasticity of GDP in that sector by about $10 \%$ (see 13b). In contrast in the relatively dispersed Transportation Equipment industry disregarding regional trade overstates the elasticity by $19 \%$. Trade has a negligible effect on the aggregate elasticities of changes to non-tradable sectors.

Figure 14 illustrates the welfare implications of sectoral changes in productivity. As with regional productivity changes, these exhibit a fairly large range. A fundamental productivity change in the Wood and Paper industry -the most dispersed industry in the U.S.- has an effect on welfare that is about $10 \%$ lower than in the much more concentrates Petroleum and Coal and Chemical industries (see Figure 3b). The sectoral distribution of welfare elasticity is also less skewed than that of GDP since measured TFP in general responds less than employment to changes in fundamental productivity (see Equation (31)).

\subsubsection{Regional Propagation of Sectoral Productivity Changes.-}

Because they lack a geographic dimension, disaggregated structural models that have been used to study 
FIG. 13. Aggregate GDP elasticities to a sectoral fundamental productivity change

a: Elasticity of aggregate GDP (model RS)

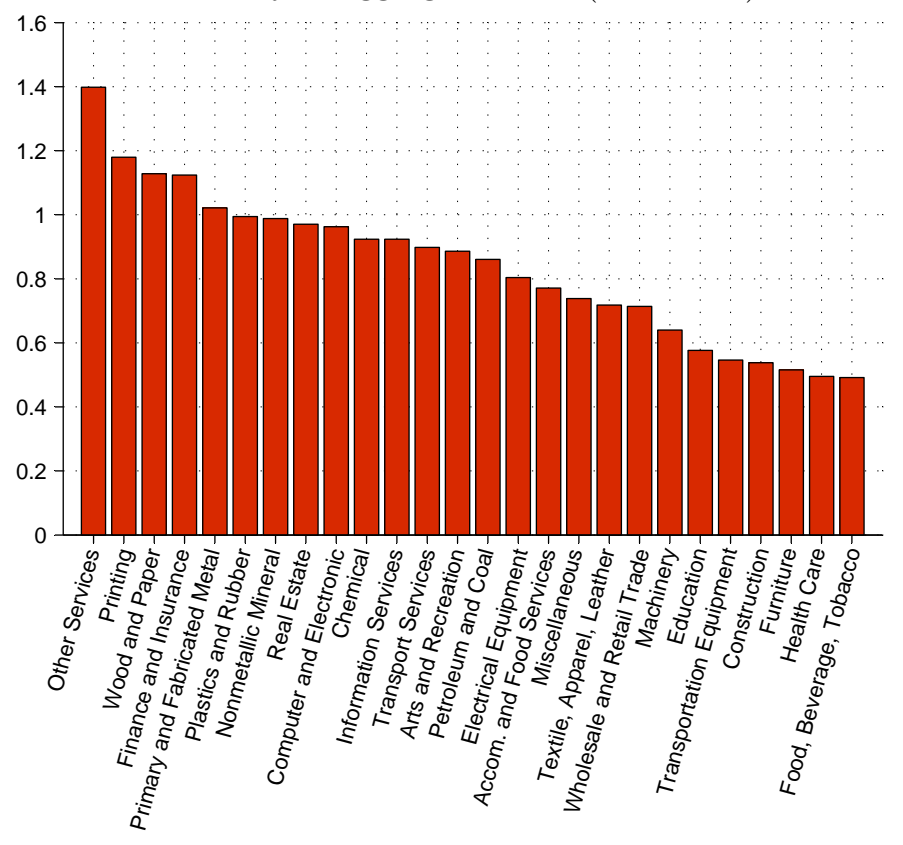

b: Ratio of GDP elasticities in RNS versus RS

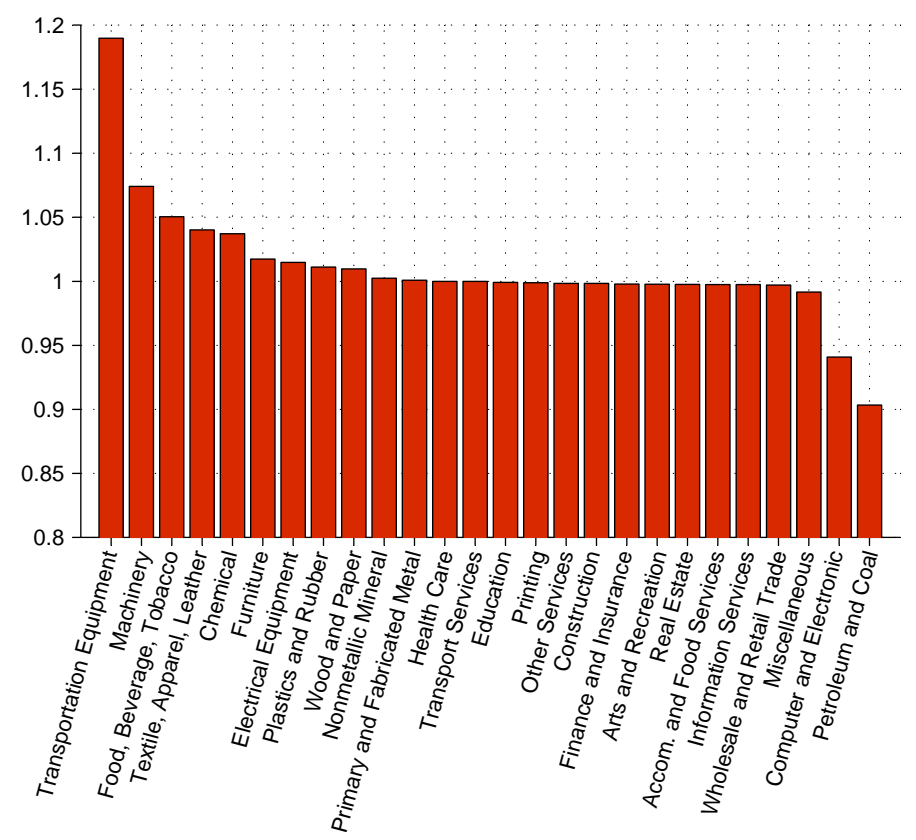

FIG. 14. Welfare elasticities to sectoral fundamental productivity changes

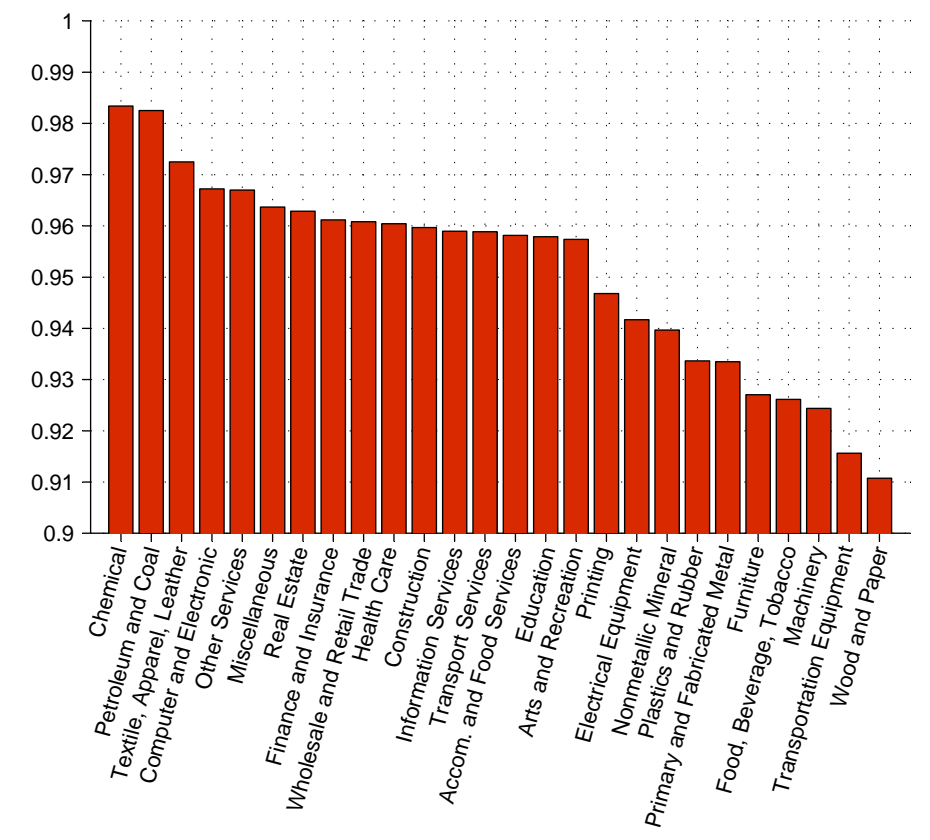

the effects of sectoral productivity changes have been silent on the consequences of these changes across regions. While improvements or worsening conditions in a given sector have aggregate consequences, it is also the case that these effects have a geographic distribution that is typically not uniform across states. 
Thus, we now turn our attention to the regional implications of sectoral fundamental TFP changes.

Figure 15 shows regional elasticities of measured TFP, GDP and employment to a fundamental TFP change in the Computer and Electronics industry. The share of the industry in total value added is slightly less than 2 percent. Evidently, states whose production is concentrated in that industry experience a more pronounced increase in measured TFP. However, as seen earlier, the direct effect of the productivity increase is mitigated somewhat by the negative selection effect in those industries. In states that do not produce in the industry, measured TFP is still affected through the selection effect, since unit costs change as a result of changes in the price of materials. As Figure 15 makes clear, the productivity change in Computer and Electronics affects mostly western states where this industry has traditionally been heavily represented.

Perhaps remarkably, the productivity increase in Computer and Electronics has very small or negative consequences for GDP and population in some states that are near those where the industry is concentrated. Consider, for instance, the cases of California and Massachusetts, two states that are active in Computers and Electronics. As the result of the productivity change, their populations grow. However, neighboring states such as Nevada, Connecticut, Rhode Island, and Vermont lose population and thus experience a decline, or a negligible increase, in GDP. These neighboring states, in fact, are the only states that experience a decline in real GDP in this case (apart from Tennessee which is affected by the growth of the sector in North Carolina). All of the effects we have described are influenced in turn by the size of the stocks of land and structures in those states. In that sense, the geographic distribution of economic activity determines the impact of sectoral fundamental productivity changes. Specifically, the aggregate impact of these changes is mitigated by these patterns, with an elasticity of aggregate GDP to fundamental productivity changes in the computer industry which is slightly lower than one.

Other industries, such as Transportation Equipment, are less concentrated geographically and yield lower elasticities of changes in aggregate GDP with respect to changes in fundamental sectoral TFP. In the case of Transportation Equipment, this elasticity is 0.55 (it is 0.54 in construction which is even more dispersed geographically, see Figure 3). The transportation industry is interesting in that although relatively small, with a value added share of just 1.84 percent, it is also more centrally located in space with Michigan and other Midwestern states being historically important producers in that sector. The implications of a productivity increase in the Transportation Equipment sector for other states is presented in Figure 16. Changes in measured TFP are clearly more dispersed across sectors and regions than for Computer and Electronics, although the largest increases in measured TFP are located in states involved in automobile production such as Michigan. In contrast to the case of Computer and Electronics, all regions see an increase in state GDP (except Vermont, Kentucky, and Wyoming which decline slightly) and much smaller population movements take place. In fact, Midwestern states, including Michigan, Illinois, and Indiana, tend to lose population while western and eastern states gain workers. To understand why, note that transportation equipment is an important material input into a wide range of industries. Therefore, increases in productivity in that sector benefit many other sectors as well. Although, in this case, a fundamental productivity increase does not 
FIG. 15. Regional elasticities to a change in fundamental productivity in the Computer and Electronics sector a: Elasticity of regional TFP (hundreds)

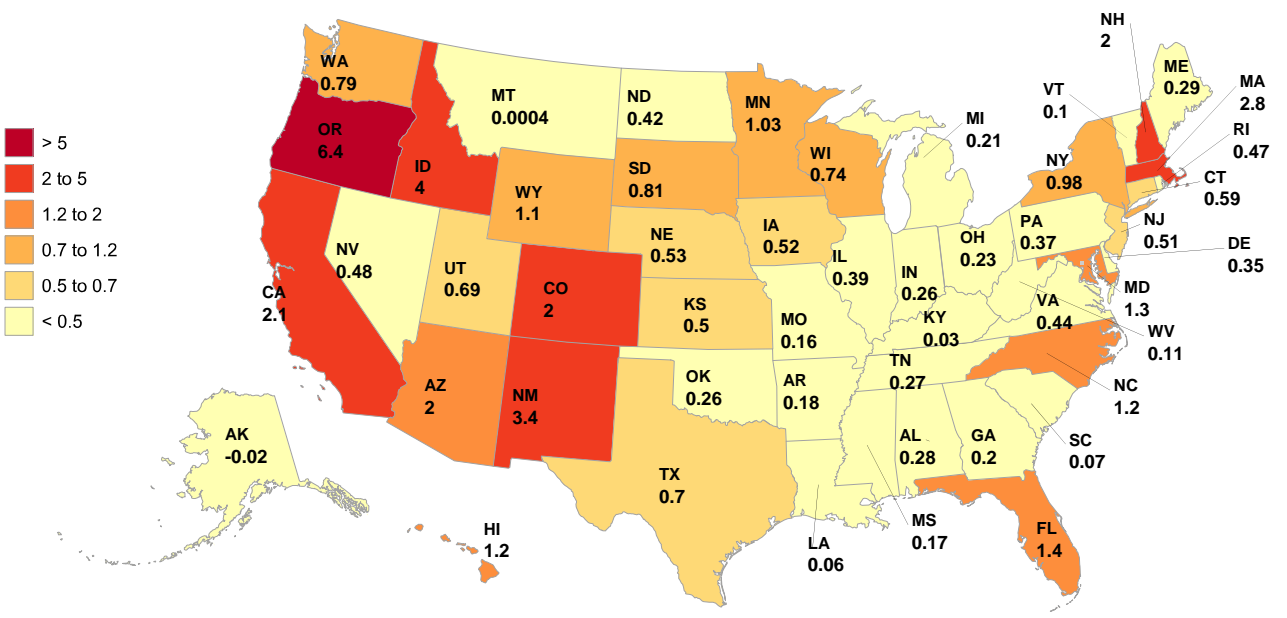

b: Elasticity of regional GDP (hundreds)

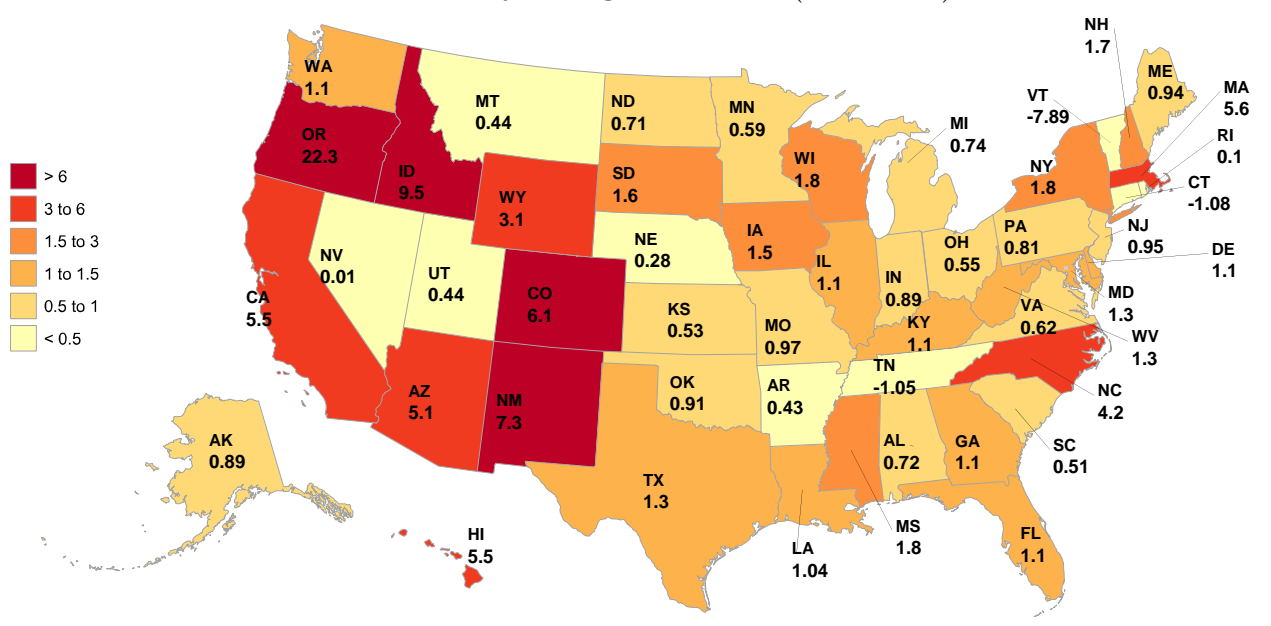

c: Elasticity of Employment (hundreds)

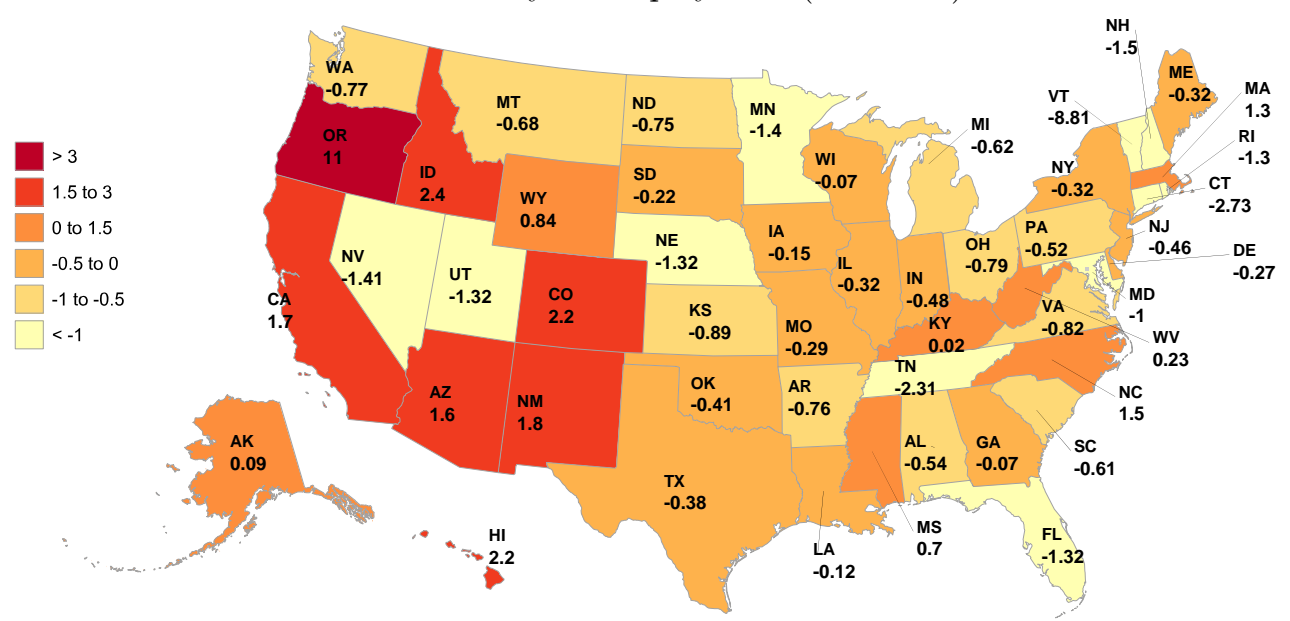


induce much migration, aggregate gains from the change are lower than in other sectors, since the change strains resources in some of already relatively congested regions. The result is a lower elasticity of real GDP to productivity gains in the Transportation sector compared to the Computer and Electronics industry, specifically 0.55 . The elasticity of welfare to the productivity change is equal to 0.92 , also smaller than the 0.97 for the Computer and Electronics sector.

\subsection{An Application: The Productivity Boom in Computers and Electronics in California}

As should now be clear, the model we have laid out allows us to calculate the regional, sectoral, and aggregate elasticities of TFP, GDP, and employment with respect to a productivity change in any sector in any region. As an example, we end this section by tracing out the effects of fundamental TFP changes in the Computers and Electronics Industry in California on other U.S. regions and sectors for an average year over the period 2002-2007.

The state of California is well known for its role as the home of prominent information and technology firms, Cisco Systems, Hewlett-Packard, Intel and many others, and generally as a center for computer innovation. In 2007, California alone accounted for $24 \%$ or essentially a quarter of all employment in the Computers and Electronics industry. For comparison, the states with the next two largest shares of employment in that sector were Texas and Massachusetts with $8 \%$ and $6 \%$ respectively, while most other states (37) had shares of employment in Computers and Electronics of less than 2\%. Despite the dot-com bust of 2001 causing a loss of significant market capitalization for many firms in Computers and Electronics, California then saw over the next five years annual TFP changes in that sector on the order of $31 \%$ on average. Given the continually rising importance of Computers and Electronics as an input to other sectors, and the importance of California as a home to computer innovation, we now describe the way in which TFP changes in that sector and state propagated to all other sectors and states of the U.S. economy.

Figure 17 shows the effects of observed changes in TFP in the Computers and Electronics industry specific to California, a sector that amounts to $5.5 \%$ of value added in that state, on measured regional TFP, GDP, and employment in other regions and states. The regional effect on measured TFP, GDP, or employment, can by computed by multiplying the size of the productivity change in California by the relevant elasticity in the region of interest. ${ }^{20}$ Thus, a $31 \%$ fundamental TFP increase in Computers and Electronics in California, which corresponds to a $14.6 \%$ yearly increase in measured TFP, results in a $0.85 \%$ increase in overall measured TFP in that state. This finding reflects in part the weight of Computers and Electronics relative to other sectors in California, and in part the dampening effects associated with negative selection, whereby newer varieties have relatively lower idiosyncratic productivities, and the fact that fundamental productivity scales

\footnotetext{
${ }^{20}$ In this section we compute all the results by feeding the annual observed change in fundamental TFP between 2002 and 2007 into the model. Alternatively, we could have computed these results by multiplying the fundamental TFP changes by the relevant regional or sectoral elasticities, as we have argued in the text. The difference between both calculations is related to the model's non-linearities. In this case, we find that the differences between the two methods are negligible, with a mean absolute deviation for the regional TFP, GDP and labor reallocation of $0.01 \%, 0.04 \%$ and $0.04 \%$, respectively.
} 
FIG. 16. Regional elasticities to a change in fundamental productivity in the Transportation Equip. sector a: Regional TFP elasticity (hundreds)

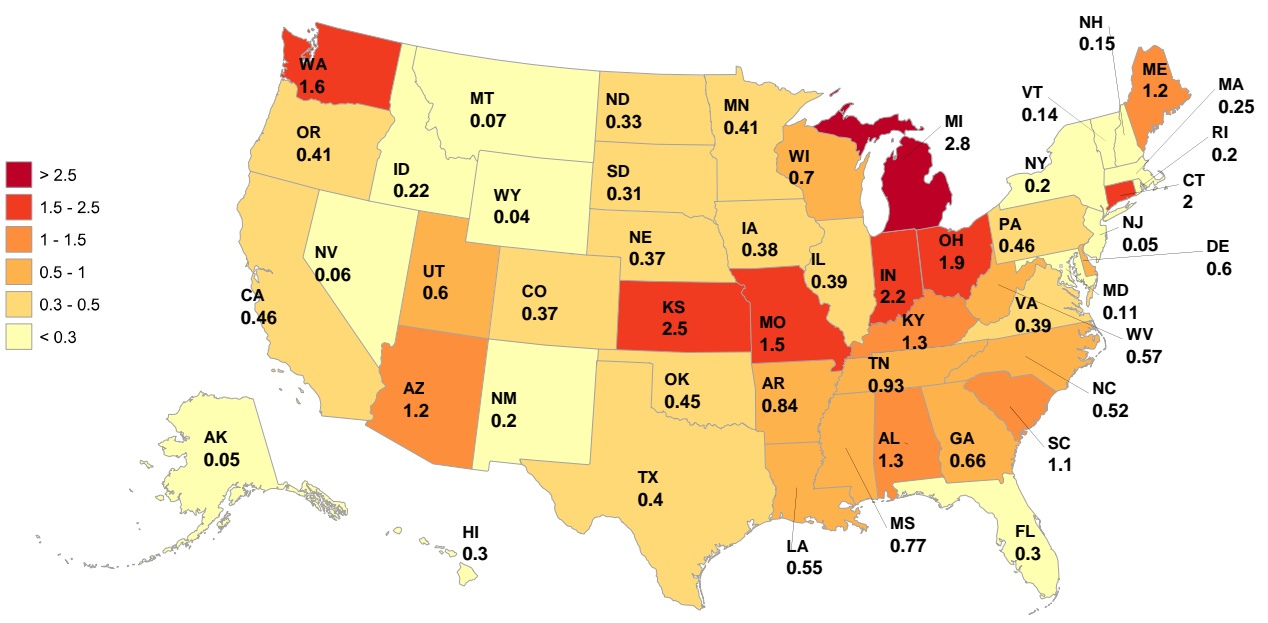

b: Regional GDP elasticity (hundreds)

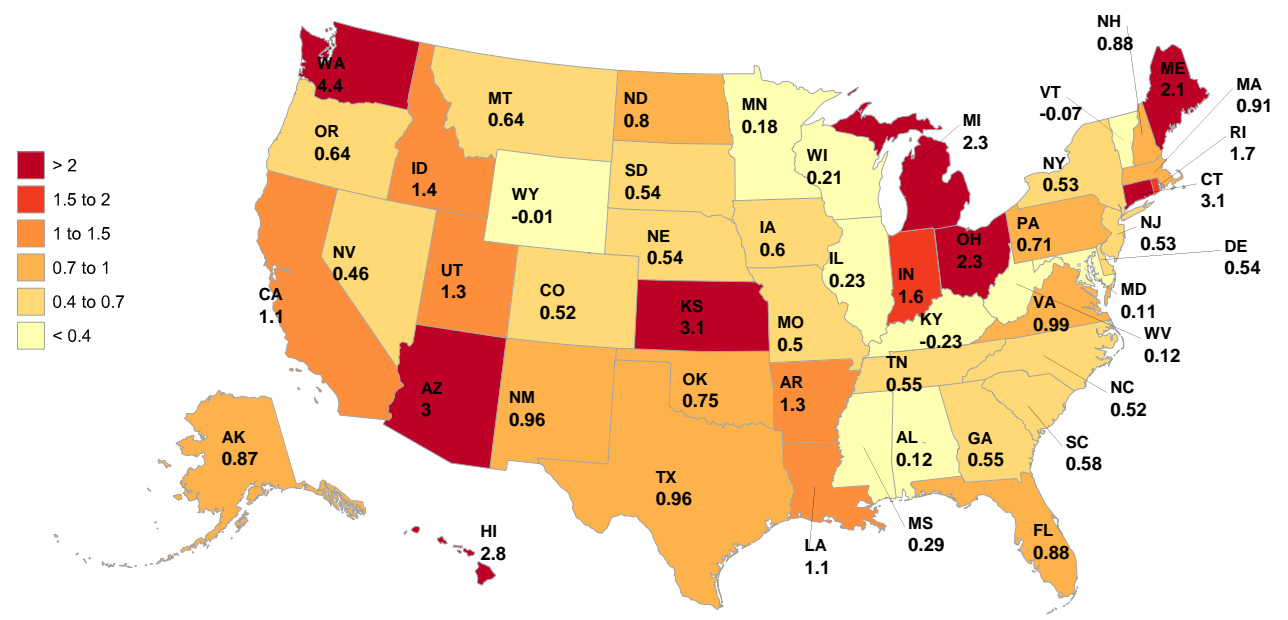

c: Regional Employment elasticity (hundreds)

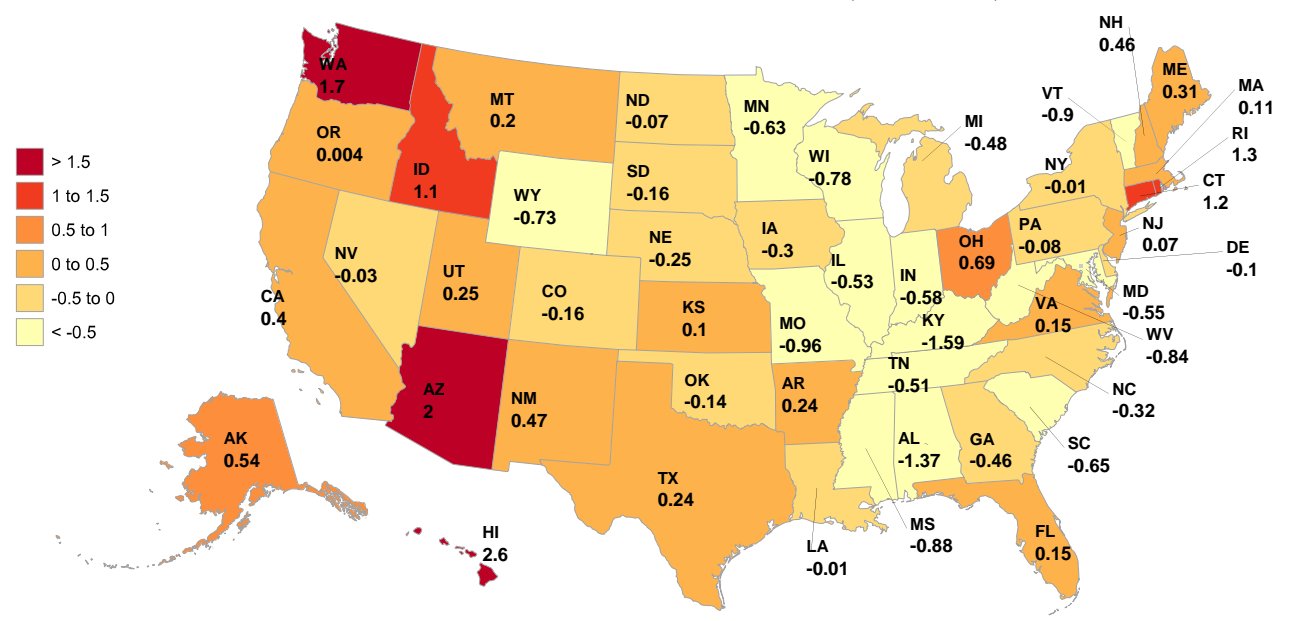


value added rather than gross output. States in the West that compete with California, such as Arizona, Oregon, and Idaho, now experience losses in TFP on the order of $-0.01 \%,-0.14 \%$ and $-0.01 \%$ respectively. Recall from Section 5.2 that, when a productivity change to Computer and Electronics affects all regions, the latter states were those that experienced the largest gains in measured TFP. Other states benefited from the productivity increase in Computer and Electronics mainly through a positive selection effect that left remaining varieties with relatively higher productivities. When the TFP increase in Computer and Electronics is specific to California, states that are close by and compete with California now experience productivity losses.

Following the change to Computer and Electronics in California, population tends to relocate to California. In addition, since the productivity change is more localized in space, this relocation is larger than that observed for a change in Computers and Electronics that affected all regions. Population tends to migrate mainly from regions that compete directly with California. Therefore, a more localized change in a given industry results in a larger GDP increase in California and generally in larger declines in other states. Observe, in particular, that declines in regional GDP tend to be larger not only in neighboring states such as Oregon (-1.53\%), Arizona (-0.91\%), and New Mexico (-1.07\%), but also in states farther out that compete directly with California in Computers and Electronics such as Massachusetts (-0.87\%).

Aside from the effects related to Computers and Electronics, the productivity improvement in California in that industry also means that California now possesses a lower comparative advantage in other sectors. Other states, therefore, benefit through sectors not related to Computers and Electronics, especially where these other sectors are relatively large such as for Petroleum and Coal in the states of Washington and West Virginia. These other sectors also see a reduction in material costs. Ultimately, while employment in the computer industry falls in the states of Washington and West Virginia, other sectors such as Petroleum and Coal, Non-Metallic Minerals, and non-tradeables, experience an increase in employment that more than offsets the decline in employment in computers. Thus, Washington, but also a state as far away from California as West Virginia with little production in Computers and Electronics, see their GDP rise by 1.05\% and $0.15 \%$ respectively.

\section{THE IMPORTANCE OF GEOGRAPHIC DISTANCE AS A TRADE BARRIER}

Once regional trade is taken into account, selection plays an essential role in understanding the impact of regional and sectoral productivity changes on aggregate measured TFP, GDP, and welfare. The two fundamental determinants of intermediate-goods-firm selection in a given region-sector pair $(n, j)$ are i) its fundamental productivity, and ii) the bilateral regional trade barriers it faces. Furthermore, the international trade literature has identified geographic distance as the most important barrier to international trade flows (see e.g. Disdier and Head 2008). The importance of the selection mechanism emphasized by trade considerations, therefore, is closely related to the role of distance as a deterrent to regional trade. In this 
FIG. 17. Regional effects to a 31 percent fundamental productivity change in Comp. and Elec. in California a: Regional TFP effects (percent)

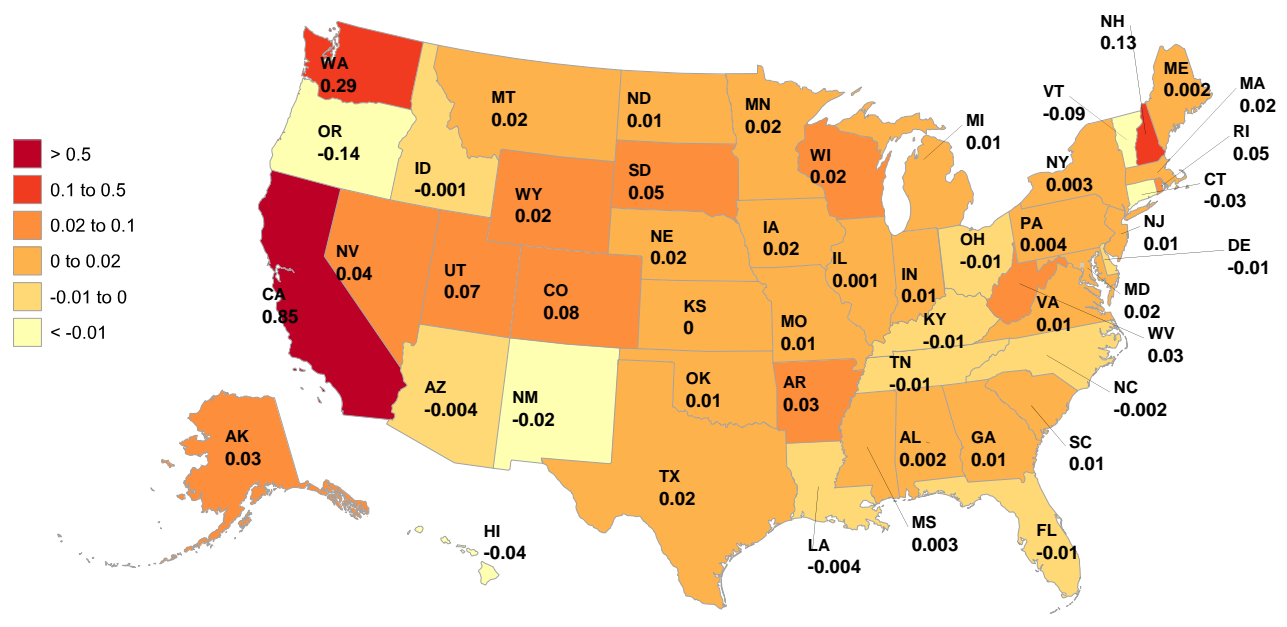

b: Regional GDP effects (percent)

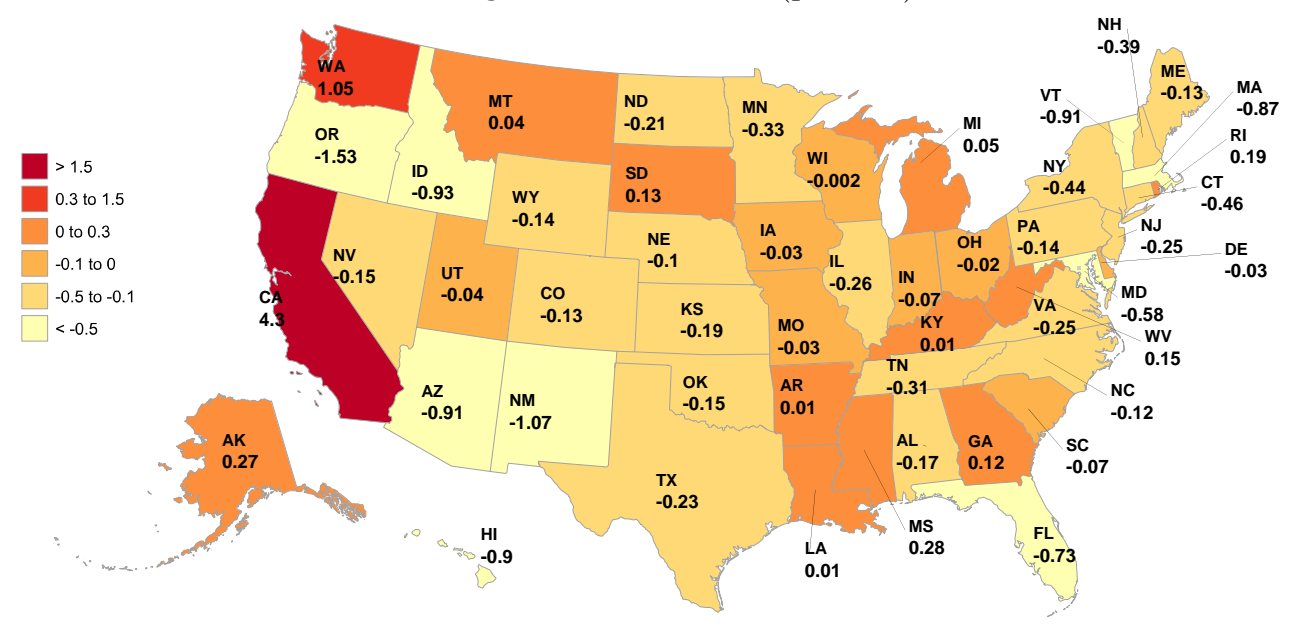

c: Regional Employment effects (percent)

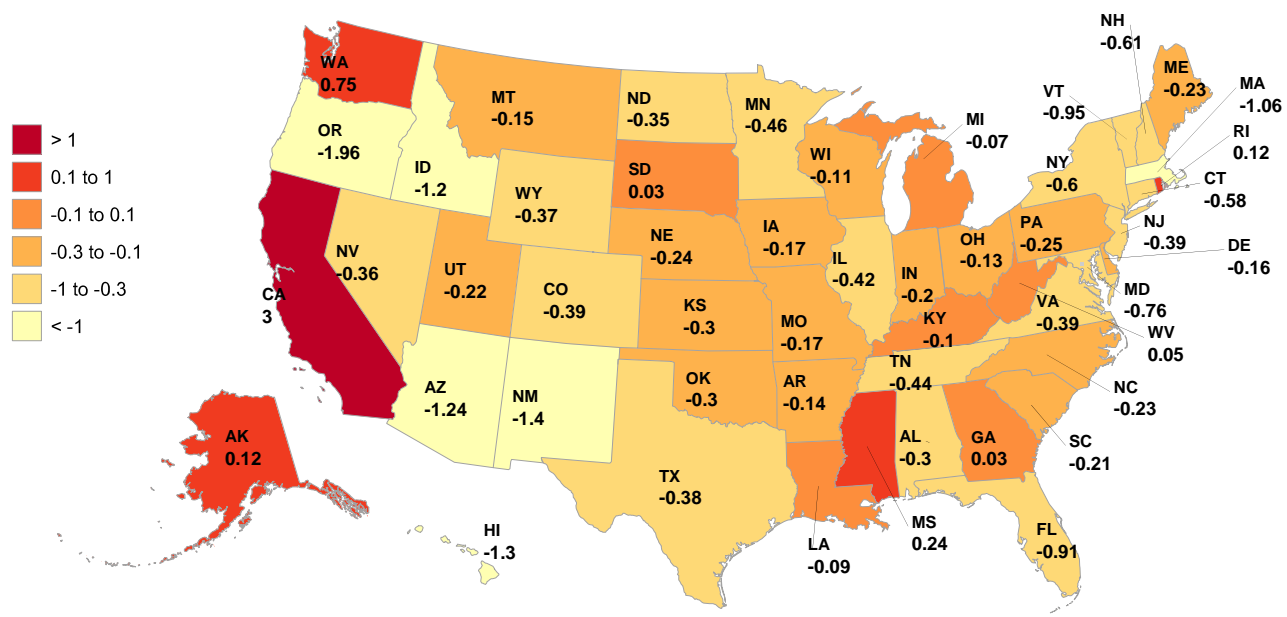


section, we evaluate the importance of geographic distance for aggregate TFP and GDP in the U.S. We do so by first separating the trade costs of moving goods across U.S. states into a geographic distance component and other regional trade barriers. We then quantify the aggregate effects arising from a reduction in each of these components of trade costs.

\subsection{Gains from Reductions in Trade Barriers}

To construct our measure of geographic distance, we use data on average miles per shipments between any two states for all 50 states and for the 15 tradable sectors considered in this paper. The data is available from the CFS which tracks ton-miles and tons shipped (in thousands) between states by NAICS manufacturing industries. We compute average miles per shipment by dividing ton-miles by tons shipped between states in each of our sectors. Average miles per shipment for goods shipped from each region of the U.S. range from 996 miles for goods shipped from Indiana to 4,154 miles for goods shipped from Hawaii.

To identify bilateral trade costs, we rely on the gravity equation implied by the model. ${ }^{21}$ Using Equation (19), and taking the product of sector $j$ goods shipped between two regions in one direction, and sector $j$ goods shipped in the opposite direction, and dividing this product by the domestic expenditure shares in each region, we obtain that

$$
\frac{\pi_{n i}^{j} \pi_{i n}^{j}}{\pi_{n n}^{j} \pi_{i i}^{j}}=\left(\kappa_{n i}^{j} \kappa_{i n}^{j}\right)^{-\theta^{j}}
$$

Assuming that the cost of trading across regions is symmetric, ${ }^{22}$ we can then infer bilateral trade costs for each sector $j$ as

$$
\kappa_{n i}^{j}=\left(\frac{\pi_{n i}^{j} \pi_{i n}^{j}}{\pi_{n n}^{j} \pi_{i i}^{j}}\right)^{-1 / 2 \theta^{j}} .
$$

Following Anderson and Van Wincoop (2003) and others, we explore how domestic bilateral trade costs vary with geographic distance using a log-linear relationship. Thus, we estimate the following trade-cost equation

$$
\log \kappa_{n i}^{j}=\delta^{j} \log d_{n i}^{j} / d_{n i}^{j, \min }+\eta_{n}+\varepsilon_{n i}^{j},
$$

where $d_{n i}^{j}$ denotes average miles per shipment from region $i$ to region $n$ in sector $j$, which we normalize by the minimum bilateral distance in that sector, $d_{n i}^{j, \min } \cdot{ }^{23}$ Consistent with evidence from Waugh (2010) based on price data, we further control for exporter fixed effects, $\eta_{n}$. The term $\varepsilon_{n i}^{j}$ is an error assumed to be orthogonal to our distance measure. OLS estimates from this regression may be used to decompose domestic bilateral trade costs, $\kappa_{n i}^{j}$, into a distance component, $\left(\delta^{j} \log d_{n i}^{j} / d_{n i}^{j, \min }\right)$, and other trade barriers $\left(\eta_{n}+\varepsilon_{n i}^{j}\right)$.

\footnotetext{
${ }^{21}$ This approach is commonly used in the international trade literature. See, for example, Head and Ries (2001), or Eaton and Kortum (2002).

${ }^{22}$ Here, we follow the literature that infers trade costs from observable trade flows, as in Head and Ries (2001) and Anderson and van Wincoop (2003).

${ }^{23}$ This normalization allows us to estimate a sectoral distance coefficient that is comparable across sectors. Note that this is equivalent to adding a distance-sectoral fixed effect to the specification.
} 
We then use this decomposition to calculate the effects of a reduction in distance and other trade barriers on measured TFP, GDP, and welfare.

Table 2 presents our findings. First, the table shows that the aggregate economic cost of domestic trade barriers is large. This finding is at the basis of our emphasis on the geography of economic activity. Furthermore, the table shows that the effect of eliminating barriers related to distance is almost an order of magnitude larger than that of eliminating other trade barriers. Therefore, focusing on distance as the main obstacle to the flow of goods across states is a good approximation. The latter observation is reminiscent of similar findings in the international trade literature, and it is noteworthy that distance plays such as a large role even domestically. In addition, changes in TFP and welfare in Table 2 are noticeably smaller than changes in GDP. As emphasized throughout the analysis, this finding reflects the effects of migration in the presence of local fixed factors. In the longer run, to the extent that some of these local factors are accumulated, such as structures, differences between TFP or welfare and GDP changes may be attenuated.

It is important to keep in mind that our counterfactual experiment in this section has no bearing on policy since reducing distance to zero is infeasible. Reductions in the importance of distance as a trade barrier may arise, however, with technological improvements related to the shipping of goods. Still, the exercise emphasizes the current importance of regional trade costs and geography in understanding changes in output and productivity. Put another way, the geography of economic activity in 2007 was, and likely still is, an essential determinant of the behavior of TFP, GDP, and welfare, in response to fundamental changes in productivity.

Table 2. : Reduction of trade cost across U.S. states

\begin{tabular}{ccc}
\hline \hline & Geographic distance & Other barriers \\
\hline Aggregate TFP gains & $50.98 \%$ & $3.62 \%$ \\
Aggregate GDP gains & $125.88 \%$ & $10.54 \%$ \\
Welfare gains & $58.83 \%$ & $10.10 \%$ \\
\hline \hline
\end{tabular}

\section{CONCLUDING REMARKS}

In this paper, we study the effects of disaggregated productivity changes in a model that recognizes explicitly the role of geographical factors in determining allocations. This geographical element is manifested in several ways.

First, following a long tradition in macroeconomics, we take account of interactions between sectors, but we further recognize that these interactions take place over potentially large distances by way of costly regional trade. Thus, borrowing from the recent international trade literature, we incorporate multiple regions and transport costs in our analysis. As shown in Section 6, the importance of transport costs is such that, were they to disappear, GDP would more than double while measured productivity and welfare would increase by 
$50 \%$. Second, we consider the mobility and spatial distribution of different factors of production. Specifically, while labor tends to be mobile across regions, other factors, such as land and structures, are fixed locally and unevenly distributed across space. We calibrate the model to match newly released data on pairwise trade flows across U.S. states by industry and other regional and industry data. Given this calibration, we are then able to provide a quantitative assessment of how different regions and sectors of the U.S. economy adjust to disaggregated productivity disturbances. Furthermore, to highlight the role of the elasticities we present, we carried out an application that describes how the large gains in fundamental productivity during the period 2002-2007 in the Computers and Electronics industry in California affected all other regions and sectors of the U.S. economy.

We find that disaggregated productivity changes can have dramatically different aggregate quantitative implications depending on the regions and sectors affected. Furthermore, particular disaggregated fundamental changes have very heterogenous effects across different regions and sectors. These effects arise in part because disaggregated productivity disturbances lead to endogenous changes in the pattern of trade. These changes in turn are governed by a selection effect that ultimately determines which regions produce what types of goods. Furthermore, labor is a mobile factor so that regions that become more productive tend to see an inflow of population. This inflow increases the burden on local fixed resources in those regions and, therefore, attenuates the direct effects of any productivity increases. Furthermore, the different estimated ownership structures of the fixed factor across states implies that changes in the returns to these factors are unequally distributed across regions, thereby exacerbating the role of geography in determining aggregate and regional elasticities. These implications of the model are the direct result of the observed trade imbalances across states.

In principle, as more data become available, future work might help identify TFP changes disaggregated by regions and sectors over an extended period of time. With the help of factor analytic methods, the resulting disaggregated disturbances might then be decomposed into common components (aggregate shocks), components that are purely sector-specific, or components that are purely region-specific. Estimates of the relative contributions of these different components to aggregate economic activity could then be obtained. These considerations, however, remain independent of our calculations of elasticities of economic outcomes to disaggregated productivity changes. Policy analysis of particular events, as well as any assessment of the effects of changes at the sectoral or regional level, such as those presented for the computer industry in California, necessarily benefits from such elasticities.

Future work might further explore how local factors that can be gradually adjusted over time, such as private structures or infrastructure in the form of public capital, affect how regional and sectoral variables interact in responding to productivity disturbances. While the accumulation of local factors might attenuate somewhat the effects of migration, these effects depend on the stock of structures which moves slowly over time. The quantitative implications of this adjustment margin, therefore, are not immediate. The framework we develop might also be extended to assess the effects of different regional policies, such as state taxes or 
regulations, or the effects of localized exogenous changes in the stock of structures resulting from extreme weather. Finally, dynamic adjustments in trade imbalances would also be informative with respect to the behavior of regional trade deficits in the face of fundamental productivity disturbances, and how this behavior then relates to macroeconomic adjustments. For now, this paper suggests that the regional characteristics of an economy appear essential to the study of the macroeconomic implications of productivity changes. 


\section{REFERENCES}

[1] Acemoglu, Daron, Vasco M. Carvalho, Asuman Ozdaglar, and Alireza Tahbaz-Salehi (2012): "The Network Origins of Aggregate Fluctuations," Econometrica, 80(5), 1977-2016.

[2] Allen, Treb, and Arkolakis, Costas (2013): "Trade and the Topography of the Spatial Economy," NBER Working Paper No 19181.

[3] Alvarez, Fernando, and Robert E. Lucas (2007): "General Equilibrium Analysis of the Eaton-Kortum Model of International Trade," Journal of Monetary Economics, 54(6), 726-68.

[4] Anderson, James E., and Eric van Wincoop (2003): "Gravity with Gravitas: A Solution to the Border Puzzle," American Economic Review, 93(1), 170-192.

[5] Arkolakis, Costas, Arnaud Costinot, and Andres Rodriguez Clare (2012): "New Theories, Same Old Gains?," American Economic Review, 102(1), 94-130.

[6] Blanchard, Olivier, and Lawrence F. Katz (1992): "Regional Evolutions," Brooking Papers of Economic Activity, 1, 1-75.

[7] Burstein, Ariel, Javier Cravino, and Jonathan Vogel (2013): "Importing Skill-Biased Technology," American Economic Journal: Macroeconomics, 5(2), 32-71.

[8] Burstein, Ariel, and Jonathan Vogel (2012): "International Trade, Technology, and the Skill Premium," unpublished working paper, Columbia University.

[9] Caliendo, Lorenzo, and Fernando Parro (2010): "Welfare Gains from Changing Partners in a Trade Bloc: The Case of MERCOSUR," in Hamid Beladi, E. Kwan Choi (ed.) New Developments in Computable General Equilibrium Analysis for Trade Policy (Frontiers of Economics and Globalization, Volume 7), Emerald Group Publishing Limited, pp.41-60.

[10] Caliendo, Lorenzo, and Fernando Parro (2014): "Estimates of the Trade and Welfare Effects of NAFTA," forthcoming, The Review of Economic Studies.

[11] Caselli, Francesco, Miklos Koren, Milan Lisicky, and Silvana Tenreyro (2012): "Diversification through Trade," mimeo LSE.

[12] Chor, Davin (2010): "Unpacking Sources of Comparative Advantage: A Quantitative Approach," Journal of International Economics, 82(2), 152-167.

[13] Costinot, Arnaud, Dave Donaldson, and Ivana Komunjer (2012): "What Goods Do Countries Trade? A Quantitative Exploration of Ricardo's Ideas?," Review of Economic Studies, 79(2), 581-608.

[14] Costinot, Arnaud, and Andres Rodriguez-Clare (2013): "Trade Theory with Numbers: Quantifying the Consequences of Globalization," Handbook of International Economics, forthcoming.

[15] Dekle, Robert, Jonathan Eaton, and Samuel S. Kortum (2008): "Global Rebalancing with Gravity: Measuring the Burden of Adjustment," IMF Staff Papers, 55(3), 511-540.

[16] Di Giovanni, Julian, Andrei Levchenko, and Jing Zhang (2013): "The GlobalWelfare Impact of China: Trade Integration and Technological Change," American Economic Journal: Macroeconomics, forthcoming.

[17] Disdier, Anne-Célia. and Keith Head (2008) "The Puzzling Persistence of the Distance Effect on Bilateral Trade," Review of Economics and Statistics, 90(1), 37-48.

[18] Donaldson, Dave (2012): "Railroads of the Raj: Estimating the Impact of Transportation Infrastructure," American Economic Review, forthcoming.

[19] Dupor, Bill (1999): "Aggregation and Irrelevance in Multi-Sector Models," Journal of Monetary Economics, 43(2), 391-409. 
[20] Eaton, Jonathan, and Samuel S. Kortum (2002): "Technology, Geography, and Trade," Econometrica, 70(5), $1741-1779$.

[21] Eaton, Jonathan, and Samuel S. Kortum (2012): "Putting Ricardo to Work," Journal of Economic Perspectives, 26(2): 65-90.

[22] Eaton, Jonathan, Sam Kortum, Brent Neiman, and John Romalis (2011): "Trade and the Global Recession", NBER Working Paper No 16666.

[23] Fieler, Cecilia (2011): "Non-Homotheticity and Bilateral Trade: Evidence and a Quantitative Explanation," Econometrica, 79(4), 1069-1101.

[24] Foerster, Andrew T, Pierre-Daniel G Sarte, and Mark W. Watson (2011): "Sectoral vs. Aggregate Shocks: A Structural Factor Analysis of Industrial Production," Journal of Political Economy, 119(1), 1-38.

[25] Fogli, Alessandra, Enoch Hill, and Fabrizio Perri (2012): "The Geography of the Great Recession," NBER Working Paper No 18447.

[26] Gabaix, Xavier (2011): "The Granular Origins of Aggregate Fluctuations," Econometrica, 79(3), 733-772.

[27] Greenwood, Jeremy, Zvi Hercowitz, and Krusell, Per (1997) "Long-Run Implications of Investment-Specific Technological Change," American Economic Review, 87(3), 342-362.

[28] Hamilton, James D., and Michael T. Owyang (2012): "The Propagation of Regional Recessions," Review of Economics and Statistics, 94(4), 935-947.

[29] Head, Keith, and John Ries (2001): "Increasing Returns versus National Product Differentiation as an Explanation for the Pattern of U.S.-Canada Trade," American Economic Review, 91(4), 858-876.

[30] Horvath, Michael (1998): "Cyclicality and Sectoral Linkages: Aggregate Fluctuations from Independent Sectoral Shocks," Review of Economic Dynamics, 1, 781-808.

[31] Horvath, Michael (2000): "Sectoral Shocks and Aggregate Fluctuations," Journal of Monetary Economics, $45,69-106$.

[32] Hsieh, Chang-Tai, and Ralph Ossa (2011): "A Global View of Productivity Growth in China," NBER working paper No 16778.

[33] Jovanovic, Boyan (1987): "Micro Shocks and Aggregate Risk," Quarterly Journal of Economics, 102(2), 395-409.

[34] Kennan, John, and James R. Walker (2011): "The Effect of Expected Income on Individual Migration Decisions," Econometrica, 79(1), 211-251.

[35] Kerr, William R. (2009): "Heterogeneous Technology Diffusion and Ricardian Trade Patterns," unpublished working paper, Harvard Business School.

[36] Kydland, Finn., and Edward C. Prescott (1982): "Time to Build and Aggregate Fluctuations," Econometrica, $50,1345-1370$.

[37] Levchenko, Andrei, and Jing Zhang (2011): "The Evolution of Comparative Advantage: Measurement and Welfare Implications," NBER Working Paper No 16806.

[38] Long, John B., Jr., and Charles I. Plosser (1983): "Real Business Cycles," Journal of Political Economy, 91, 39-69.

[39] Oberfield, Ezra (2012): "Business Networks, Production Chains, and Productivity: A Theory of InputOutput Architecture," mimeo Princeton University.

[40] Ossa, Ralph (2012): "Why Trade Matters After All," NBER working paper No 18113. 
[41] Parro, Fernando (2013): "Capital-Skill Complementarity and the Skill Premium in a Quantitative Model of Trade," American Economic Journal: Macroeconomics, 5(2), 72-117.

[42] Ramondo, Natalia, and Andres Rodriguez-Clare (2013): "Trade, Multinational Production, and the Gains from Openness," Journal of Political Economy, 121(2), 273-322.

[43] Redding, Stephen (2012): "Goods Trade, Factor Mobility and Welfare," NBER Working Paper No18008.

[44] Shikher, Serge (2011): "Capital, Technology, and Specialization in the Neoclassical Model," Journal of International Economics, 83(2), 229-242.

[45] Waugh, Michael (2010): "International Trade and Income Differences," American Economic Review, 100(5), 2093-2124.

\section{APPENDIX}

\section{A.1 Equilibrium Conditions with exogenous Inter-regional Trade Deficit}

Income of households in region $n$ is given by $I_{n}=w_{n}+\chi+\left(1-\iota_{n}\right) \frac{r_{n} H_{n}}{L_{n}}-s_{n}$, where $s_{n}=S_{n} / L_{n}$ represents the part of observed per-capita trade surplus in region $n$ unexplained by the model. Utility of an agent in region $n$ is given by $U=\frac{I_{n}}{P_{n}}$. Using the equilibrium condition $r_{n} H_{n}=\frac{\beta_{n}}{1-\beta_{n}} w_{n} L_{n}$, and the definition of $\omega_{n}=\left(r_{n} / \beta_{n}\right)^{\beta_{n}}\left(w_{n} /\left(1-\beta_{n}\right)\right)^{1-\beta_{n}}$, we can express wages as $\frac{w_{n}}{1-\beta_{n}}=\omega_{n}\left(\frac{H_{n}}{L_{n}}\right)^{\beta_{n}}$. Therefore, $U$ may be expressed as

$$
U=\left(\frac{H_{n}}{L_{n}}\right)^{\beta_{n}} \frac{\omega_{n}}{P_{n}}-\frac{u_{n}}{P_{n}}-\frac{s_{n}}{P_{n}},
$$

where $u_{n}=\Upsilon_{n} / L_{n}=\left(\iota_{n} r_{n} H_{n}-\chi L_{n}\right) / L_{n}$. Solving for $L_{n}$ and use the labor market clearing condition $\sum_{n=1}^{N} L_{n}=L$, to solve for $U$

$$
U=\frac{1}{L} \sum_{n=1}^{N}\left(\frac{\omega_{n}}{P_{n}}\left(H_{n}\right)^{\beta_{n}} L_{n}^{1-\beta_{n}}-\frac{\Upsilon_{n}}{P_{n}}-\frac{S_{n}}{P_{n}}\right) .
$$

Finally we can use these conditions to obtain,

$$
L_{n}=\frac{H_{n}\left[\frac{\omega_{n}}{P_{n} U+u_{n}+s_{n}}\right]^{1 / \beta_{n}}}{\sum_{i=1}^{N} H_{i}\left[\frac{\omega_{i}}{P_{i} U+u_{i}+s_{i}}\right]^{1 / \beta_{i}}} L .
$$

The expenditure shares are given by

$$
\pi_{n i}^{j}=\frac{\left[x_{i}^{j} \kappa_{n i}^{j}\right]^{-\theta^{j}} T_{i}^{j \theta^{j} \gamma_{i}^{j}}}{\sum_{i=1}^{N}\left[x_{i}^{j} \kappa_{n i}^{j}\right]^{-\theta^{j}} T_{i}^{j \theta^{j} \gamma_{i}^{j}} .}
$$

the input bundle and prices by

$$
\begin{aligned}
& x_{n}^{j}=B_{n}^{j}\left[r_{n}^{\beta_{n}} w_{n}^{1-\beta_{n}}\right]^{\gamma_{n}^{j}} \prod_{k=1}^{J}\left(P_{n}^{k}\right)^{\gamma_{n}^{j k}} \\
& P_{n}^{j}=\Gamma\left(\xi_{n}^{j}\right)^{1-\eta_{n}^{j}}\left[\sum_{i=1}^{N}\left[x_{i}^{j} \kappa_{n i}^{j}\right]^{-\theta^{j}}\left(T_{i}^{j}\right)^{\theta^{j} \gamma_{i}^{j}}\right]^{-1 / \theta^{j}}
\end{aligned}
$$

Regional market clearing in final goods is given by

$$
X_{n}^{j}=\sum_{k} \gamma_{n}^{k j} \sum_{i} \pi_{i n}^{k} X_{i}^{k}+\alpha^{j}\left(\omega_{n}\left(H_{n}\right)^{\beta_{n}}\left(L_{n}\right)^{1-\beta_{n}}-\Upsilon_{n}-S_{n}\right)
$$


Trade balance then is given by

$$
\sum_{j=1}^{J} X_{n}^{j}+\Upsilon_{n}+S_{n}=\sum_{j=1}^{J} \sum_{i=1}^{N} \pi_{i n}^{j} X_{i}^{j}
$$

Note that combining trade balance with goods market clearing we end up with the following equilibrium condition,

$$
\omega_{n}\left(H_{n}\right)^{\beta_{n}}\left(L_{n}\right)^{1-\beta_{n}}=\sum_{j} \gamma_{n}^{j} \sum_{i=1}^{N} \pi_{i n}^{j} X_{i}^{j}
$$

\section{A.2 Equilibrium Conditions in Relative Terms}

Labor mobility condition ( $N$ equations):

$$
\hat{L}_{n}=\frac{\left(\frac{\hat{\omega}_{n}}{\varphi_{n} \hat{P}_{n} \hat{U}+\left(1-\varphi_{n}\right) \hat{b}_{n}}\right)^{1 / \beta_{n}}}{\sum_{i} L_{i}\left(\frac{\hat{\omega}_{i}}{\varphi_{i} \hat{P}_{i} \hat{U}+\left(1-\varphi_{i}\right) \hat{b}_{i}}\right)^{1 / \beta_{i}}} L .
$$

Regional market clearing in final goods ( $J N$ equations):

$$
X_{n}^{j \prime}=\sum_{k=1}^{J} \gamma_{n}^{k, j}\left(\sum_{i=1}^{N} \pi_{i n}^{k \prime} X_{i}^{k \prime}\right)+\alpha^{j}\left(\hat{\omega}_{n}\left(\hat{L}_{n}\right)^{1-\beta_{n}}\left(I_{n} L_{n}+\Upsilon_{n}+S_{n}\right)-S_{n}^{\prime}-\Upsilon_{n}^{\prime}\right) .
$$

Price index ( $J N$ equations):

$$
\widehat{P}_{n}^{j}=\left(\sum_{i=1}^{N} \pi_{n i}^{j}\left[\widehat{\kappa}_{n i}^{j} \widehat{x}_{i}^{j}\right]^{-\theta^{j}} \hat{T}_{i}^{j} \theta^{j} \gamma_{i}^{j}\right)^{-1 / \theta^{j}}
$$

Input bundle ( $J N$ equations):

$$
\widehat{x}_{n}^{j}=\left(\hat{\omega}_{n}\right)^{\gamma_{n}^{j}} \prod_{k=1}^{J}\left(\widehat{P}_{n}^{k}\right)^{\gamma_{n}^{k j}}
$$

Trade shares $\left(J N^{2}\right.$ equations $)$

$$
\pi_{n i}^{j^{\prime}}=\pi_{n i}^{j}\left(\frac{\widehat{x}_{i}^{j}}{\widehat{P}_{n}^{j}} \widehat{\kappa}_{n i}^{j}\right)^{-\theta^{j}} \hat{T}_{i}^{j \theta^{j} \gamma_{i}^{j}}
$$

Labor market clearing ( $N$ equations)

$$
\hat{\omega}_{n}\left(\hat{L}_{n}\right)^{1-\beta_{n}}\left(L_{n} I_{n}+\Upsilon_{n}+S_{n}\right)=\sum_{j} \gamma_{n}^{j} \sum_{i} \pi_{i n}^{\prime j} X_{i}^{\prime j}
$$

where $\hat{b}_{n}=\frac{u_{n}^{\prime}+s_{n}^{\prime}}{u_{n}+s_{n}}, \varphi_{n}=\frac{1}{1+\frac{\Upsilon_{n}+S_{n}}{L_{n} I_{n}}}, \hat{U}=\frac{1}{L} \sum_{n} L_{n} \frac{1}{\varphi_{n}} \frac{\hat{\omega}_{n}}{\hat{P}_{n}}\left(\hat{L}_{n}\right)^{1-\beta_{n}}-\frac{1}{L} \sum_{n} L_{n} \frac{1-\varphi_{n}}{\varphi_{n}} \frac{\hat{L}_{n} \hat{b}_{n}}{\hat{P}_{n}}$, and $\widehat{P}_{n}=$ $\prod_{j=1}^{J}\left(\hat{P}_{n}^{j}\right)^{\alpha^{j}}$

The total number of unknowns is: $\hat{\omega}_{n}(N), \hat{L}_{n}(N), X_{n}^{j \prime}(J N), \hat{P}_{n}^{j}(J N), \pi_{n i}^{j \prime}(J \times N \times N), \hat{x}_{n}^{j}(J N)$. For a total of $2 N+3 J N+J N^{2}$ equations and unknowns.

\section{A.3 Computation: Solving for counterfactuals}

Consider an exogenous change in $S_{n}^{\prime}, \widehat{\kappa}_{n i}^{j}$ and/or $\widehat{T}_{n i}^{j}$. To solve for the counterfactual equilibrium in relative changes, we proceed as follows:

Guess the relative change in regional factor prices $\hat{\boldsymbol{\omega}}$.

Step 1. Obtain $\hat{P}_{n}^{j}$ and $\widehat{x}_{n}^{j}$ consistent with $\hat{\omega}$ using

$$
\widehat{x}_{n}^{j}=\hat{\omega}_{n}^{\gamma_{n}^{j}} \prod_{k=1}^{J}\left(\hat{P}_{n}^{k}\right)^{\gamma_{n}^{k j}}, N \times J
$$


and

$$
\hat{P}_{n}^{j}=\left(\sum_{i=1}^{N} \pi_{n i}^{j}\left[\widehat{\kappa}_{n i}^{j} \widehat{x}_{i}^{j}\right]^{-\theta^{j}} \hat{T}_{i}^{j} \theta^{j} \gamma_{i}^{j}\right)^{-1 / \theta^{j}}, N \times J .
$$

Step 2. Solve for trade shares, $\pi_{n i}^{j^{\prime}}(\hat{\boldsymbol{\omega}})$, consistent with the change in factor prices using $\hat{P}_{n}^{j}(\hat{\boldsymbol{\omega}})$ and $\widehat{x}_{n}^{j}(\hat{\boldsymbol{\omega}})$ as well as the definition of trade shares,

$$
\pi_{n i}^{j^{\prime}}(\widehat{\boldsymbol{\omega}})=\pi_{n i}^{j}\left(\frac{\widehat{x}_{i}^{j}(\widehat{\boldsymbol{\omega}})}{\hat{P}_{n}^{j}(\widehat{\boldsymbol{\omega}})} \widehat{\kappa}_{n i}^{j}\right)^{-\theta^{j}} \hat{T}_{i}^{j \theta^{j} \gamma_{i}^{j}}
$$

Step 3. Solve for the change in labor across regions consistent with the change in factor prices $\hat{L}_{n}(\hat{\boldsymbol{\omega}})$, given $\hat{P}_{n}^{j}(\hat{\boldsymbol{\omega}})$, and $\hat{x}_{n}^{j}(\hat{\boldsymbol{\omega}})$, using

$$
\hat{L}_{n}=\frac{\left(\frac{\hat{\omega}_{n}}{\varphi_{n} \hat{P}_{n} \hat{U}+\left(1-\varphi_{n}\right) \hat{b}_{n}}\right)^{1 / \beta_{n}}}{\sum_{i} L_{i}\left(\frac{\hat{\omega}_{i}}{\varphi_{i} \hat{P}_{i} \hat{U}+\left(1-\varphi_{i}\right) \hat{b}_{i}}\right)^{1 / \beta_{i}}} L,
$$

where $\hat{b}_{n}=\frac{v_{n}^{\prime}+s_{n}^{\prime}}{v_{n}+s_{n}}, \hat{P}_{n}(\hat{\boldsymbol{\omega}})=\prod_{j=1}^{J} \hat{P}_{n}^{j}(\hat{\boldsymbol{\omega}})^{\alpha^{j}}$, and $\hat{U}=\frac{1}{L} \sum_{n} L_{n} \frac{1}{\varphi_{n}} \frac{\hat{\omega}_{n}}{\hat{P}_{n}}\left(\hat{L}_{n}\right)^{1-\beta_{n}}-\frac{1}{L} \sum_{n} L_{n} \frac{1-\varphi_{n}}{\varphi_{n}} \frac{\hat{L}_{n} \hat{b}_{n}}{\hat{P}_{n}}$.

Step 4. Solve for expenditures in the counterfactual equilibrium consistent with the change in factor prices $X_{n}^{j^{\prime}}(\hat{\boldsymbol{\omega}})$.

$$
X_{n}^{j \prime}(\hat{\boldsymbol{\omega}})=\sum_{k=1}^{J} \gamma_{n}^{k, j}\left(\sum_{i=1}^{N} \pi_{i n}^{k \prime}(\hat{\boldsymbol{\omega}}) X_{i}^{k \prime}(\hat{\boldsymbol{\omega}})\right)+\alpha^{j}\left(\hat{\omega}_{n}\left(\hat{L}_{n}(\hat{\boldsymbol{\omega}})\right)^{1-\beta_{n}}\left(I_{n} L_{n}+\Upsilon_{n}+S_{n}\right)-S_{n}^{\prime}-\Upsilon_{n}^{\prime}\right),
$$

which constitutes $N \times J$ linear equations in $N \times J$ unknown, $\left\{X_{n}^{j^{\prime}}(\hat{\boldsymbol{\omega}})\right\}_{N \times J}$. This can be solved through matrix inversion. Observe that carrying out this step first requires having solved for $\hat{L}_{n}(\hat{\boldsymbol{\omega}})$.

Step 5. Obtain a new guess for the change in factor prices, $\hat{\omega}_{n}^{*}$, using

$$
\hat{\omega}_{n}^{*}=\frac{\sum_{j} \gamma_{n}^{j} \sum_{i} \pi_{i n}^{\prime j}(\hat{\boldsymbol{\omega}}) X_{i}^{\prime j}(\hat{\boldsymbol{\omega}})}{\hat{L}_{n}(\hat{\boldsymbol{\omega}})^{1-\beta_{n}}\left(L_{n} I_{n}+\Upsilon_{n}+S_{n}\right)} .
$$

Repeat Steps 1 through 5 until $\left\|\hat{\omega}^{*}-\hat{\omega}\right\|<\varepsilon$.

\section{A.4 Data and calibration}

We calibrate the model to the 50 U.S. states and a total of 26 sectors classified according to the North American Industry Classification System (NAICS), 15 of which are tradable goods, 10 service sectors, and construction. We assume that all service sectors and construction are non-tradable. We present below a list of the sectors that we use, and describe how we combine a subset of these sectors to ease computations. As stated in the main text, carrying out structural quantitative exercises on the effects of disaggregated fundamental changes requires data on $\left\{I_{n}, L_{n}, S_{n}, \pi_{n i}^{j}\right\}_{n=1, i=1, j=1}^{N, N, J}$, as well as values for the parameters $\left\{\theta^{j}, \alpha^{j}, \beta_{n}, \gamma_{n}^{j k}\right\}_{n=1, j=1, k=1}^{N, J, J}$. We now describe the main aspects of the data.

\section{A.4.1 Regional Employment and Income.-}

We set $L=1$ so that, for each $n \in\{1, \ldots, N\}, L_{n}$ is interpreted as the share of state $n$ 's employment in total employment. Regional employment data is obtained from the Bureau of Economic Analysis (BEA), with aggregate employment across all states summing to 137.3 million in 2007 . We obtain $I_{n}$ by calculating total value added in each state and then dividing the result by total population for that state in 2007 .

\section{A.4.2 Interregional Trade Flows and Surpluses.-}


To measure the shares of expenditures in intermediates from region-sector $(i, j)$ for each state $n, \pi_{n i}^{j}$, we use data from the Commodity Flow Survey (CFS). The dataset tracks pairwise trade flows across all 50 states for 18 sectors of the U.S. economy (three of these are aggregated for a total of 15 tradable goods sectors as described in A.4.5). The CFS contains data on the total value of trade across all states which amounts to 5.2 trillion in 2007 dollars. The most recent CFS data covers the year 2007 and was released in 2012. This explains our choice of 2007 as the baseline year of our analysis.

Even though the CFS aims to quantify only domestic trade, and leaves out all international transactions, some imports to a local destination that are then traded in another domestic transaction are potentially included. To exclude this imported part of gross output, we calculate U.S. domestic consumption of domestic goods by subtracting exports from gross production for each NAICS sector using sectoral measures of gross output from the BEA and exports from the U.S. Census. We then compare the sectoral domestic shipment of goods implied by the CFS for each sector to the aggregate measure of domestic consumption. As expected, the CFS domestic shipment of goods is larger than the domestic consumption measure for all sectors, by a factor ranging from 1 to 1.4. We thus adjust the CFS tables proportionally so that they represent the total amount of domestic consumption of domestic goods.

A row sum in a CFS trade table associated with a given sector $j$ represents total exports of sector $j$ goods from that state to all other states. Conversely, a column sum in that trade table gives total imports of sector $j$ goods to a given state from all other states. The difference between exports and imports allows us to directly compute domestic regional trade surpluses in all U.S. states. Given $\left\{\iota_{n}\right\}_{N \times 1}$, we use information on value added by regions to calculate regional national portfolio balances, $\Upsilon_{n}=\iota_{n} r_{n} H_{n}-\chi L_{n}$, where $\chi=$ $\sum_{i} \iota_{i} r_{i} H_{i} / \sum_{i} L_{i}$. We then solve for $\left\{S_{n}\right\}_{N \times 1}$ as the difference between observed trade surplus in the data and the one implied by regional national portfolio balances. We then solve for $\left\{\iota_{n}\right\}_{N \times 1}$ by minimizing the sum square of $\left\{S_{n}\right\}_{N \times 1}$.

\section{A.4.3 Value Added Shares and Shares of Material Use.-}

In order to obtain value added shares observe that, for a particular sector $j$, each row-sum of the corresponding adjusted CFS trade table equals gross output for that sector in each region, $\left\{\sum_{i=1}^{N} \pi_{i n}^{j} X_{i}^{j}\right\}_{n=1}^{N}$. Hence, we divide value added from the BEA in region-sector pair $(n, j)$ by its corresponding measure of gross output from the trade table to obtain the share of value added in gross output by region and sector for all tradeable goods, $\left\{\gamma_{n}^{j}\right\}_{n=1, j=1}^{N, 15}$. For the 11 non-tradeable sectors, gross output is not available at the sectoral level by state. In those sectors, we assume that the value added shares are constant across states and equal to the national share of value added in gross output , $\gamma_{n}^{j}=\gamma^{j} \forall n \in\{1, \ldots, N\}$ and $j>15$. Aggregate measures of gross output and value added in non-tradeable sectors are obtained from the BEA.

While material input shares are available from the BEA by sector, they are not disaggregated by state. Given the structure of our model, it is nevertheless possible to infer region-specific material input shares from a national input-output (IO) table and other available data. The BEA Use table gives the value of inputs from each industry used by every other industry at the aggregate level. This use table is available at 5 year intervals, the most recent of which was released for 2002 data. A column sum of the BEA Use table gives total dollar payments from a given sector to all other sectors. Therefore, at the national level, we can compute $\gamma^{j k}$, the share of material inputs from sector $k$ in total payments to materials by sector $j$. Since $\sum_{k=1}^{N} \gamma^{j k}=1$, one may then construct the share of payments from sector $j$ to material inputs from sector $k$, for each state $n$, as $\gamma_{n}^{j k}=\left(1-\gamma_{n}^{j}\right) \gamma^{j k}$ where recall that $\gamma_{n}^{j}$ 's are region-sector specific value added shares.

\section{A.4.4 Share of Final Good Expenditure.-}

The share of income spent on goods from different sectors is calculated as follows,

$$
\alpha^{j}=\frac{Y^{j}+M^{j}-E^{j}-\sum_{k} \gamma^{k, j}\left(1-\gamma^{k}\right) Y^{k}}{\sum_{j}\left(Y^{j}+M^{j}-E^{j}-\sum_{k} \gamma^{k, j}\left(1-\gamma^{k}\right) Y^{k}\right)},
$$

where $E^{j}$ denotes total exports from the U.S. to the rest of the world, $M^{j}$ represents total imports to the U.S., and all intermediate input shares are national averages.

\section{A.4.5 Payments to Labor and Structure Shares.-}


As noted in the previous section, we assume that the share of payments to labor in value added, $\left\{1-\beta_{n}\right\}_{n=1}^{N}$, is constant across sectors. Disaggregated data on compensation of employees from the BEA is not available by individual sector in every state. To calculate $1-\beta_{n}$ in a given region, we first sum data on compensation of employees across all available sectors in that region, and divide this sum by value added in the corresponding region. The resulting measure, denoted by $1-\bar{\beta}_{n}$, overestimates the value added share of the remaining factor in our model, $\bar{\beta}_{n}$, associated with land and structures. That is, part of the remaining factor used in production involves equipment in addition to fixed structures. Accordingly, to adjust these shares, we rely on estimates from Greenwood, Hercowitz, and Krusell (1997) who measure separately the share of labor, structures, and equipment, in value added for the U.S. economy. These shares amount to 70 percent, 13 percent, and 17 percent respectively. We thus use these estimates to infer the share of structures in value added across regions by taking the share of non-labor value added by region, $\bar{\beta}_{n}$, subtracting the share of equipment, and renormalizing so that the new shares add to one. Specifically, we calculate the share of land and structures as $\beta_{n}=\left(\bar{\beta}_{n}-0.17\right) / 0.83$. Since our model explicitly takes materials into account, we assign the share of equipment to that of materials. In other words, we adjust the share of value added to $0.83 \gamma_{n}^{j}$, and adjust all calculations above accordingly. In this way, our quantitative exercise uses shares for labor as well as for land and structures at the regional level that are consistent with aggregate value added shares in the U.S.

\section{A.4.6 List of sectors.-}

The paper uses newly released data from the Commodity Flow Survey (CFS), jointly produced by the Census and the Bureau of Transportation. The trade tables resulting from the CFS was released for the first time in December 2010 and last revised in 2012 for data pertaining to 2007. Each trade table corresponds to a particular sector and is a $50 \times 50$ matrix whose entries represent pairwise trade flows for that sector among all U.S. states. The CFS contains comprehensive data for 18 manufacturing sectors with a total value of trade across all states amounting to 5.2 trillion in 2007 dollars. These sectors are Food Product \& Beverage and Tobacco Product, (NAICS 311 \& 312), Textile and Textile Product Mills, (NAICS 313 \& 314), Apparel \& Leather and Allied Product, (NAICS 315 \& 316), Wood Product, (NAICS 321), Paper, (NAICS 322), Printing and Related support activities, (NAICS 323), Petroleum \& Coal Products, (NAICS 324), Chemical, (NAICS 325), Plastics \& Rubber Products, (NAICS 326), Nonmetallic Mineral Product, (NAICS 327), Primary Metal, (NAICS 331), Fabricated Metal Product, (NAICS 332), Machinery, (NAICS 333), Computer and Electronic Product, (NAICS 334), Electrical Equipment and Appliance, (NAICS 335), Transportation Equipment, (NAICS 336), Furniture \& Related Product, (NAICS 337), Miscellaneous, (NAICS 339). We aggregate 3 subsectors. Sectors Textile and Textile Product Mills (NAICS 313 \& 314) together with Apparel \& Leather and Allied Product (NAICS 315 \& 316), Wood Product (NAICS 321) with Paper (NAICS 322) and sectors Primary Metal (NAICS 331) with Fabricated Metal Product (NAICS 332). We end up with a total of 15 manufacturing tradable sectors.

The list of non-tradable sectors are: Construction, Wholesale and Retail Trade, (NAICS 42 - 45), Transport Services, (NAICS 481 - 488), Information Services, (NAICS 511 - 518), Finance and Insurance, (NAICS 521 - 525), Real Estate, (NAICS 531 - 533), Education, (NAICS 61), Health Care, (NAICS 621 - 624), Arts and Recreation, (NAICS 711 - 713), Accom. and Food Services, (NAICS 721 - 722), Other Services, (NAICS 493 \& $541 \& 55 \& 561 \& 562 \& 811-814$ )

\section{A.4.7 Sectoral distribution of productivities.-}

We obtain the dispersion of productivities from Caliendo and Parro (2014). They compute this parameter for 20 tradable sectors, using data at two-digit level of the third revision of the International Standard Industrial Classification (ISIC Rev. 3). We match their sectors to our NAICS 2007 sectors using the information available in concordance tables. In five of our sectors Caliendo and Parro present estimates at an either more aggregated or disaggregated level. When Caliendo and Parro report separates estimates for sub-sectors which we aggregate into a single sector, we use their data to compute the dispersion of productivity in our aggregate sector. In cases where a sector in our data is integrated to another sector in Caliendo and Parro, we input that elasticity.

The dispersion of productivity for our sector "Wood and Paper" (NAICS 321-322) is estimated separately for wood products and paper products in Caliendo and Parro. In this case, using their data we proceed to 
estimate the aggregate dispersion of productivity for these two sub-sectors. Similarly, they present separate estimates for primary metals and fabricated metals (NAICS 331-332), thus we use their data to estimate the aggregate elasticity of these two sectors. We also estimate the dispersion of productivity for Transport Equipment (NAICS 336), which is divided into motor vehicles, trailers and semi-trailers, and other transport equipment in Caliendo and Parro. Our sector "Printing and Related Support Activities" (NAICS 323) is estimated together with pulp and paper products (ISIC3 21-22) in Caliendo and Parro, thus we input that estimate. Similarly, Furniture (NAICS 337) is estimated together with other manufacturing (ISIC 3 36-37) in Caliendo and Parro, and therefore we input that estimated elasticity in the Furniture sector.

\section{A.4.8 Average miles per shipment by sector.-}

The data on average mileage of all shipments from one state to another by NAICS manufacturing industries comes from the special release of the Commodity Flow Survey. 